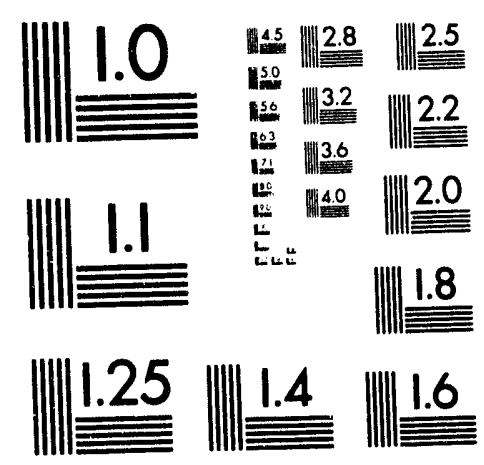



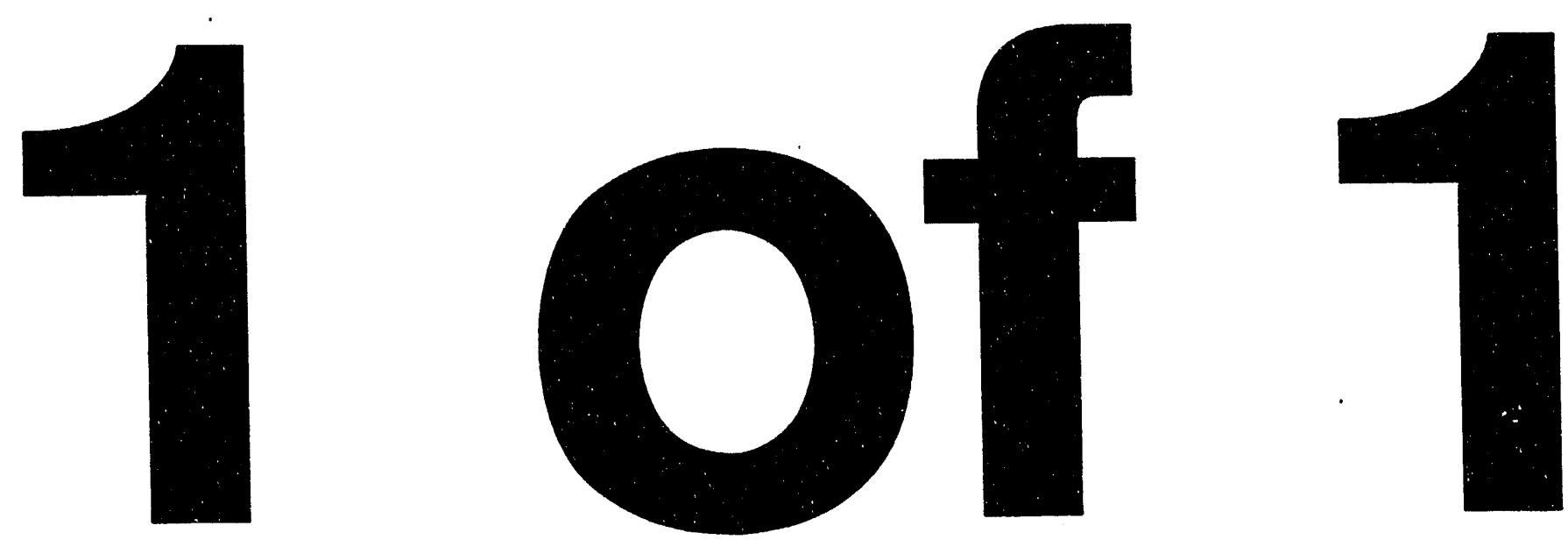
NUREG/CR-6078

BNL-NUREG-52383

\section{Analysis of Crack Initiation and Growth in the High Level Vibration Test at Tadotsu}

Manuscript Completed: August 1993

Date Published: August 1993

Prepared by

M. K. Kassir, Y. J. Park, C. H. Hofmayer, K. K. Bandyopadhyay, S. Shteyngart

Brookhaven National Laboratory

Upton, NY 11973

Prepared for

Division of Engineering

Office of Nuclear Regulatory Research

U.S. Nuclear Regulatory Commission

Washington, DC 20555-0001

NRC FIN L1381 


\begin{abstract}
The High Level Vibration Test data are used to assess the accuracy and usefulness of current engineering methodologies for predicting crack initiation and growth in a cast stainless steel pipe elbow under complex, large amplitude loading. The data were obtained by testing at room temperature a large scale modified model of one loop of a FWR primary coolant system at the Tadotsu Engineering Laboratory in Japan. Fatigue crack initiation time is reasonably predicted by applying a modified local strain approach (Coffin-Mason-Goodman equation) in conjunction with Miner's rule of cumulative damage. Three fracture mechanics methodologies are applied to investigate the crack growth behavior observed in the hot leg of the model. These are: the $\Delta \mathrm{K}$ methodology (Paris law), $\Delta \mathrm{J}$ concepts and a recently developed limit load stress-range criterion. The report includes a discussion on the pros and cons of the analysis involved in each of the methods, the role played by the key parameters influencing the formulation and a comparison of the results with the actual crack growth behavior observed in the vibration test program. Some conclusions and recommendations for improvement of the methodologies are also provided.
\end{abstract}


Page No.

ABSTRACT $\ldots \ldots \ldots \ldots \ldots \ldots \ldots \ldots \ldots \ldots \ldots \ldots \ldots \ldots \ldots \ldots \ldots \ldots \ldots \ldots$ ii

TABLE OF CONTENTS $\ldots \ldots \ldots \ldots \ldots \ldots \ldots \ldots \ldots \ldots \ldots \ldots \ldots \ldots \ldots \ldots \ldots$

LIST OF FIGURES $\ldots \ldots \ldots \ldots \ldots \ldots \ldots \ldots \ldots \ldots \ldots \ldots \ldots \ldots \ldots \ldots \ldots$ vii

LIST OF TABLES $\ldots \ldots \ldots \ldots \ldots \ldots \ldots \ldots \ldots \ldots \ldots \ldots \ldots \ldots \ldots \ldots \ldots \ldots \ldots \ldots \ldots$

EXECUTIVE SUMMARY $\ldots \ldots \ldots \ldots \ldots \ldots \ldots \ldots \ldots \ldots \ldots \ldots \ldots \ldots \ldots \ldots \ldots \ldots \ldots$

ACKNOWLEDGMENTS $\ldots \ldots \ldots \ldots \ldots \ldots \ldots \ldots \ldots \ldots \ldots \ldots \ldots \ldots \ldots \ldots \ldots$ xiii

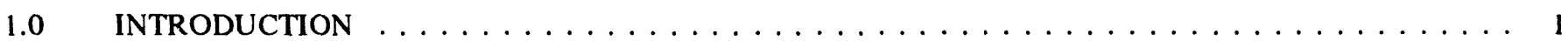

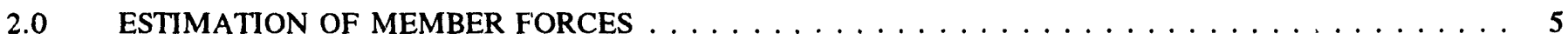

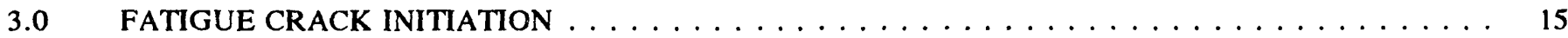

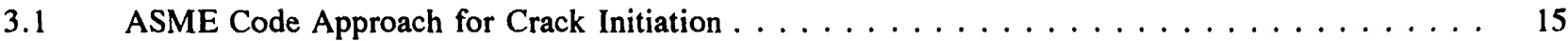

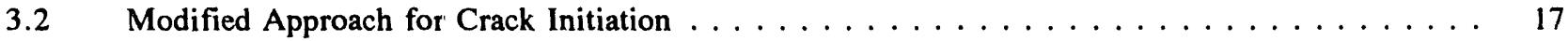

3.3 Alternate Methods of Predicting Crack Initiation $\ldots \ldots \ldots \ldots \ldots \ldots \ldots \ldots$

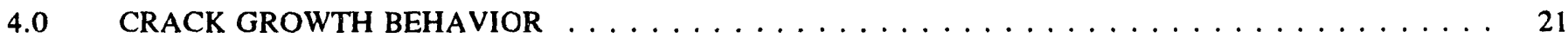

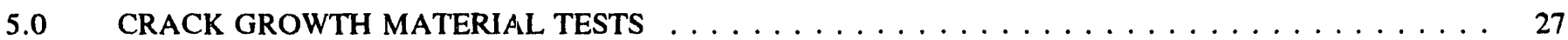

6.0 METHODOLOGIES OF PREDICTING CRACK GROWTH $\ldots \ldots \ldots \ldots \ldots \ldots \ldots \ldots \ldots$

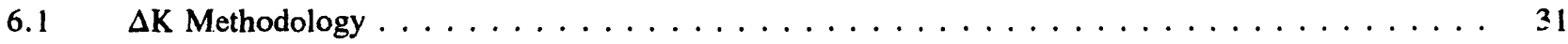

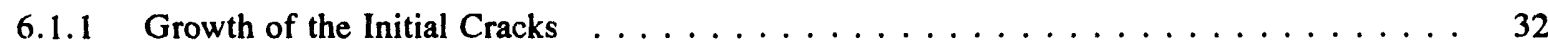

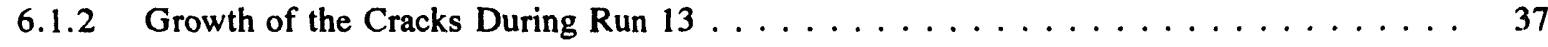

6.1.3 Growth of a Part Through Crack During Run $14 \ldots \ldots \ldots \ldots \ldots$

6.2 USE OF J-INTEGRAL PARAMETERS $\ldots \ldots \ldots \ldots \ldots \ldots \ldots \ldots \ldots$

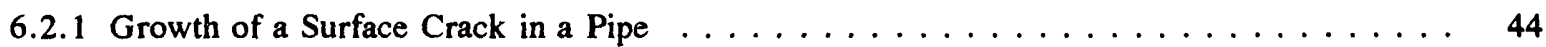

$6.3 \quad$ NET-SECTION STRESS RANGE $\ldots \ldots \ldots \ldots \ldots \ldots \ldots \ldots \ldots \ldots \ldots \ldots$

7.0 CONCLUSIONS AND RECOMMENDATIONS $\ldots \ldots \ldots \ldots \ldots \ldots \ldots \ldots \ldots \ldots$

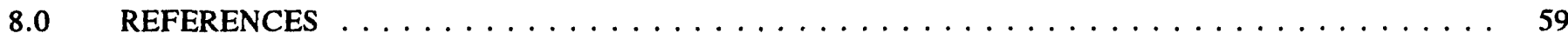

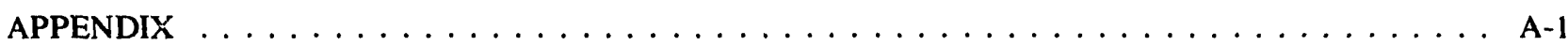




\section{LIST OF FIGURES}

Figure

Page

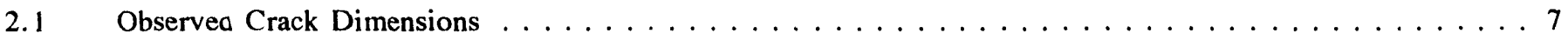

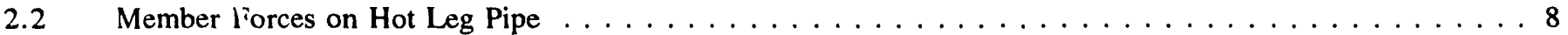

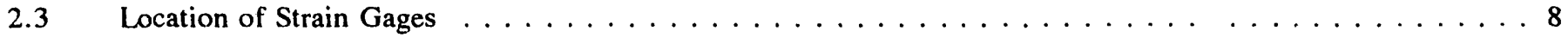

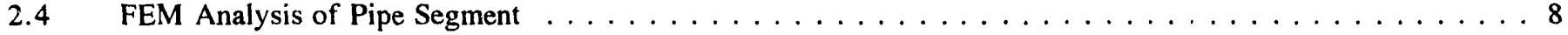

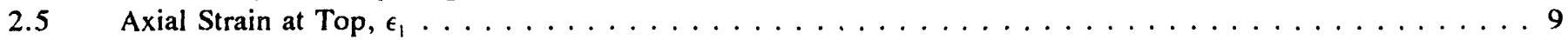

2.6 Axial Strain at Middle, $\epsilon_{2} \ldots \ldots \ldots \ldots \ldots$

$2.7 \quad$ Axial Strain at Bottom, $\epsilon_{3} \ldots \ldots \ldots \ldots \ldots$

$2.8 \quad$ Estimated Bending Moment, $\mathrm{M} \ldots \ldots \ldots$

2.9 Estimated Axial Force, $\mathbf{F} \ldots \ldots \ldots \ldots$

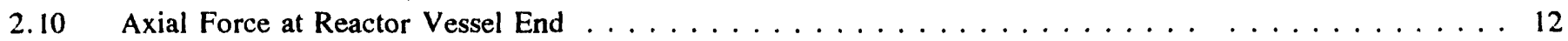

2.11 Bending Moment Using Higher Yield Stress $\ldots \ldots \ldots \ldots$

2.12 Axial Force Using Higher Yield Stress $\ldots \ldots \ldots \ldots \ldots$

3.1 Longitudinal Section of the Elbow Showing

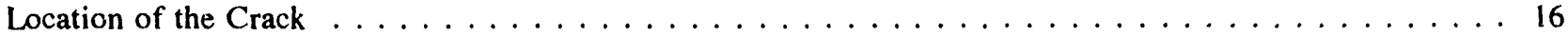

$4.1 \quad$ Initial Cracks Observed After Loading Run $11 \ldots \ldots \ldots$

$4.2 \quad$ Crack Dimensions After Loading Run $12 \ldots \ldots \ldots$

4.3 Dimensions of the Part-Through Crack Appearing After Run $13 \ldots \ldots$

4.4 Dimensions of the Crack After Termination of the Test $\ldots \ldots \ldots$

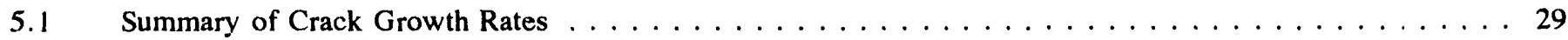

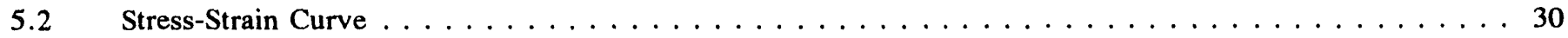

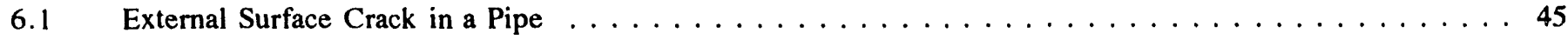

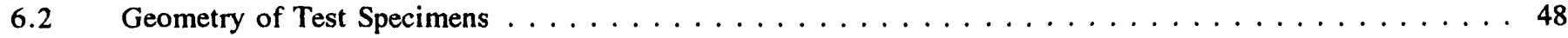

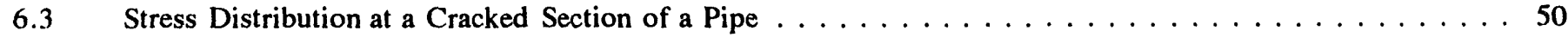

6.4 Relation Between Net-Section Stress Range and Number

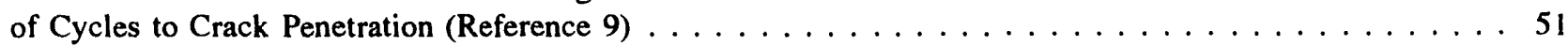

6.5 Geometry of the Cracked Pipe and Fully Plastic Stress

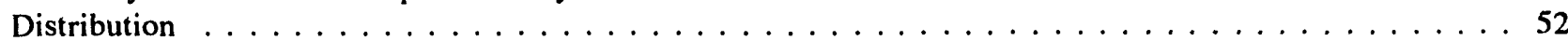




\section{LIST OF TABLES}

Table

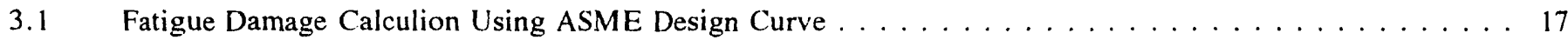

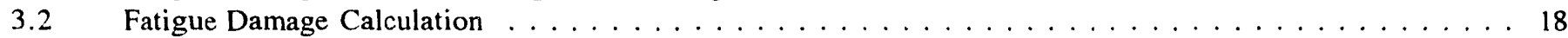

$3.3 \quad$ Fatigue Damage Calculation for Magnified Strains $\ldots \ldots \ldots \ldots$

6.1 Predicted Dimensions of Crack A after Loading Run $12 \ldots \ldots \ldots$

6.2 Predicted Dimensions of Crack 3 after Loading Run $12 \ldots \ldots \ldots$

6.3 Predicted Dimensions of Crack $\mathrm{C}$ after Loading Run $12 \ldots \ldots \ldots$

6.4 Predicted Dimensions of Crack D after Loading Run $12 \ldots \ldots \ldots$

6.5 Predicted Dimensions of Crack E after Loading Run $12 \ldots \ldots \ldots$

6.6 Predicted Dimensions of Crack F after Loading Run $12 \ldots \ldots \ldots$

6.7 Predicted Dimensions of Layer Cracks $A+B+C$ after Loading Run $13 \ldots \ldots \ldots \ldots$

6.8 Predicted Dimensions of Layer Cracks D + E after Loading Run $13 \ldots \ldots \ldots \ldots$

6.9 Predicted Dimensions of Crack $F$ after Loading Run $13 \ldots \ldots \ldots$

6.10 Boundary Correction Factor $C_{1}$ and $C_{b}$ Appearing in Equation $(6.5) \ldots \ldots$

6.11 Predicted Dimensions of Modified Cracks D $+E$ after

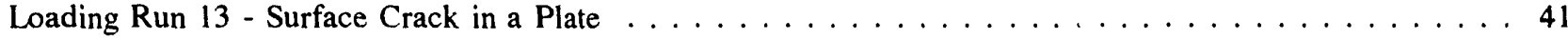

6.12 Predicted Dimensions of Modified Cracks D + E after Loading Run 13 - Surface Crack in a Pipe . . . . . . . . . . . . . . . . . . . . 41

6.13 Predicted Dimensions after Loading Run 14 - Surface

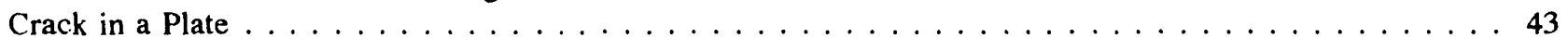

6.14 Values of $\mathrm{H}_{1}$ for a Semi-Elliptical Crack in Tension $(n=4) \ldots \ldots$

6.15 Predicted Dimensions of the Cracks Appearing after Run $12 \ldots \ldots$

6.16 Predicted Dimensions of the Cracks Appearing after Run $13 \ldots \ldots$

6.17 Crack Geometry for Type 304 Stainless Steel Test Specimens . . . . . . . . . . . . . . . . . . . . 48

6.18 Number of Loading Cycles Computed from Equation (6.16) $\ldots \ldots \ldots \ldots$

6.19 Values of Angles $\beta$ and Ratios $M_{c} / M_{o}$ for the Cracks

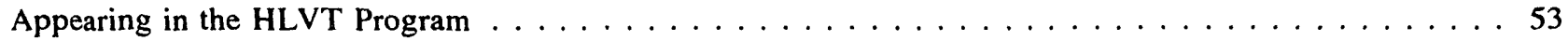

6.20 Net Section Stress Range Values and the Predicted Number of Loading Cycles for Complete Penetration of the Cracks . . . . . . . . . . . . . . . . . . . . . 54

A. 1 Peak Values of the Member Forces $(F) \ldots \ldots \ldots \ldots$

A-2 Peak Values of the Member Moments $(\mathrm{M}) \ldots \ldots \ldots$ 


\section{EXECUTIVE SUMMARY}

In a recent High Level Vibration Test (HLVT) Program performed on a modified model of one loop of a PWR primary coolant system, the input motion applied to the vibration table consisted of 14 major runs each consisting of four segments of random motion lasting about 36-40 seconds. The amplitude of the applied loading increased progressively throughout the initial test runs and for Runs 10-14 the input motion was scaled up to the limit of the vibration table so as to induce inelastic response in the model. After Run 11, several small fatigue cracks were observed on the outside surface of the elbow region of the hot leg and during subsequent runs, the cracks grew and merged together to form one large circumferential crack which continued to grow until it penetrated up to $94 \%$ of the wall thickness and extended over $31 \%$ of the circumference at the termination of the testing. The hot leg elbow was fabricated from Japanese cast stainless steel which is almost equivalent to ASME specification SA-351-CF8M. Throughout the testing the time histories of the strains and the crack openings were recorded. The crack depths and arc lengths were also measured after each loading sequence. During Run 12 and the beginning of Run 13 the cracks were mainly driven by low cycle fatigue. This was evident by the striation marks observed after exposure of the crack surface. In the remaining cycles of loading the crack propagation was due to dimple rupture and ductile tearing. During the vibration tests, the piping was subjected to a hydraulically produced internal pressure of $1.57 \mathrm{kgf} / \mathrm{mm}^{2}(2.23 \mathrm{ksi})$, which is a typical design pressure for such systems, and maintained at that pressure throughout each test. The tests were carried out at room temperature.

This report presents the results of an investigation involving the use of the HLVT data to assess the accuracy and usefulness of current state-of-the-art methodologies of predicting crack initiation and growth behavior in stainless steel pipes sunjected to complex, large amplitude loading. Several tasks are carried out to address these issues.

The time histories of the net axial force and bending moment acting on the cracked section of the pipe are developed from measurements of the axial strains in locations nearest to the cracked region. For this purpose a finite element analysis is carried out to convert the strain values, assuming a bilinear stress-strain relationship and von Mises yield criterion, into the member forces. The maximum values of the member forces are found to exceed the elastic limits due to the strain hardening of the material.

The crack initiation time is investigated by means of a local strain approach and by using the design curve of Section III of the ASME Boiler and Pressure Vessel Code. A modified strain-life equation containing an applied stress term is used in conjunction with Miner's rule of cumulative damage to compute the fatigue usage factor in the component. For the strain values (ranges) and cycles recorded through Run 11, the usage factor is found to vary between 0.502 and 1.087 . A usage factor of 0.721 is computed corresponding to the average recorded strains in the same cycles of loading. In the initial HLVT study a strain concentration factor of $k=1.35$ was estimated to occur at the cracked region. Elevating the recorded strain history through Run 11 by this factor the usage factor is found to vary between 0.925 and 2.023 . Since the crack initiation is usually associated with a usage factor of unity, the usage factors obtained in this study correlate reasonably with the HLVT experience. Using the ASME design curve for austenitic steel the average fatigue usage factors are computed as 2.179 for the strains without strain concentration and 4.670 for the elevated strains. Clearly, the ASME Code provides conservative results. The report also provides a discussion on alternate methods of treating the crack initiation phenomenon. The latter methods include those based on the classical approach of micro-mechanics formulation and the modern approach utilizing local damage theories. However, no quantitative results are derived.

The next task is an assessment of the crack growth behavior of the material involving cyclic loading. The material's crack growth characteristics were initially investigated as part of the HLVT Program. In particular, the fatigue crack growth rate of the material was determined using compact tension specimens cracked in the circumferential direction. As part of this project additional tests were performed at the David Taylor Research Center. These tests included elastic and elasticplastic fatigue crack growth rates, monotonic and cyclic J-R curve tests and tensile tests. For the fatigue crack growth rates, specimens cracked in the radial as well as the circumferential directions were used. No significant difference in the crack growth behavior between the two orientations was observed. A crack growth rate which is an order of magnitude faster than the rate determined initially in the HLVT Program was obtained for the elbow material. The discrepancy between the two rates can be attributed to the interpretation of the definition of the closure load in measuring the fluctuation in the crack driving force for specimens subjected to compressive loading. These two rates are used in the present analysis to assess the 
crack extension behavior. A third crack growth rate pertaining to stainless steel piping material is also used in the present investigation. The third rate is a fatigue crack propagation rate for austenitic piping material recently developed by a working group under the sponsorship of the ASME Pressure Vessel Research Committee and the Metals Properties Council. This growth rate was obtained by statistical correlation of all availai: data on the material in air environment.

Three engineering methodologies are used to investigate the crack growth behavior. These are: the $\Delta \mathrm{K}$ methodology (Paris law), application of $\Delta \mathrm{J}$ rates and a recently developed net-section limit load criterion. The underlying assumptions and limitations of each methodology are discussed in the report. In applying the $\Delta K$ methodology, a parametric study is undertaken to find out the role played by the various parameters influencing the analysis. In the present application. the key parameters include, the experimental crack growth rates of the material, two-directional vs. self-similar growth of the surface crack and the influence of compressive stresses on crack surfaces. It is found that the experimental rates determined for the material do not predict the crack extension behavior. However, the third rate referred to above provides, from the engineering viewpoint, better results. The maximum crack penetration may be predicted by using either a selfsimilar or two-directional growth model while the crack arc length is best predicted using a self-similar model. In the $\Delta \mathrm{J}$ methodology, which is basically similar to the $\Delta \mathrm{K}$ approach, an engineering estimate of the J-integral parameter (crack driving force) is used to compute the crack growth. The results indicate substantial improvement in the prediction capability. The net-section limit load criterion is relatively new and still untested from the practical point of view. The limit-load criterion developed in this study is based on a limited experimental data base involving pressurized cracked stainless steel pipes. The results obtained compare favorably with the actual behavior and with the results of the other methodologies. Finally, the report includes a section on the conclusions reached as a result of this effort and recommendations for refinements of the methodologies considered. 
This work was performed at Brookhaven National Laboratory and the City College of the City University of New York under the program "Analysis of Crack Initiation and Growth in the High Level Vibration Test at Tadotsu". This program was sponsored by the Office of Nuclear Regulatory Research of the U.S. Nuclear Regulatory Commission (NRC). The technical monitors for the NRC were M.E. Mayfield and A.L. Hiser.

The assistance provided by J.A. Joyce of the U.S. Naval Academy and E.M. Hackett and C. Roe of David Taylor Research Center in performing additional material testing in support of the analytical effort is sincerely appreciated. The comments provided by G. Wilkowski of Battelle Columbus Laboratory and J.A. Joyce on a draft of this report are also greatly appreciated.

The High Level Vibration Test (HLVT) Program was performed by BNL and NUPEC as part of a nuclear power technical croperative agreement between the USNRC and MITI in Japan. The authors wish to thank S. Kawak?mi, N. Tanaka, K. Koyama, as well as the many other members of the NUPEC and Mitsubishi staff who contributed to the successful completion of this prograni.

The authors would also like to express special thanks to M. Chaloupka and J. Hodgkinson for their secretarial help and dedication to the preparation of this report. 
1.0

\section{INTRODUCTION}

A High Level Vibration Test (HLVT) program was carried out recently on the seismic table at the Tadotsu Engineering Laboratory of Nuclear Power Engineering Center (NUPEC) in Japan (Reference 1). The tests were performed on a large scale modified model of one loop of a PWR primary coolant system which was previously tested by NUPEC as part of their seismic proving test program. The input motion applied to the vibration table consisted of a modified earthquake excitation of a high level which was increased up to the limit of the table so as to induce inelastic response in the model. The peak of the response spectrum of the input motion occurred at a frequency close to, but less than, the natural frequency of the test model $(6.4 \mathrm{~Hz})$. A total of 14 major test runs were performed, each consisting of four segments of random motion lasting about 36-40 seconds. * The ampliiude of the applied loading irsreased progressively throughout the initial test runs. During the early test runs (up through Run 4), the model's response was mainly elastic. For Runs 10-14 the input motion was scaled up to the capacity of the vibration table. Run 14 was terminated after applying one segment of the motion which lasted about 9-10 seconds. During the vibration tests, the piping was subjected to a hydraulically produced internal pressure of $1.57 \mathrm{kgf} / \mathrm{mm}^{2}(2.23 \mathrm{ksi})$, which is a typical design pressure for such systems, and maintained at that pressure throughout each test. The tests were carried out at room temperature.

After Run 11, several small fatigue cracks were observed on the outside surface of the elbow near a weld joint connecting the straight and elbow parts of the hot leg, and continued to grow during subsequent runs. In the same run, the upper region of the straight pipe registered the highest strain of $2.28 \%$ recorded in the test program. During Runs 12-14 the surface crack grew and merged together to form one large part-through circumferential crack which continued to propagate until it penetrated up to $94 \%$ of the wall thickness and extended over approximately $31 \%$ of the circumference at the termination of the testing. The pipe's mean radius is

\footnotetext{
*There were actually more than 14 test runs performed since some test runs were repeated and there were a number of low level preliminary tests. For some tests only one segment of random motion was applied. A complete description of the test runs is contained in Reference 1 .
}

$161.9 \mathrm{~mm}(6.4$ inches $)$ and its thickness is $29 \mathrm{~mm}(1.14$ inches). The elbow part was fabricated from Japanese cast stainless steel which is almost equivalent to ASME specification SA-351-CF8M. The outer surface of the elbow region in which the cracks were located was weld repaired by the material manufacturer before commencing the vibration testing. The yield and ultimate strengths of the weld material were higher than the base metal. The time histories of the crack openings were monitored and measured by three clip gages installed after Run 11 . Crack depths were measured by the electro-resistance method and also by means of installing a thin piano wire into the cracks.

The purpose of the current study is to analyze the crack initiation and growth behavior using current stateof-the-art methodologies. Fatigue life and fatigue crack propagation have been studied extensively in the iiterature (see, for example, References 2-5). A widely used method of predicting fatigue life is through the application of the fatigue design curves ( $\mathrm{S} / \mathrm{N}$ curves) of Section III of the ASME Boiler and Pressure Vessel Code (Reference 5). These curves are based on experimental data relating the stress (or strain) to the number of loading cycles required to fail an unnotched specimen of the material. Several methods have been proposed to predict the behavior of crack extensions in real structures. The most commonly used method is the so-called " $\Delta K$ methodology" (Paris Law) in which the fatigue crack growth is expressed as a power function in $\Delta \mathrm{K}$, the fluctuation in the stress-intensity factor. For loads beyond the elastic limit the concept of the stress-intensity factor is not strictly applicable and other parameters are needed. One possibility is to use the range in the $J$-integral parameter $(\Delta \mathrm{J})$ to describe the crack driving force (Reference 6). Other methods which have been proposed to treat crack growth in the plastic range include linear summation of fatigue crack growth and ductile tearing (Reference 7), the use of cyclic J-R parameters (Reference 8), net-section stress range method (Reference 9), and crack-tip opening displacement (Reference 3 ).

Section 2.0 presents an estimate of the time histories of the net axial force $(F)$ and bending moment (M) acting on the cracked section of the pipe. These were developed from measurements of the strains in strain gages nearest to the crack locality. A finite element analysis was performed to convert the strain values into the member forces assuming a bilinear stress-strain relationship. The von Mises yield criterion and kinematic strain hardening rule were assumed for the analysis. 
The crack initiation analysis of the HLVT data is discussed in Section 3.0 (see also Reference 1). A widely used local strain equation (Reference 10) and the design curve of Section III of the ASME Boiler and Pressure Vessel Code are used in conjunction with Miner's rule for variable amplitude loading cycles to compute the fatigue damage factor. The fundamentals of the crack initiation phenomenon are also discussed from the view point of micro-mechanics (References 11-14) and the modern damage theory approach (References 15-16).

Section 4.0 describes the crack growth behavior observed in the HLVT program and illustrates the progress of the crack growth and the measured crack depths and arc lengths after loading Runs 11-14, respectively. During Run 12 and the beginning of Run 13, the cracks propagated mainly by fatigue. This was evident by the striation marks observed after the crack surface was exposed and examined by scanning electron microscope (Reference 1). The number of striation marks correspond approximately to the number of loading cycles. During Runs 13 and 14 the crack propagation was essentially due to dimple rupture and ductile tearing.

The crack growth material characteristics are discussed in Section 5.0. Tests were performed in Japan (Reference 1) and at the David Taylor Research Center [DTRC](Reference 17) to establish the crack growth characteristics of the elbow piping material. The tests in Japan utilized compact tension specimens, cracked in the circumferential direction (L-C), to establish the crack growth rate (see Equation 5.1). The tests conducted at DTRC consisted of cyclic elastic and elastic-plastic fatigue crack growth rate tests, monotonic and cyclic J-R curve tests and monoconic and cyclic tensile tests. The fatigue crack growth rate tests included both low cycle as well as high cycle data generated using specimens cracked in the circumferential (L-C) and the radial directions (L-R). No significant difference between the L-C and L-R test results were observed. The resulting crack growth rate is given in Equation (5.2). The rate in Equation (5.2) differs from the one generated from the Japanese data, Equation (5.1), by about one order of magnitude due to the interpretation of the closure load in measuring the fluctuation in the crack driving force for specimens subjected to compressive loading. The material's true stress-strain characteristics can be expressed in a Ramberg-Osgood form with the strain exponent, $n=4$, and the coefficient, $\propto=3.5$ (see Equation 5.5). A third crack growth rate used in the present analysis is a fatigue crack propagation rate for austenitic piping materials recently developed by a working group under the sponsorship of the Pressure Vessel Research Committee and Metals Properties Council (References 18-19) and is represented by Equation (5.3). This growth rate, i.e., Equation (5.3), was obtained by statistical correlation of all available data on austenitic stainless steels of various chemical compositions in air environment.

Section 6.0 presents the methods used to predict the crack growth behavior observed in the HLVT Program. Three methods are used: The $\Delta \mathrm{K}$ methodology (Paris Law), the $J$-integral and $\Delta J$ concept, and the netsection stress range method for circumferentially cracked piping. For the $\Delta \mathrm{K}$ methodology, ear $h$ surface crack was modeled by a semi-elliptical shape and a sensitivity study was performed to find the influence of the various parameters affecting the analysis of crack propagation. In the present application three key parameters are found to influence the results. These are: the experimental fatigue crack growth rates of the material, two-directional versus self-similar growth of a semi-elliptical crack and the influence of compressive stresses on crack surfaces. An in-house fatigue crack growth computer program was used to compute the predicted dimensions of the cracks appearing after loading Run. 11-14 and the results are shown in tabular form. For ease of comparison, the tables of results also give the measured initial and final crack dimensions. The $\mathrm{J}$-integral methodology is similar to the $\Delta \mathrm{K}$ methodology except that the crack driving force is now expressed in terms of the range in the $\mathrm{J}$-integral which consists of an elastic and a plastic part. The elastic part is related to the stress-intensity factor used in the $\Delta \mathrm{K}$ methodology while for the plastic contribution an estimation scheme based on the deformation theory of plasticity is typically used. A recently published Jintegral estimation of a semi-elliptical part-through circumferential crack in a pipe opened out by an axial load is used to compute the crack growth (Reference 28). The solution gives the value of the J-integral at the deepest point on the surface crack which allow selfsimilar crack growth anaiysis. Utilizing the crack growth rates of the material, the predicted maximum penetrations of the cracks are computed and compared with the measured values. The net-section stress range method is based on the net-section limit load failure criterion (Reference 32). It involves computing a net-section stress range for a cracked pipe section and determining the corresponding number of loading cycles required to drive the crack through the pipe's thickness. The relation between the net-section stress range and the number of loading cycles is based on experimental data (Reference 
9) which indicates a linear relationship between the netsection stress range and the logarithm of the number of loading cycles required for through-thickness crack penetration.

Finally, Section 7.0 , presents the conclusions reached in this investigation and some recommendations for improving the state-of-the-art methodologies of predicting crack initiation and growth behavior in stainless steel piping material. The advantages, capabilities and limitations of each of the methodologies are pointed out and suggestions for refinement of the analyses involved are included. 


\section{ESTIMATION OF MEMBER FORCES}

The recorded time histories of the strain gages (Reference 1) were used to estimate the member forces (axial force and bending moment) in the hot leg pipe of the HLVT specimen. Since each recording only represents the strain or relative displacement at a single location, certain assumptions and additional anal ses were necessary to determine the above quantities as described below. The location and measured dimensions of the cracks observed in the HLVT test runs are shown in Figure 2.1.

The time history of member forces, i.e., the bending moment $M$ and the axial force $F$, were estimated at the location of the cracks for Run No.11. Figure 2.2 shows the definition of the positive directions of the member forces on the hot leg pipe. The member forces are determined using the axial strain gage readings at the cross-section HR3A (Reference 1), which is nearest to the crack location. Figure 2.3 shows the location of six strain gages at this cross-section. Among these strain gages, the gage No. 153 failed after recording a peak strain of about $2.3 \%$ and the gage No.144 also failed during Run 11 . Based on the study of the HLVT, the strain reading at No. 153 was replaced by the reading of gage No. 149 after multiplying by a factor of 1.6. The following three strain time histories were used in the analysis:

$$
\begin{aligned}
& \text { Strain at Top, } \epsilon_{1} \ldots \ldots \ldots 1.6 \times \mathrm{G} 149 \\
& \text { Strain at Middle, } \epsilon_{2} \ldots \ldots . .0 .5 \times(\mathrm{G} 152+\mathrm{G} 155) \\
& \text { Strain at Bottom. } \epsilon_{2} \ldots \ldots . \mathrm{G} 156
\end{aligned}
$$

The time histories of the above three strains are shown in Figures 2.5 to 2.7 .

A finite element analysis was performed to convert the strain values to the member forces, $F$ and $M$. Figure 2.4 shcws the finite element model and the assumed parabolic strain distribution at the cross-section. Only a short segment of the straight portion of the hot leg pipe was modeled using 24 plate elements. Each element has a uniform strain distribution in the axial direction. The internal static pressure of $157 \mathrm{kgf} / \mathrm{cm}^{2}$ $(2.23 \mathrm{ksi})$ was first applied and the axial strain was then applied for each element. This axial strain was obtained by an interpolation from the parabolic distribution at every calculation step as illustrated in Figure $2.4(b)$. As for the bouidary condition. the axial displacement at one end was restricted while the above strain distribution was applied at the other end. No restriction was imposed on the deformation of the cross-section (e.g., ovalization) at both ends. The following material parameters were used:

Elastic Modulus, $\mathrm{E}=1.99 \times 10^{6} \mathrm{kgf} / \mathrm{cm}^{2}\left(28.3 \times 10^{3} \mathrm{ksi}\right)$

Post-Yield Modulus, $E_{y}=4.94 \times 10^{4} \mathrm{kgf} / \mathrm{cm}^{2}(700 \mathrm{ksi})$

Yield Stress, $\sigma_{y}=2430 \mathrm{kgf} / \mathrm{cm}^{2}(3 千 .6 \mathrm{ksi})$ at bottom

$$
3190 \mathrm{kgf} / \mathrm{cm}^{2}(45.4 \mathrm{ksi}) \text { at top }
$$

The yield stress for each element of the model was determined by linearly interpolating the top and bottom values given in Equation (2.2). The von Mises yield criterion ar.d kinematic strain hardening rule were assumed in the analysis. Figures 2.8 and 2.9 display the calculated member forces, $M$ and $F$. The maximum values are found as follows:

$$
\begin{aligned}
& M_{\max }=9.3 \times 10^{7} \mathrm{kgf}-\mathrm{mm}(8072 \mathrm{kip}-\mathrm{in}) \\
& F_{\max }=7.7 \times 10^{5} \mathrm{kgf}(1698 \mathrm{kips})
\end{aligned}
$$

Using the average yield stress, $\sigma_{\mathrm{y}}=28.1 \mathrm{kgf} / \mathrm{mm}^{2}(40$ ksi) the yield moment and axial force are found as follows:

$$
\begin{aligned}
& M_{y}=6.21 \times 10^{7} \mathrm{kgf}-\mathrm{mm}(5390 \mathrm{kip}-\mathrm{in}) \\
& \mathrm{F}_{y}=8.29 \times 10^{4} \mathrm{kgf}(1828 \mathrm{kips})
\end{aligned}
$$

The comparison of the two sets of values in Equations (2.3) and (2.4) indicate that the estimated applied moment exceeded the elastic limit due to the strain hardening of the material.

To further check the adequacy of the analysis model, the axial force of a cross-section of the hot leg pipe at the reactor vessel end (R.V.-end), i.e.. HRI, was calculated using the same analysis procedure. The time history of the calculated axial force is shown in Figure 2.10. The maximum values are compared as follows:

$$
\begin{array}{ll}
\text { At elbow-end: } & F_{\max }=7.7 \times 10^{5} \mathrm{kgf}(1698 \mathrm{kips}) \\
\text { At RV-end: } & F_{\max }=7.1 \times 10^{5} \mathrm{kgf}(1565 \mathrm{kips})
\end{array}
$$

It seems that the time histories at the two cross-sections of the hot leg pipe are quite similar in magnitude and shape. 


\subsection{Member Forces}

An additional analysis was performed using a higher yield stress at the top of the pipe as follows:

$$
\text { Yield stress, } \begin{aligned}
\sigma_{\mathrm{y}} & =2430 \mathrm{kgf} / \mathrm{cm}^{2}(34.5 \mathrm{ksi}) \text { at bottom } \\
& =4100 \mathrm{kgf} / \mathrm{cm}^{2}(58 \mathrm{ksi}) \text { at top }
\end{aligned}
$$

The remaining material properties are as stated in Equation (2.2). In Equation (2.6) the stress at the top is the nominal flow stress which is the arithmetic mean of the yield and ultimate strengths. Figures 2.11 and 2.12 show the calculated bending moment and axial force. A numerical listing of the peaks of these time histories is given in the Appendix. It should be mentioned that the time histories of the strains used in the analysis to compute the member forces contained many small cycles which can be attributed to noises in the recorded data. These so called "noise cycles" produced small member force cycles and, accordingly, were filtered out from the results given in Figures 2.11 and 2.12 and also from the numerical listing of the peak values given in the Appendix. The peaks of the filtered cycles were approximately one order of magnitude smaller than the minimum peaks included in the member forces $M$ and $F$. 


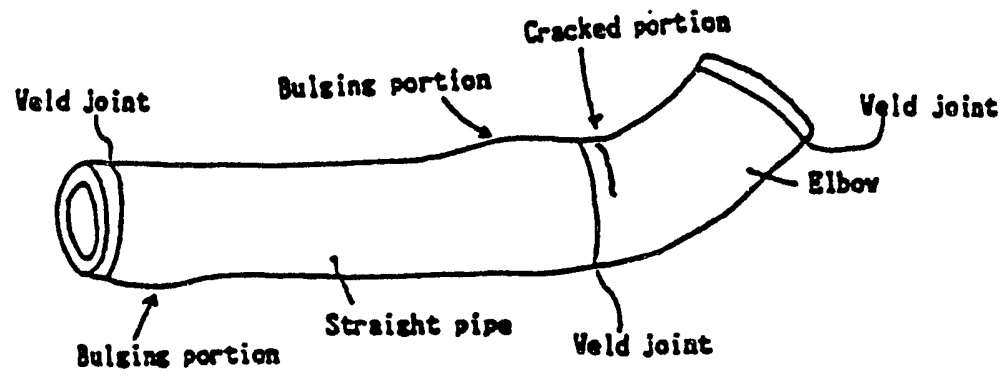

Crack depth 28
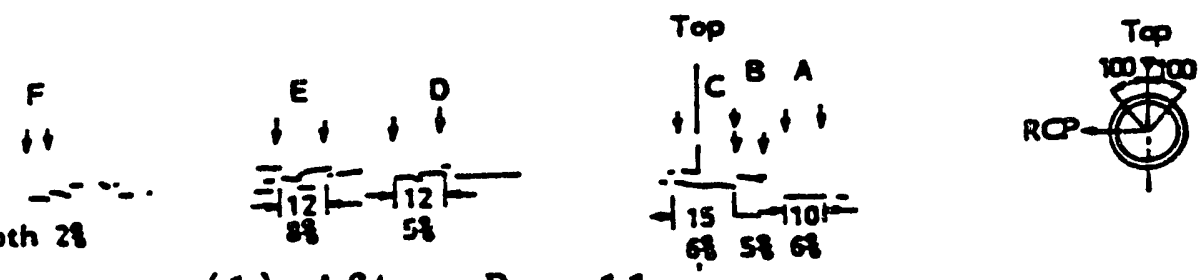

\section{(1) After Run 11}

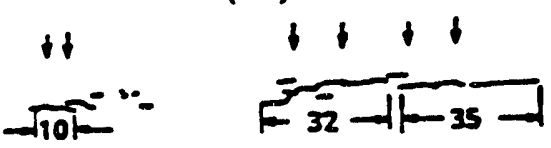

Crack depth of

$$
148168
$$
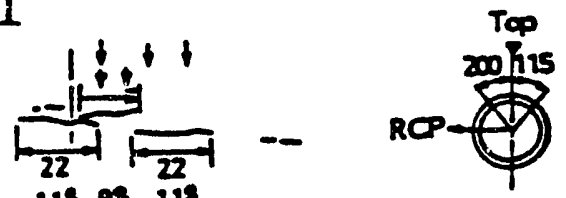

\section{(2) After Run 12}

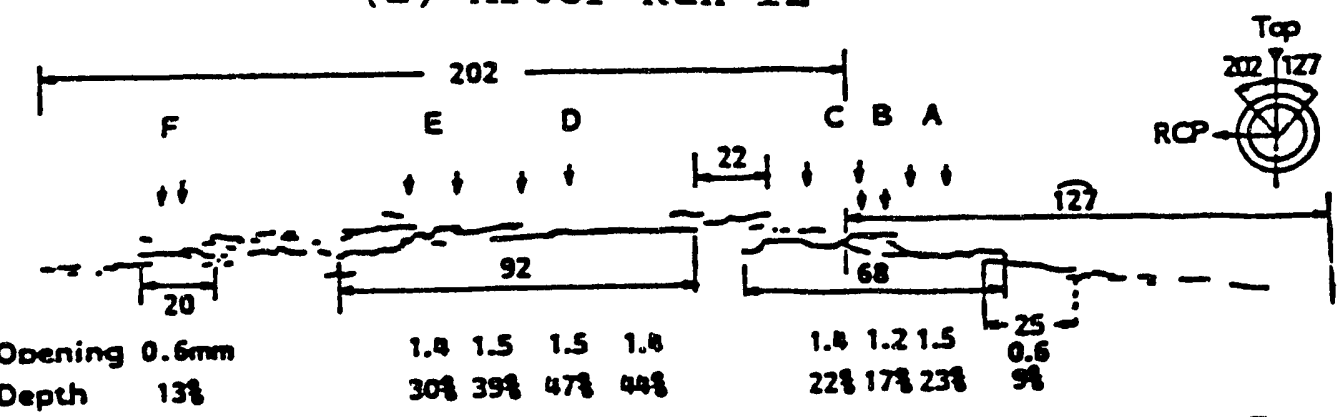

Depeth 138

\section{(3) After Run 13}

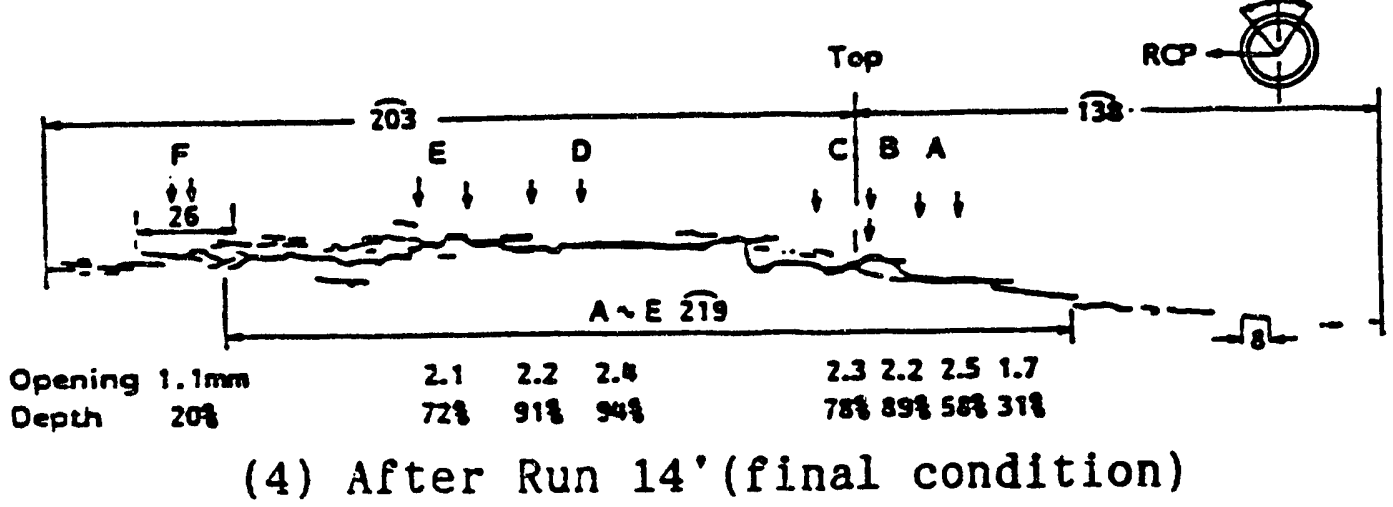

Figure 2.1 Observed Crack Dimensions 


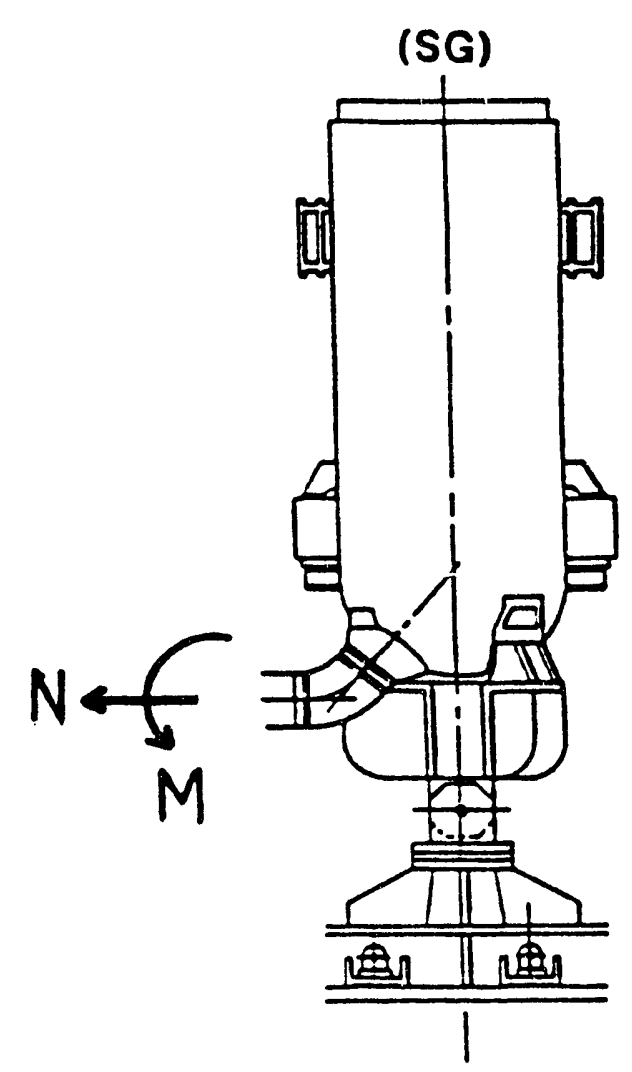

Figure 2.2 Member Forces on Hot Leg Pipe

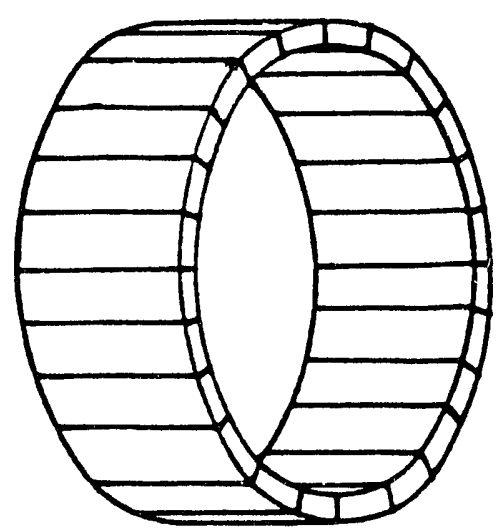

(a) Analysis Model
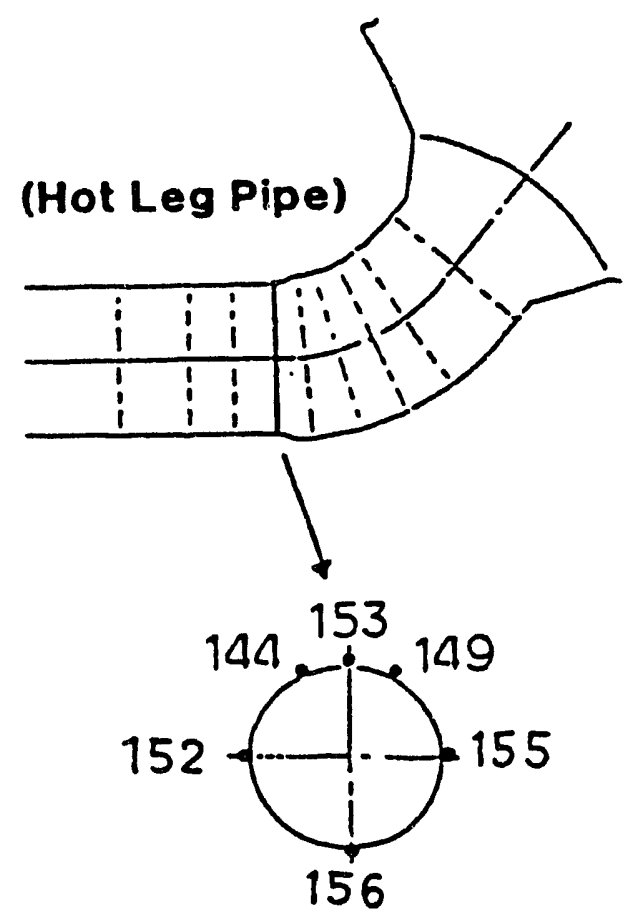

Figure 2.3 Location of Strain Gages

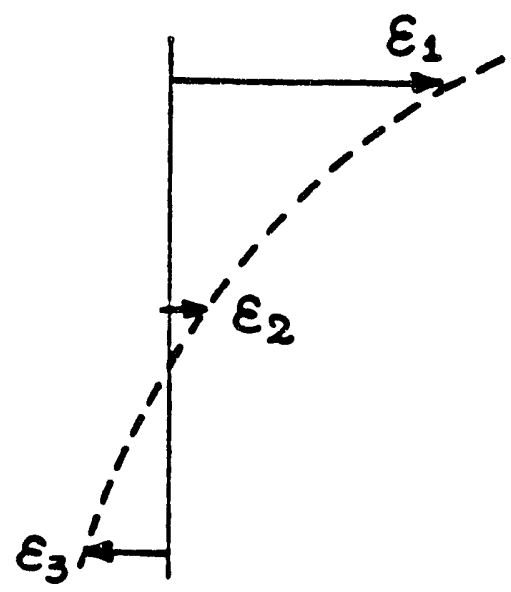

(b) Strain Distribution

Figure 2.4 FEM Analysis of Pipe Segment 


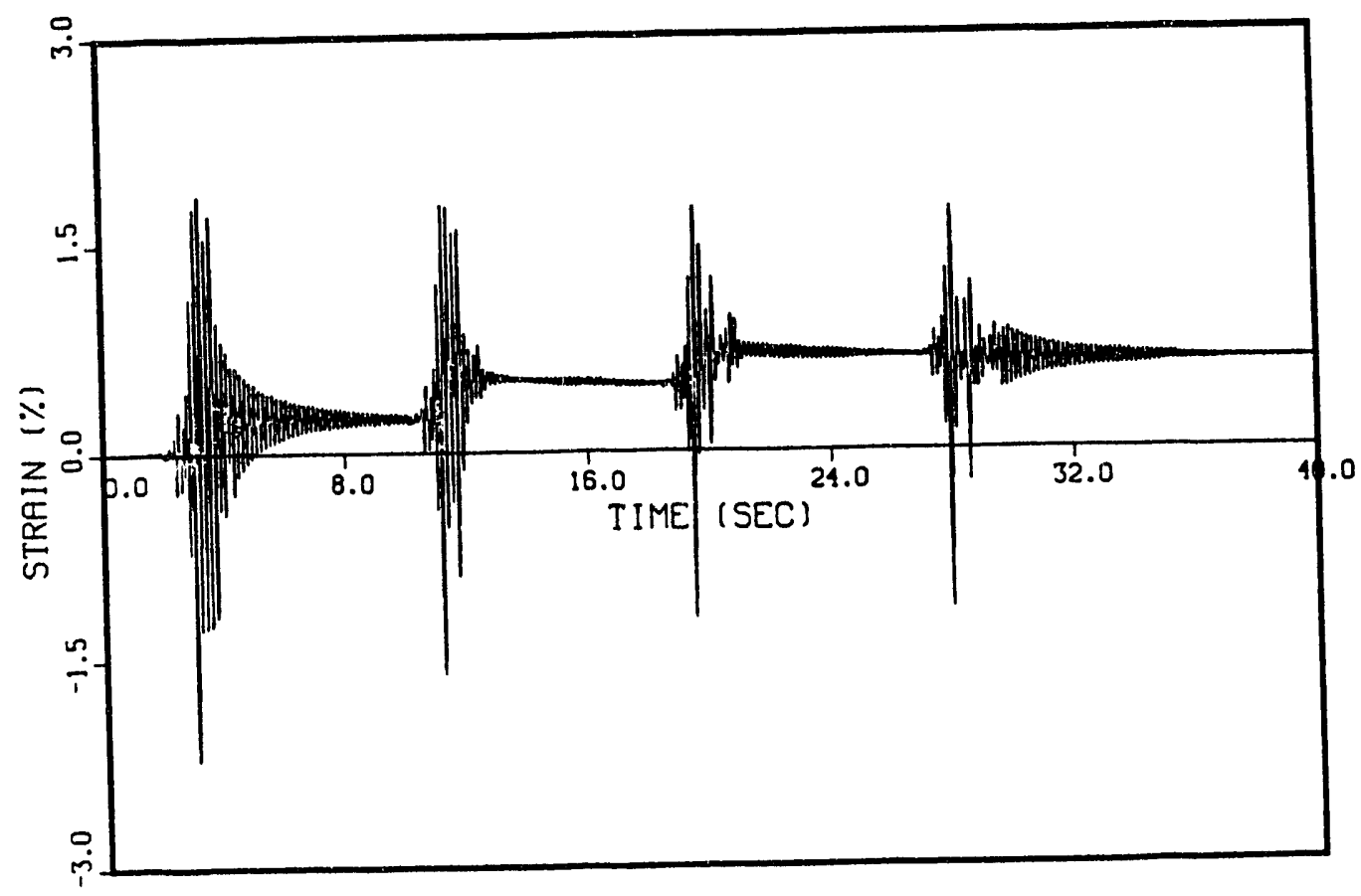

Figure 2.5 Axial Strain at Top, $\epsilon_{1}$

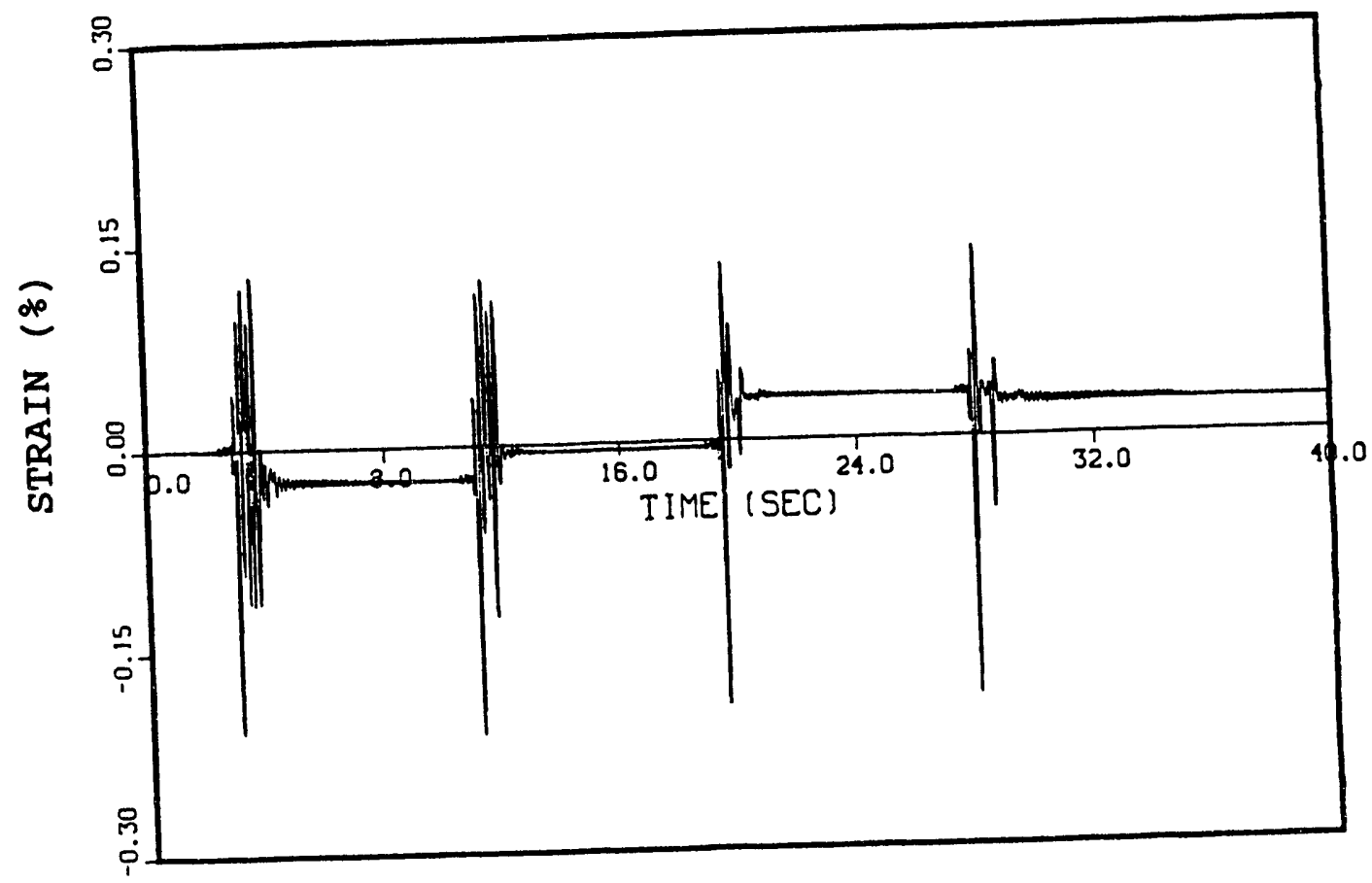

Figure 2.6 Axial Strain at Middle, $\epsilon_{2}$ 
2.0 Member Forces

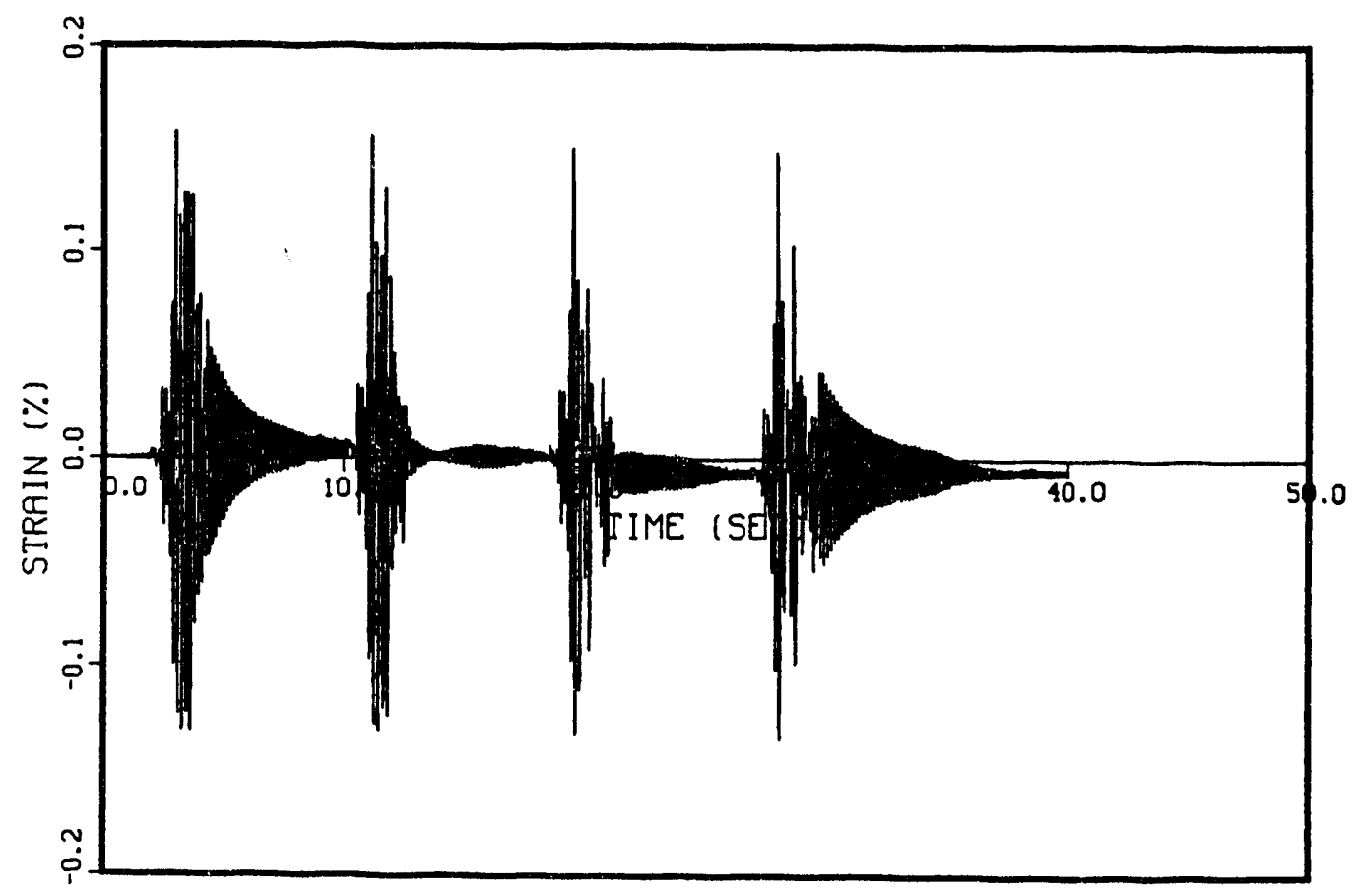

Figure 2.7 Axial Strain at Bottom, $\epsilon_{3}$ 


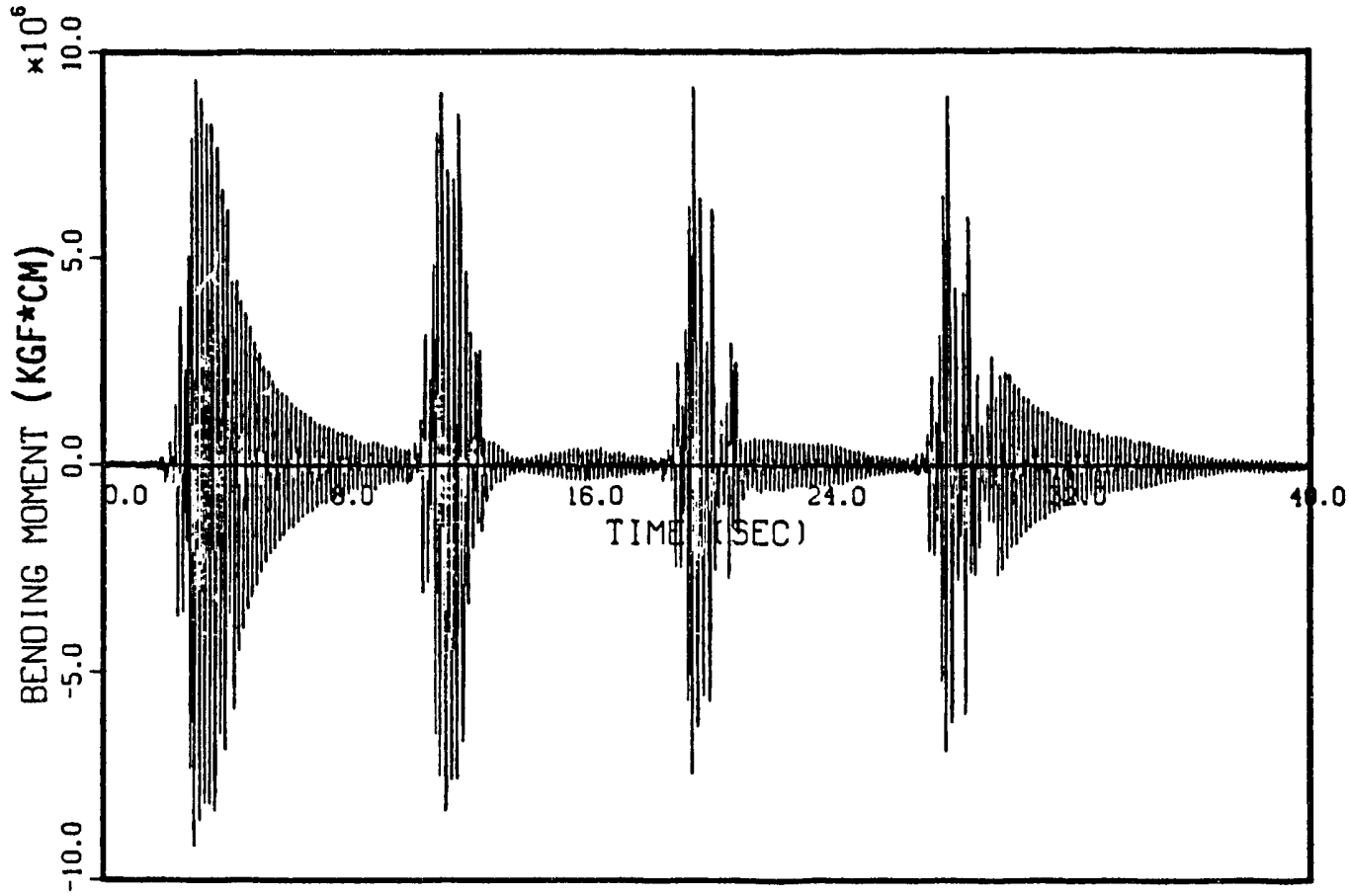

Figure 2.8 Estimated Bending Moment, M

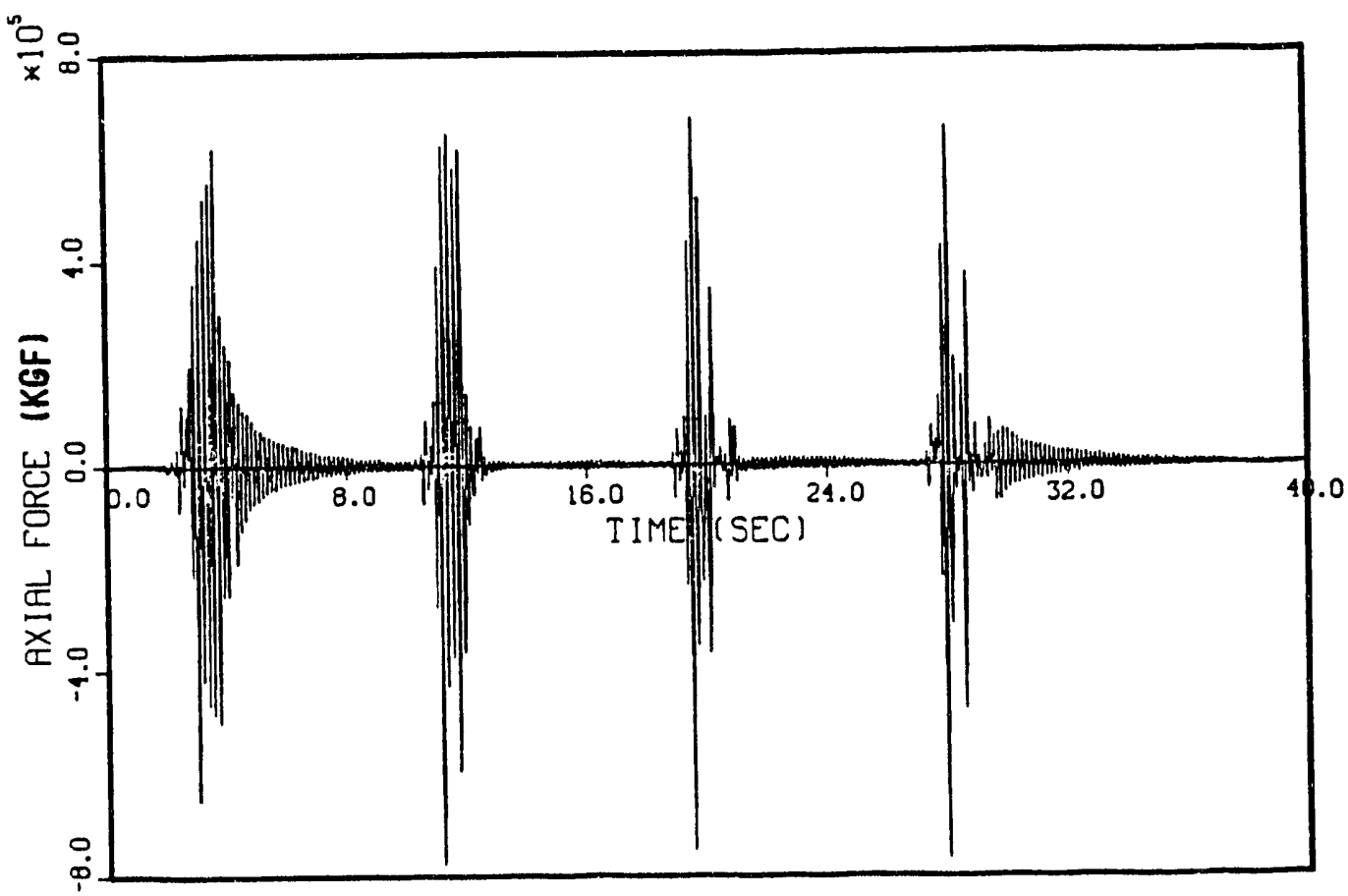

Figure 2.9 Estimated Axial Force, F 


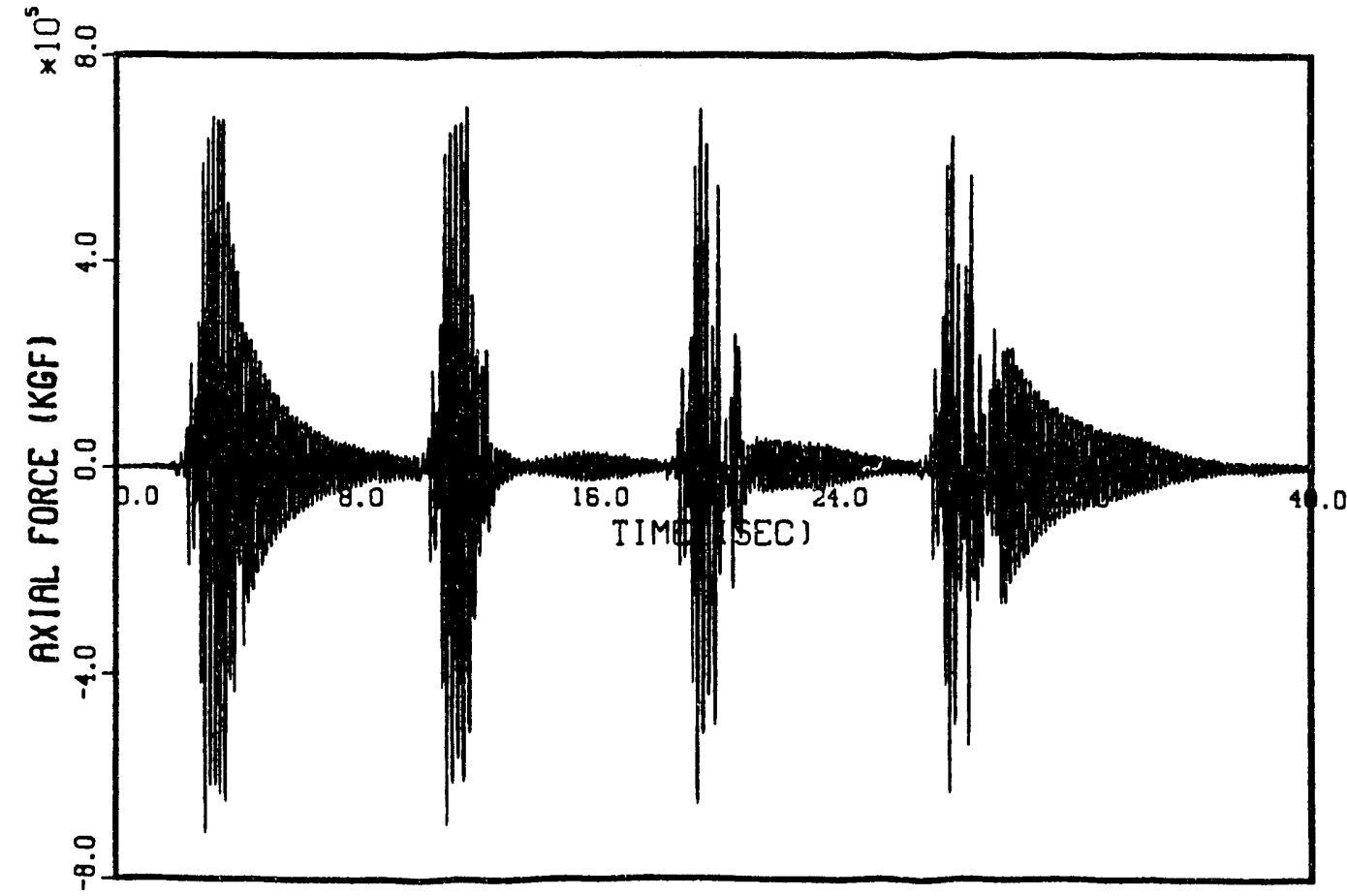

Figure 2.10 Axial Force at Reactor Vessel End 


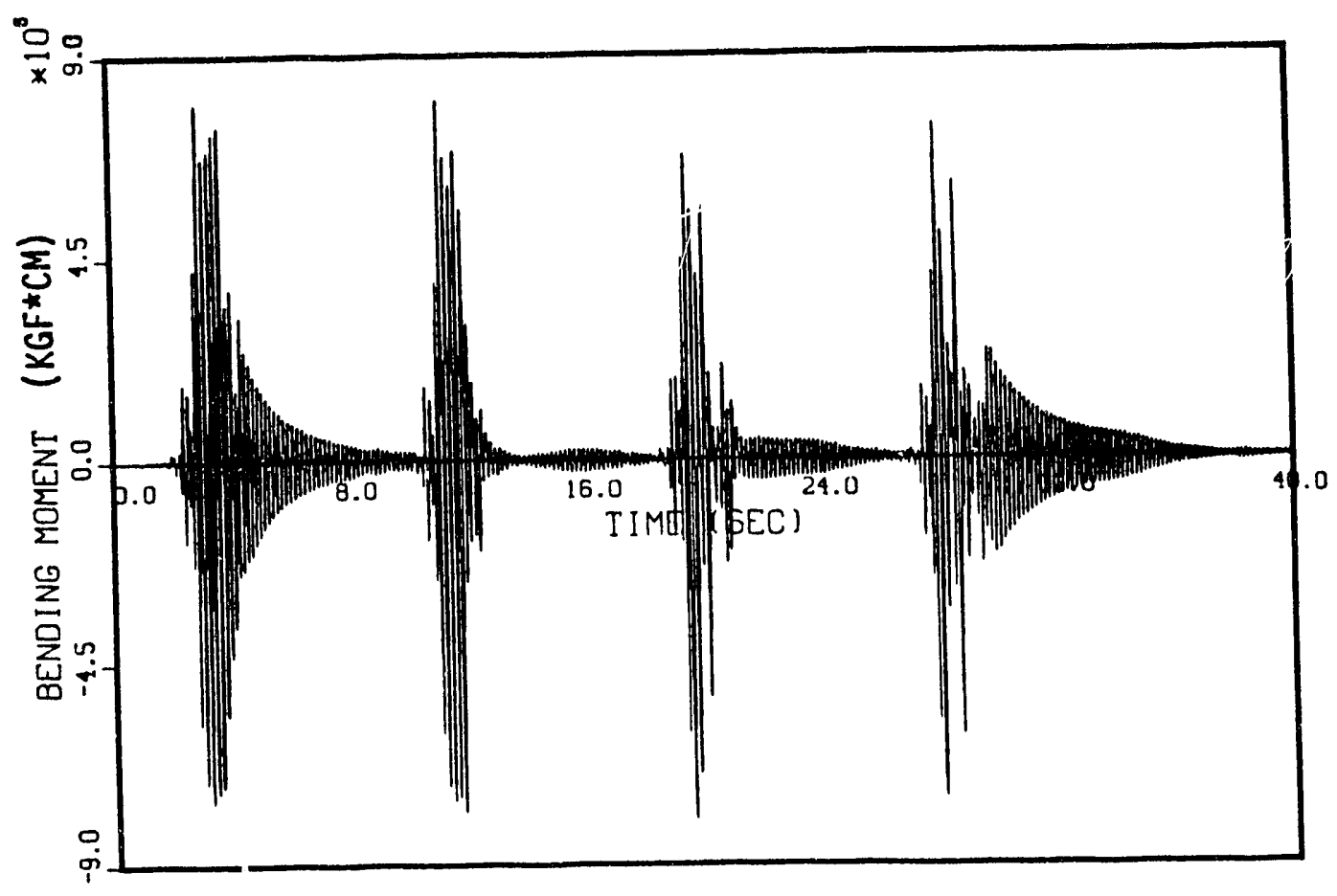

Figure 2.11 Bending Moment Using Higher Yield Stress

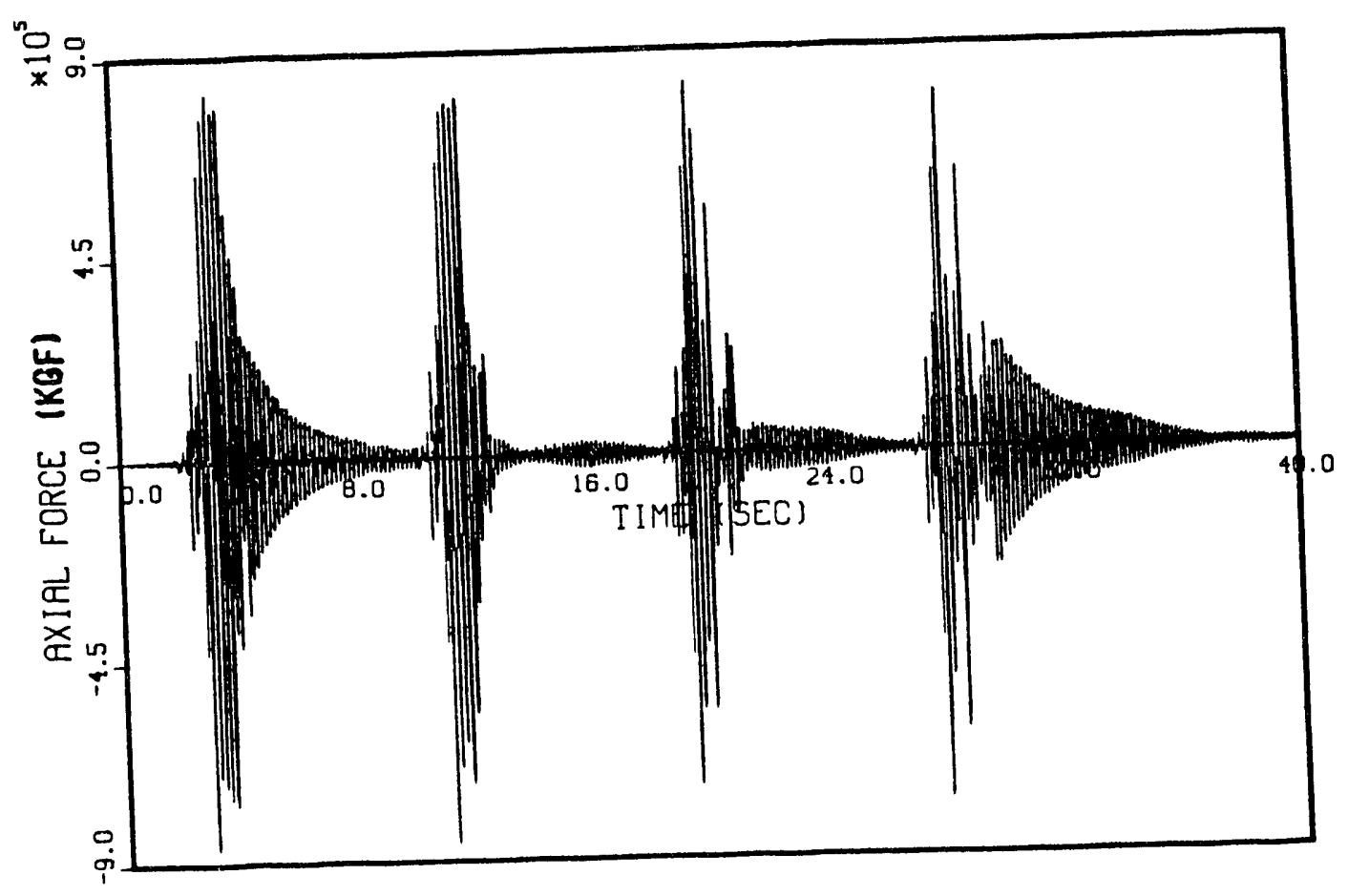

Figure 2.12 Axial Force Using Higher Yield Stress 
After Run 11 of the HLVT Program, small fatigue cracks were observed on the outside surface of the elbow near a welded joint connecting the straight and elbow parts of the hot leg as indicated in Figure 3.1. The elbow part was fabricated from Japanese cast stainless steel which is almost equivalent to ASME specification SA-351-CF8M. Initially, several cracks were observed, and during subsequent runs (Runs 12-14), the cracks grew, joined together and formed one dominant crack which continued to grow until it penetrated almost $94 \%$ of the wall thickness and $31 \%$ of the outside circumference before the termination of the test. The outer surface of the elbow region in which the cracks were located was weld repaired by the material manufacturer before commencing the vibration testing. The $0.2 \%$ yield stress and ultimate strength of the weld material, which was identical to that used for the weld joint, were higher than the base metal (Reference 1). The welding process was the Shielded Metal Arc Welding method, and after welding, the material was buff polished to obtain a smooth finish $(2-3 \mathrm{~mm}$ thick). The residual stresses in the weld region most likely were smoothed out by the high amplitude cyclic loading of the HLVT Program. This section provides a discussion on the mechanisms of crack initiation and the various engineering methods of predicting the initiation time or fatigue life. The methodologies involved are described in the following subsections.

\subsection{ASME Code Approach for Crack Initiation}

The most commonly used method of predicting fatigue life is through the application of the fatigue design curves (S/N curves) of Section III, Appendix I, of the ASME Boiler and Pressure Vessel Code (Reference 5). These curves are based on experimental data relating the stress (or strain) to the number of loading cycles required to fail an unnotched specimen of the material. To achieve conservatism, safety factors of 2 on stress range and 20 on number of cycles to failure have been applied to the data to account for environmental and other factors. The code requires that a component's cumulative usage factor should not exceed unity during its design life. In the present application, the fatigue usage factor can be computed using the approach of Miner's rule to account for fatigue damage under variable amplitude cyclic loading and the rain flow method of counting the number of loading cycles. This methodology was applied in Reference 1 to the HLVT data using three different fatigue strength curves, namely, the ASME best-fit curve for the material, a Japanese design curve and a curve based on experimental fatigue data obtained from test specimens of the elbow material after termination of the vibration test. Using the ASME best-fit data, the fatigue usage factor accumulated through Run 11 is found to be 0.231 while after run 14 , where the crack almost penetrated the thickness of the pipe, the usage factor is computed to be $\mathbf{0 . 4 5 4}$. The Japanese design curve yielded usage factors of 2.389 after run 11 and 3.804 after run 14 . The corresponding results using the fatigue curve developed from the post-test data were 0.491 and 1.040 , respectively. If one interprets the fatigue life as the time required to crack initiation then the design curve yields conservative results; however, the curves based on the ASME best-fit data and the post-test fatigue data do not correlate with what was observed in the HLVT Program. If one interprets the fatigue life as the time required for through-thickness penetration of the crack then the posttest fatigue data yielded reasonable results while the design curve yielded conservative results. Refer to Reference 1 for the assumptions made in reaching these results.

In this study the fatigue usage factors were also obtained using the fatigue design curve for austenitic steel in the ASME code (Fiqure I.9.2.1 in Section III of the code, Reference 5). For runs 1 through 11 , the strain cycle count, $\mathrm{N}_{\mathrm{i}}$, determined by the rain-flow method, and the corresponding strain ranges, $\Delta \epsilon(\%)$ were determined in the initial HLVT study. This data appears in Table 3.1 below. Utilizing this data equivalent stress intensity components, $s_{i}$, are computed for each strain range and the corresponding number of cycles, $N_{f i}$, are found from the ASME design curve. The results of the calculations for the fatigue damage appear in Table 3.1. The fatigue usage factor varies between 1.375 and 2.982 .

In order to include the influence of strain concentration at the crack location, the strain ranges, $\Delta \epsilon$, in Table 3.1 need to be multiplied by a strain concentration factor. Following Neuber's approach a strain concentration factor of $k=1.35$ was estimated in Reference 1 (see Appendix $H$ of this Reference). Multiplying the strain ranges, $\Delta \epsilon$, in Table 3.1 by $\mathrm{k}=$ 1.35 , repeating the fatigue damage computation using the ASME code design curve, it is found that the average usage factor is 4.670 . These results clearly indicate that the ASME design curve provides conservative results. 


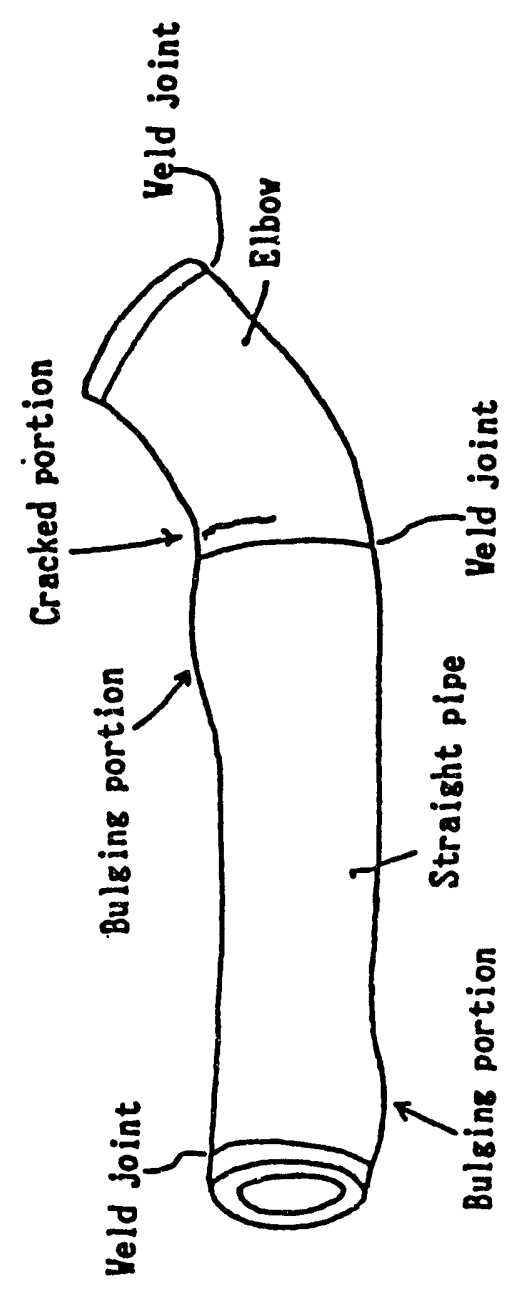

NUREG/CR-6078

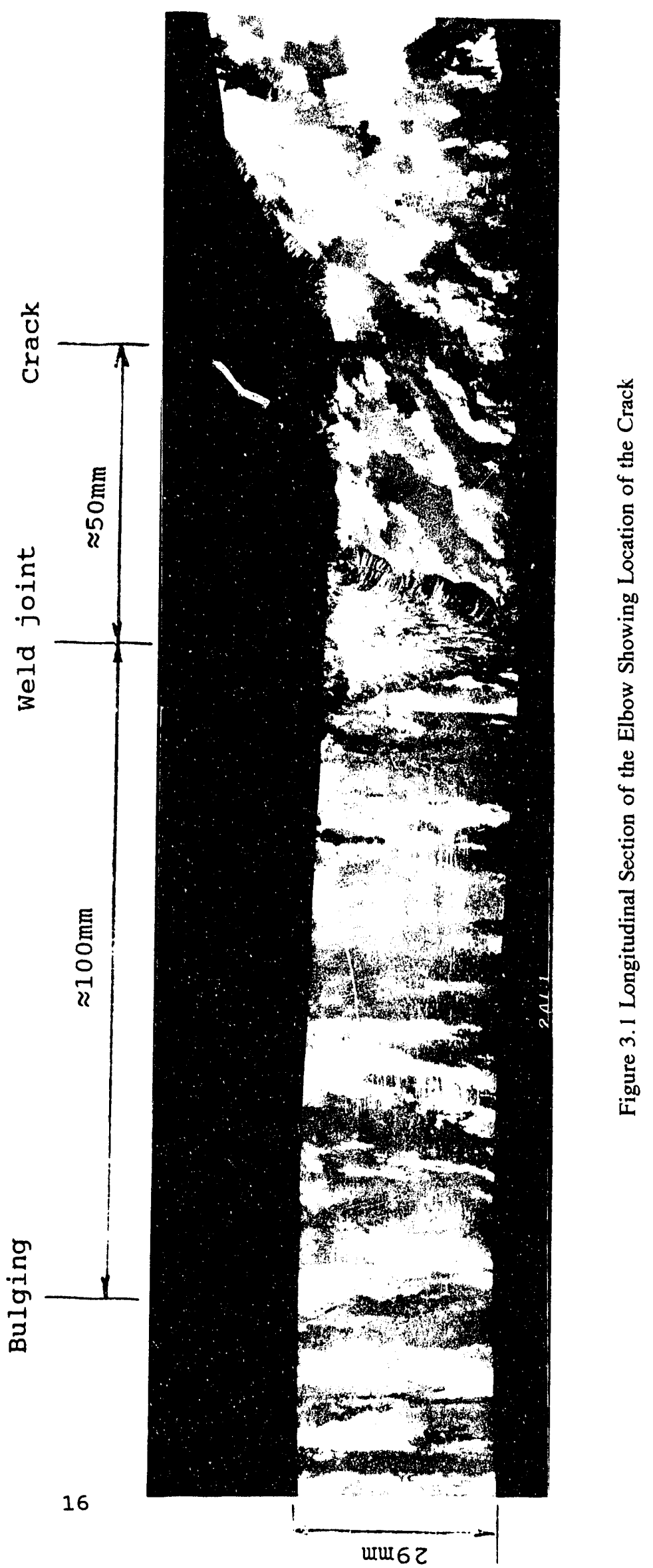


Table 3.1 Fatigue Damage Calculations Using ASME Design Curve

\begin{tabular}{|c|c|c|c|c|c|c|c|c|}
\hline \multirow{2}{*}{$\begin{array}{r}\text { Strain Range } \\
\Delta \epsilon(\%)\end{array}$} & \multirow[t]{2}{*}{$\mathrm{n}_{\mathrm{i}}$} & \multirow{2}{*}{$\begin{array}{c}\text { Stress } \\
\text { Intensity }\end{array}$} & \multirow{2}{*}{\multicolumn{2}{|c|}{$\begin{array}{l}\mathrm{N}_{\mathrm{fi}} \\
\text { ASME Design } \\
\text { Curve }\end{array}$}} & \multicolumn{4}{|c|}{ Usage Factor } \\
\hline & & & & & & U.F. & & Total \\
\hline $0.1-0.5$ & 620 & $14-17$ & $2^{10}$ & -6674 & 0.0 & -0.093 & 0.0 & $-\quad 0.093$ \\
\hline $0.5-1.0$ & 230 & $71-42$ & 6674 & -577 & 0.35 & - $\quad 0.399$ & 0.035 & - 0.492 \\
\hline $1.0-1.5$ & 101 & $142-212$ & 577 & -173 & 0.175 & - 0.584 & 0.210 & -1.076 \\
\hline $1.5-2.0$ & 43 & $212-283$ & 173 & -82 & 0.249 & -0.524 & 0.459 & -1.600 \\
\hline $2.0-2.5$ & 29 & $283-354$ & 82 & $-\quad 48$ & 0.354 & -0.604 & 0.813 & $-\quad 2.200$ \\
\hline $2.5-3.0$ & 12 & $354-425$ & 48 & -31 & 0.250 & -0.387 & 1.063 & - 2.591 \\
\hline $3.0-3.5$ & 6 & $425-495$ & 31 & $-\quad 22$ & 0.194 & $-\quad 0.273$ & 1.257 & $-\quad 2.864$ \\
\hline $3.5-4.0$ & 0 & $495-566$ & 22 & $-\quad 17$ & 0.0 & & 1.257 & - 2.864 \\
\hline 4.0 & 2 & 566 & 17 & & 0.118 & & 1.375 & - 2.982 \\
\hline
\end{tabular}

\subsection{Modified Approach for Crack Initiation}

An improved S-N procedure for predicting the number of loading cycles to crack initiation consists of applying a local strain approach. The local strain approach is basically a modified S-N analysis which incorporates the effects of stress concentrations at notches and variable amplitude loading. It is based on experimental data relating the total strain range, $\Delta \epsilon$, to the fatigue life $(\mathrm{N})$ of the material. In this work a commonly used equation is proposed, namely, the modified CoffinManson-Goodman equation (Reference 10):

$$
\Delta \varepsilon / 2=(1 / E)\left(\sigma_{f}-\sigma_{o}\right)(2 N)^{b}+\varepsilon(2 N)^{c}
$$

where, $\sigma_{f}$ and $\epsilon_{f}$, are the fatigue-strength and fatiguestrain, respectively, $b$ is the fatigue-strength coefficient and $c$ stands for the fatigue-ductility coefficient. In equation (3.1), $\sigma_{\mathrm{o}}$ denotes the applied mean stress and $\mathrm{E}$ is Young's modulus of the material. The fatigue-strength, $\sigma_{\mathrm{f}}$, and fatigue-strain, $\epsilon_{\mathrm{f}}$, are approximately equivalent to the true fracture strength and strain in a tensile test, respectively, and in turn, may be related to the nominal fracture strength, $\sigma_{n}$, and nominal fracture strain, $\epsilon_{n}$, through the relations:

$$
\begin{aligned}
& \varepsilon_{f}=\ln \left(1+\varepsilon_{n}\right) \\
& \sigma_{f}=\left(1+\varepsilon_{n}\right) \sigma_{n}
\end{aligned}
$$

For application to low cycle fatigue, the coefficient, $b$, is usually set at -0.1 , and the coefficient, $c$, is determined from the relation:

$$
c=-1 /(1+5 n)
$$

where $\mathrm{n}^{\prime}$ is the cyclic strain hardening component. A linear cumulative damage approach (Miner's rule) is also needed in the present application to account for variable cyclic loading.

The appropriate values of the parameters appearing in equation (3.1) are: $E=19900 \mathrm{kgf} / \mathrm{mm}^{2}, \sigma_{\mathrm{n}}$ $=55 \mathrm{kgf} / \mathrm{mm}^{2}, \epsilon_{\mathrm{n}}=0.4$, and $\mathrm{c}=-0.6$ (References 1 and 10). As for the values of the applied mean stress, $\sigma_{\mathrm{o}}$, they can be estimated from the member forces, $F$ and $M$, found in Section 2.0. Thus, during Run 11, the applied mean stress is determined as $\sigma_{\mathrm{o}}=16.9 \mathrm{kgf} / \mathrm{mm}^{2}$, and for Runs 1 through 10 , its value may be estimated as $\sigma_{0}=$ $8.5 \mathrm{kgf} / \mathrm{mm}^{2}$. The next step in the analysis is to compute the fatigue damage factor by using Equation (3.1).

Utilizing the HLVT data in conjunction with the number of loading cycles required for crack initiation, $N_{f}$, determined from Equation (3.1), the fatigue damage factor, $D=\Sigma n_{i} / N_{f}$, was computed and the results appear 
Table 3.2 Fatigue Damage Calculation

\begin{tabular}{||l|l|l|l|l||}
\hline \multicolumn{1}{|c|}{$\begin{array}{r}\text { Strain Range } \\
\Delta \epsilon(\%)\end{array}$} & \multicolumn{1}{|c|}{$\mathrm{N}_{\mathrm{fi}}$} & \multicolumn{2}{c||}{ Usage Factor } \\
\cline { 4 - 5 } & & \multicolumn{1}{c|}{ Eq. (3.1) } & \multicolumn{1}{c|}{ U.F. } & \multicolumn{1}{c|}{ Total } \\
\hline $0.1-0.5$ & 620 & $2 \times 10^{8}-6950$ & $0.0-0.089$ & $0.0-0.089$ \\
\hline $0.5-1.0$ & 230 & $6950-1100$ & $0.033-0.209$ & $0.033-0.298$ \\
\hline $1.0-1.5$ & 101 & $1100-440$ & $0.092-0.223$ & $0.125-0.521$ \\
\hline $1.5-2.0$ & 43 & $440-245$ & $0.098-0.176$ & $0.223-0.697$ \\
\hline $2.0-2.5$ & 29 & $245-160$ & $0.118-0.181$ & $0.341-0.878$ \\
\hline $2.5-3.0$ & 12 & $160-110$ & $0.075-0.106$ & $0.416-0.984$ \\
\hline $3.0-3.5$ & 6 & $110-83$ & $0.055-0.072$ & $0.471-1.056$ \\
\hline $3.5-4.0$ & 0 & $83-65$ & 0 & $0.471-1.056$ \\
\hline 4.0 & 2 & 65 & $0.031-0.031$ & $0.502-1.087$ \\
\hline
\end{tabular}

in Table 3.2. For the strain range given in the Table, the usage factor lies between 0.502 and 1.087. The usage factor was also computed for the average values of the strain range during Runs $1-11$ and the result is: cumulative usage factor $=0.721$. It is clear from this analysis that Equation (3.1) provides a good prediction of the time required for crack initiation. At the upper limit of the strain values for Runs 1-11, the fatigue usage factor is 1.087 .

In order to include the influence of strain concentration, the magnified strains and the accompanying fatigue damage analysis is given in Table 3.3. In this case, the fatigue usage factor varies between 0.925 and 2.023 with a usage factor of 1.376 for the average magnified strain ranges. Based on these results, it can be concluded that Equation (3.1) provides a reasonable engineering estimate of the time required for crack initiation.

\subsection{Alternate Methods of Predicting Crack Initiation}

Generally speaking, crack initiation and development is a local phenomenon of material behavior. It is concerned with a damaged part of the component due to the progressive softening of the material with strain or time. At the microscale level, $10^{-5}-10^{-3} \mathrm{~mm}$, it can be described in terms of slip zones and formation of microvoids and microcracks. Various dislocation models have been proposed to explain the formation of crack nucleation sites. Essentially, they are based on the following sequence of events. The plastic straining causes the development of slip planes in the material. Usually, a slip plane coincides with the maximum shearing stress and become the nucleus of a fatigue crack initiation site when subjected to tensile stress. Thus, in the region of highest strain, the material deforms along a slip plane and slip bands of highly localized deformation are generated. As a result, intrusions and/or extrusions are formed which notch the surface of the material, give rise to stress concentration and consequently trigger the development of a crack initiation in that region. Because of the stochastic character of the process such initiation sites could occur at various locations within the surface layer of the component resulting in a cluster of fatigue cracks as observed in the HLVT Program. The initiation and growth of such microvoids can be studied by micromechanic analysis (see, e.g., the works of McClintock (Reference 11) and Rice and Tracy (Reference 13) and others). However, such an analysis cannot be applied to large scale structural components to predict either crack initiation or failure because of the small dimensions involved and lack of accuracy of local stress calculations. 
Table 3.3 Fatigue Damage Calculation for Magnified Strains

\begin{tabular}{||c|c|l|l|l||}
\hline \multirow{2}{*}{$\begin{array}{c}\text { Magnified } \\
\text { Strains } \\
\Delta \epsilon(\%)\end{array}$} & $\mathrm{n}_{\mathrm{i}}$ & \multicolumn{1}{c|}{$\mathrm{N}_{\mathrm{fi}}$} & \multicolumn{2}{c||}{ Usage Factor } \\
\cline { 3 - 5 } & & \multicolumn{1}{c|}{ Eq. $(3.1)$} & \multicolumn{1}{c|}{ U.F. } & \multicolumn{1}{c|}{ Total } \\
\hline $0.135-0.675$ & 620 & $12 \times 10^{6}-2900$ & $0-0.214$ & $0-0.214$ \\
\hline $0.675-1.350$ & 230 & $2900-565$ & $0.079-0.407$ & $0.079-0.621$ \\
\hline $1.350-2.025$ & 101 & $565-240$ & $0.179-0.412$ & $0.258-1.033$ \\
\hline $2.025-2.700$ & 43 & $240-138$ & $0.179-0.312$ & $0.437-1.345$ \\
\hline $2.700-3.375$ & 29 & $138-92$ & $0.210-0.315$ & $0.647-1.660$ \\
\hline $3.375-4.050$ & 12 & $92-63$ & $0.130-0.185$ & $0.777-1.845$ \\
\hline $4.050-4.725$ & 6 & $63-47$ & $0.095-0.125$ & $0.872-1.970$ \\
\hline $4.725-5.400$ & 0 & $47-38$ & 0 & $0.872-1.970$ \\
\hline 5.400 & 2 & 38 & $0.053-0.053$ & $0.925-2.023$ \\
\hline
\end{tabular}

At the macroscale level, a modern continuum mechanics approach to crack initiation is based on postulating a damage function which predicts when nucleation and growth of microvoids and microcracks occur in ductile materials subjected to large plastic strain (References 14-16). The damage function need not be accompanied by specific physical interpretation of the event. It should simply give the state of stress or strain at which microcracks initiate in the material and grow to a size where established fracture mechanics or any other continuum mechanics theory become applicable. Many such postulates are available in the literature. They are based in part on predicting a complex state of stress or strain required to initiate a crack in real material from information about the behavior of the material obtained from simple loading conditions like the tensile test or the bend test. A simple form of such a criterion can be based on a local strain approach, namely, crack initiation will occur when the principal strain reaches a critical value, i.e.,

$$
\epsilon_{p}=\epsilon_{c r}
$$

where $\epsilon_{\mathrm{ur}}$ is a material property determined from single loading tests.
Another approach which can be used to investigate crack initiation is based on the hydrostatic stress, $\sigma_{H}=1 / 3\left(\sigma_{x}+\sigma_{y}+\sigma_{z}\right)$. The plastic strains at which micro-cracks initiate in a material and grow to a size which can be treated by conventional fracture mechanics theories are known to be dependent upon the hydrostatic stress (Reference 12). The dependency is usually expressed in terms of the triaxiality factor, TF, defined by the relation

$$
\mathrm{TF}=\sigma_{\mathrm{H}} / \sigma_{\text {eff. }}
$$

where $\sigma_{\text {eff. }}$ is the effective stress given by

$$
\sigma_{\text {eff. }}=\left(3 \mathrm{~J}_{2}\right)^{1 / 2}
$$

in which $\mathrm{J}_{2}$ is the second invariant of the deviatoric stress tensor

$$
\begin{aligned}
& \mathbf{J}_{2}=\left(1 / 2 S_{i j} S_{i j}\right)^{1 / 2} \\
& S_{i j}=\sigma_{i j}-\sigma_{H} \delta_{i j}
\end{aligned}
$$

A simple crack initiation criterion can be stated as follows: Crack initiation takes place when

$$
\epsilon_{\text {eff. }}^{\mathrm{P}} / \epsilon_{\mathrm{T}}=1 / \mathrm{TF}
$$




\section{C Crack Initiation}

Here, $\epsilon_{\mathrm{T}}$ is the true strain to failure in a tensile test and $\epsilon_{\text {erf. }}^{\mathrm{p}}$ is the effective plastic strain in the component. The effective plastic strain is defined by the relation

$$
\epsilon_{\text {eff. }}^{P}:=\left(2 / 3 \epsilon_{i j}^{P} \epsilon_{i j}^{P}\right)^{1 / 2}
$$

where $\epsilon_{i j}^{p}$ are the plastic strain contributions. A similar criterion to that of Equation (3.7) is (Reference 14).

$$
\epsilon^{\mathrm{P}}{ }_{\mathrm{cfr}} / \epsilon_{\mathrm{T}}=\mathrm{e}^{-1 / 2(\mathrm{Tr}-1)}
$$

The modern approach to crack initiatir a utilizes damage theory by assigning a degraded property of the material to the suspected region of crack initiation which is usualiy a local region of maximum stress (References 15-16). The approach permits the use of standard finite element stress analysis to evaluate the initiation and propagation of microcracks to a structural scale amenable to treatment by continuum mechanics theories. It envisages a model in which a microelement inclusion is embedded in a conventional continuum mechanics element. In the microelement the yield strength of the material is reduced to the endurance limit since there can be no damage if the stress in the microelement does not exceed the endurance limit. Equilibrium and strain compatibility requirements are then imposed across the border between the local region of the microelement and the surrounding structure. This resulis in a coupled set of equations to be solved for the stress in the local region which initiate the cracking. In Reference 16, the specific initiation criterion used is that the effective damage stress, $\sigma_{\text {eff. }}{ }^{*}$, in the microelement is maximum. In this regard, the effective damage stress is given in terms of the triaxiality factor as follows:

$$
\sigma_{\text {eff }}^{*}=\left\{(2 / 3)(1+2 v)+3(1-2 v)(\mathrm{TFF}\}^{2}\right\}^{1 / 2} \sigma_{\text {eff. }}
$$

In Reference 16, the number of loading cycles to crack initiation is shown to be computed from a knowledge of the material damage parameters and the induced strain.

It was not in the scope of this work to pursue a crack initiation analysis based on the above principles. However, it is believed that such an analysis utilizing the HLVT data would yield fruitful results. 


\section{CRACK GROWTH BEHAVIOR}

This section describes the crack growth behavior observed in the HLVT Program. Figures 4.1 - 4.4 illustrate the observed cracks, shown in shaded areas, and give the measured dimensions after each of excitation Runs 11 - 14 (see Figure 2.1). Each of Runs 11 - 13 consisted of four segments of cyclic loading lasting about 36 seconds. Run 14 consisted of one segment of the loading lasting about 8 to 9 seconds. In Figures 4.1 - 4.4 the crack size is given in terms of crack depth/thickness ratio and arc length along the outside surface of the elbow. The crack depths were measured by the ElectroResistance Method (ERT) and also directly by means of installing a thin piano wire into the crack.

The initial configurations of the cracks are displayed in Figure 4.1. A cluster of layer surface cracks were observed and identified as cracks at locations A, B, C, D, E and F. There are several additional small cracks in each location. The crack depth/thickness ratios of the dominant cracks in each locality varied between 2 to $8 \%$ and the arc length varied between 5 to $15 \mathrm{~mm}$. When the model was subjected to excitation Run 12 , these cracks grew and merged with in between smaller cracks and formed three main groups of cracks as indicated in Figure 4.2. The three groups of cracks are identified as cracks $A+B+C$. Cracks D $+E$ and Crack F. The crack depth/thickness ratios of these cracks varied between 5 to $16 \%$ and the corresponding arc length between 10 to 35 $\mathrm{mm}$. When experiencing loading Run 13, these cracks grew further and joineo together to form one part-through circumferential crack as indicated in Figure 4.3. This part-through crack developed a maximum crack depth/thiciness ratio of $47 \%$ (the maximum crack depth $=14 \mathrm{~mm}$; and a total arc length of $329 \mathrm{~mm}$. When subjected to Run 14, which consisted of approximately $1 / 4$ of the number of loading cycles of Runs 11-13, the crack grew and penetrat: $d$ to about $94 \%$ of the pipe's thickness and extended to about $341 \mathrm{~mm}$ of the outside circumference of the elbow before termination of the vibration testing. The final profile of the crack is shown in Figure 4.4.

After the vibration testing the crack surface was exposed and examined from the metallurgical viewpoint by Scanning Electron Microscope (Reference 1). Striation marks were evident after Runs 11,12 and the beginning of Run 13, indicating that the crack propagated during these runs by fatigue. The number of striation marks corresponds (approximately) to the number of loading cycles. An increasing amount of dimple rupture was also observed beginning after Run 11 and progressively increasing towards the end of Run 13 at which striation marks were no longer evident. The rapid crack propagation observed during Runs 13 and 14 was essentially due to dimple rupture and ductile tearing. 

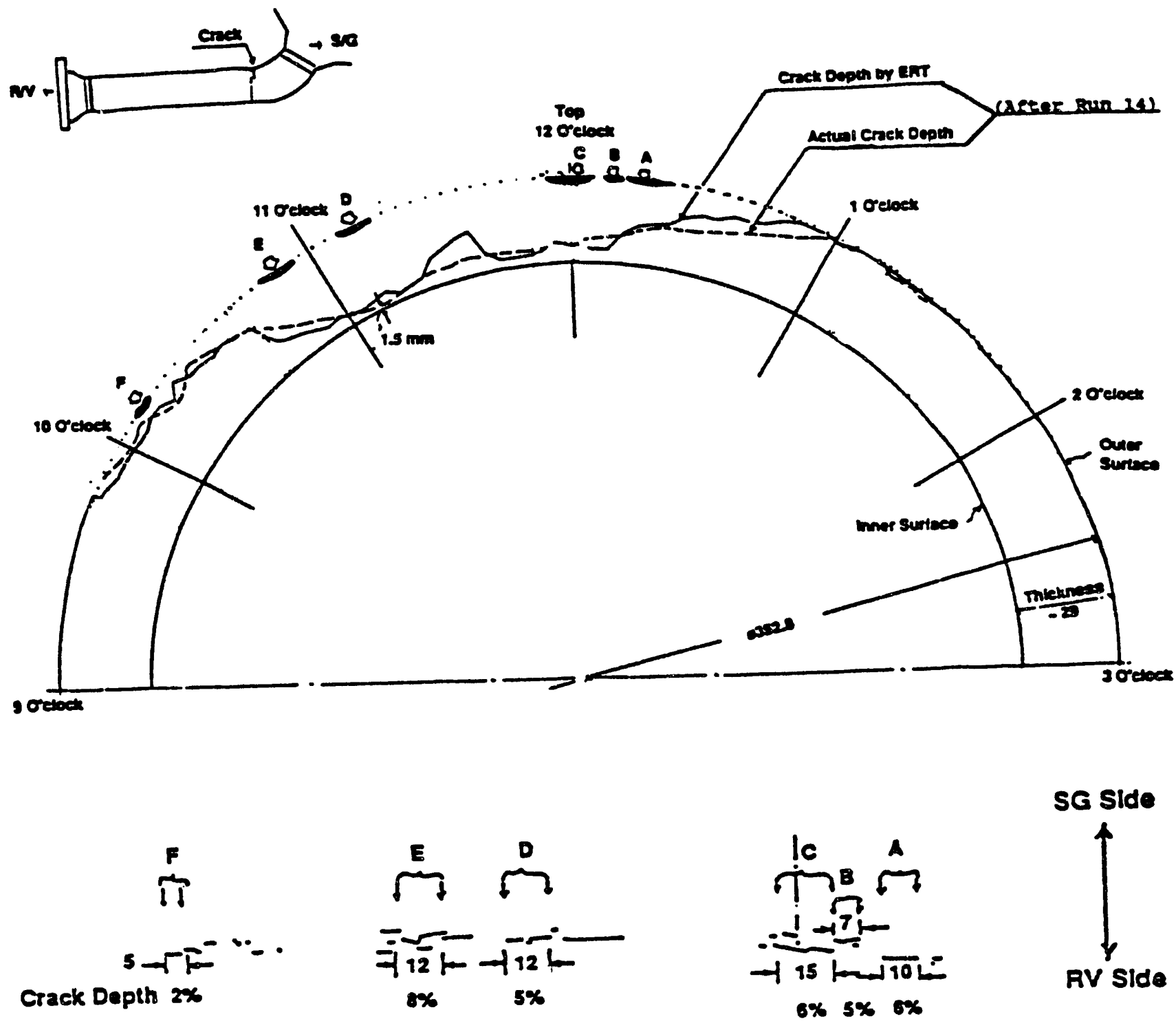

Figure 4.1 Initial Cracks Observed After Loading Run 11 

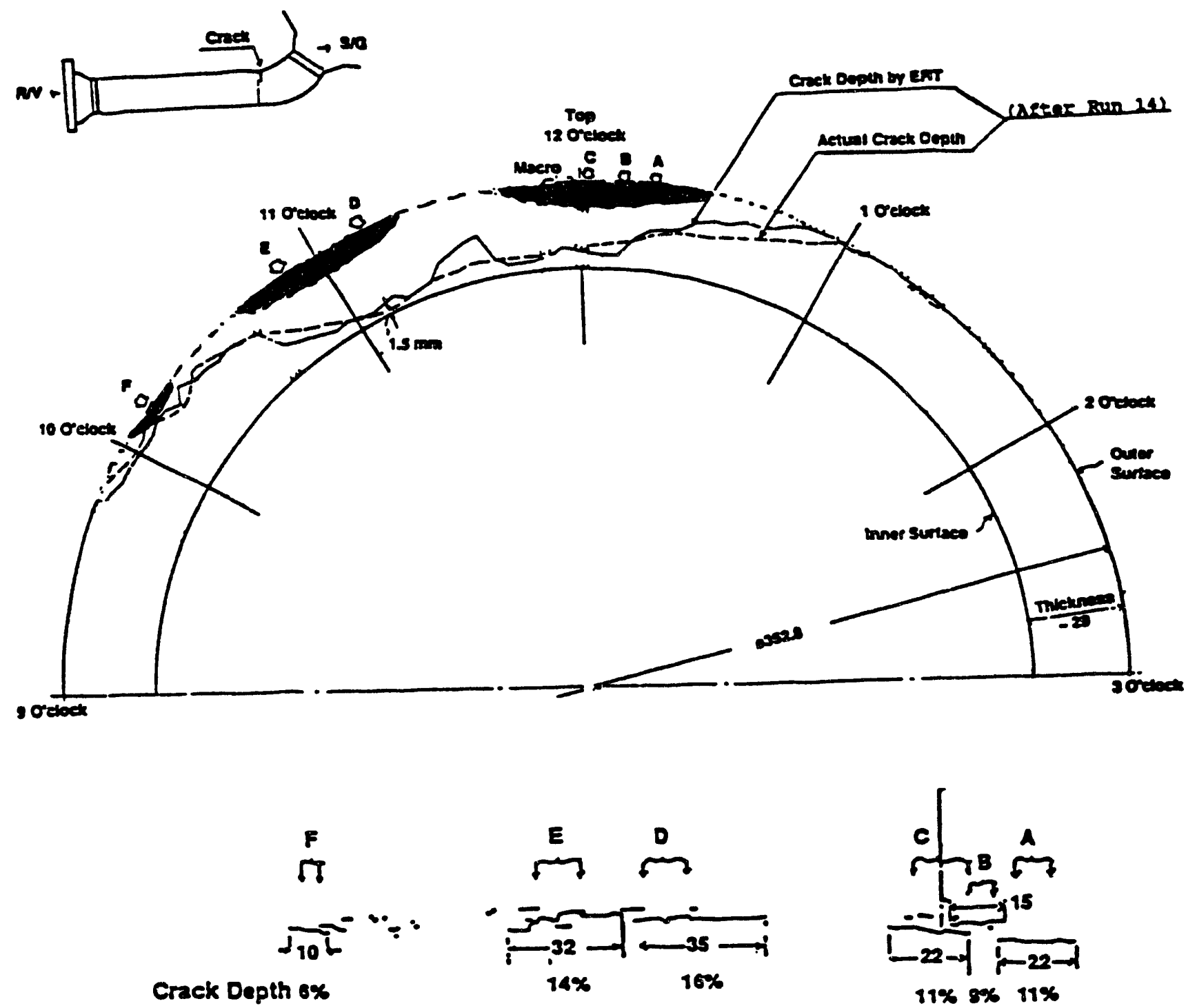

Figure 4.2 Crack Dimensions After Loading Run 12 
4.0 Crack Growth Behavior
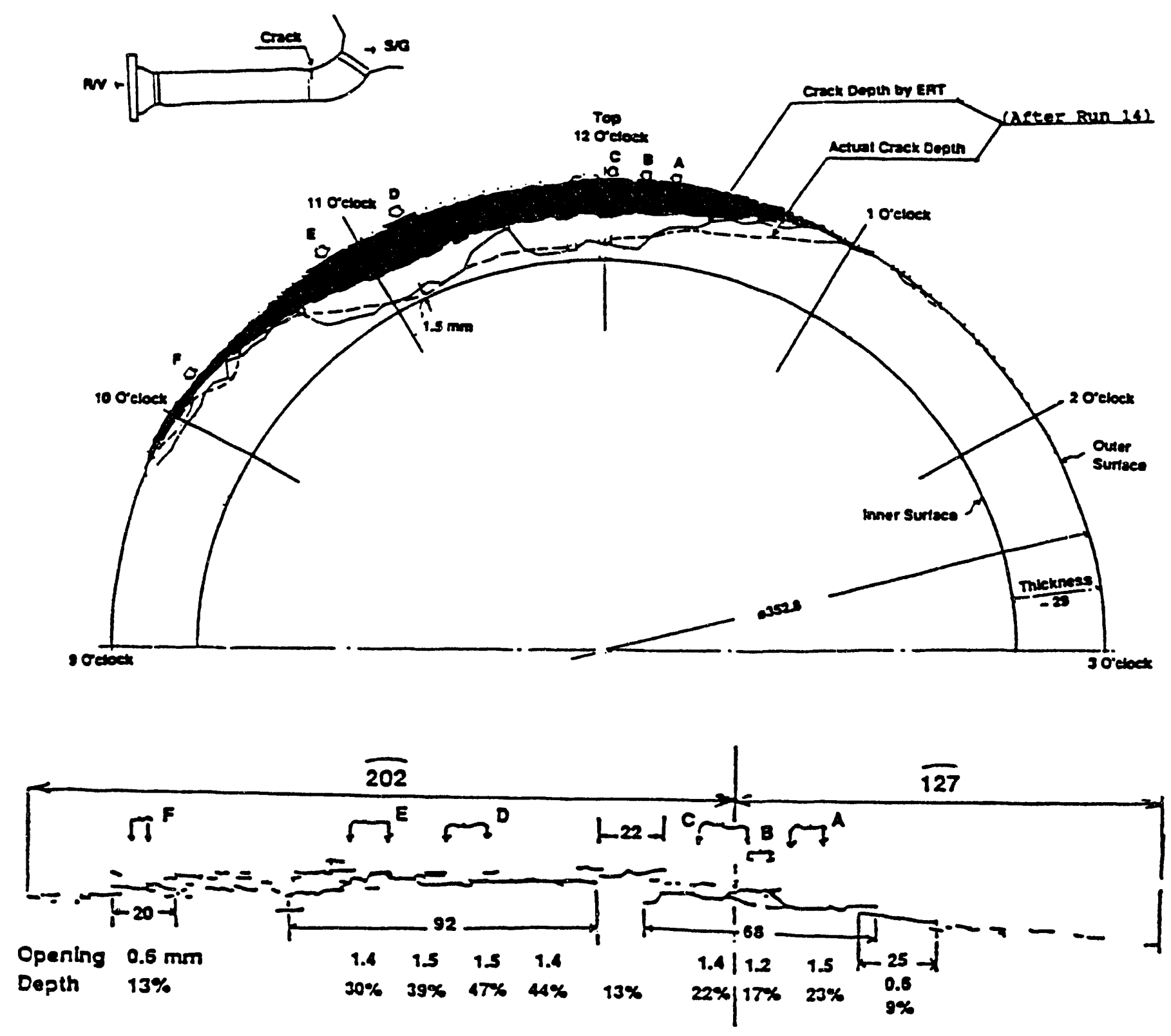

Figure 4.3 Dimensions of the Part-Through Crack Appearing After Run 13 

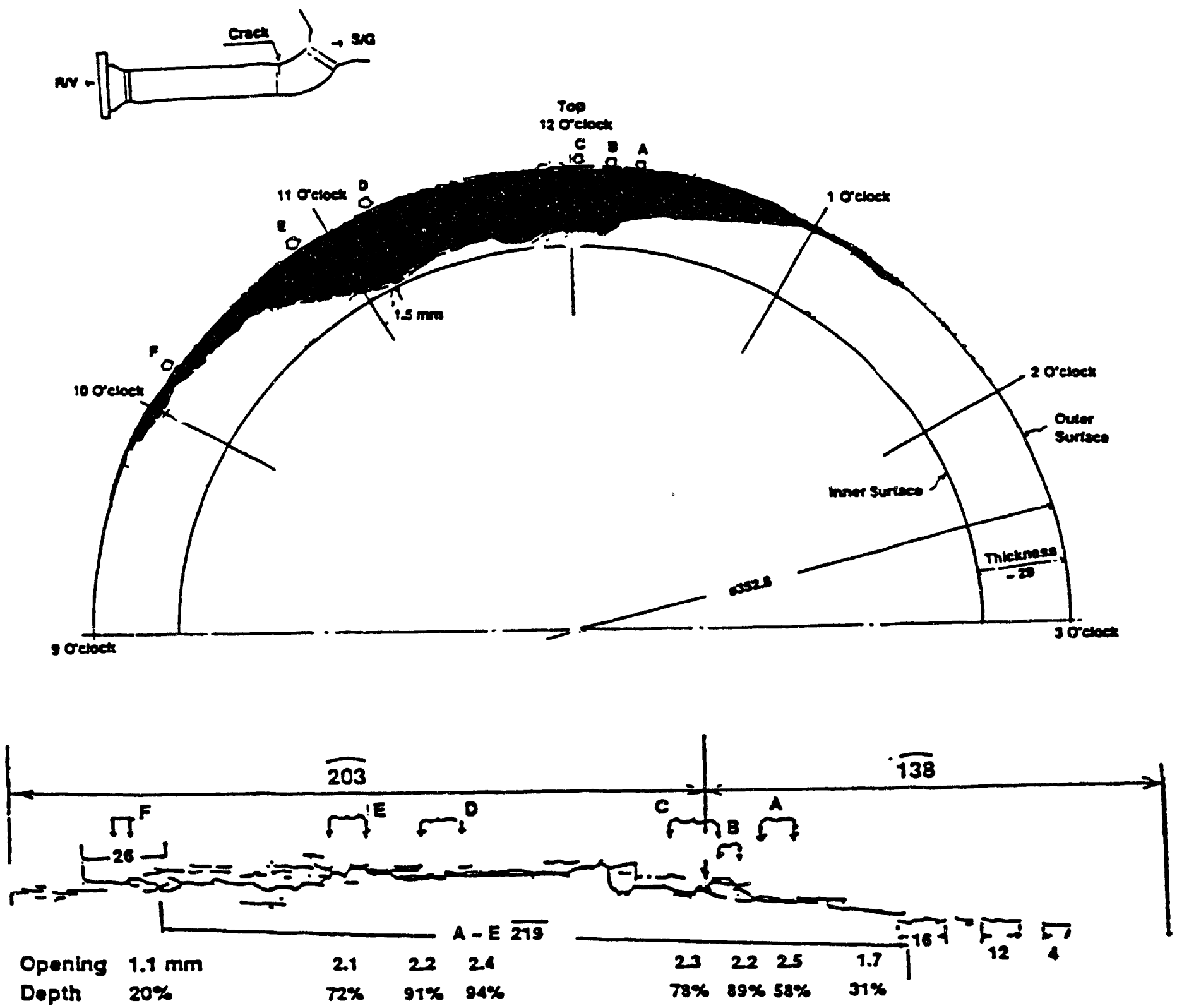

Figure 4.4 Dimensions of the Crack After Termination of the Test 


$$
d a / d N=1248.88 \times 10^{-13}[\Delta K]^{3.25}
$$

The crack growth material characteristics are discussed in this section. Tests were performed in Japan (Reference 1) and at the David Taylor Research Center (DTRC) to establish the crack growth characteristics of the elbow piping material. The details of the latter tests are given in Reference 17.

The tests in Japan utilized compact tension specimens with the cracks extending in the circumferential direction ( $\mathrm{L}-\mathrm{C}$ direction). A high amplitude load was applied to the specimen so as to induce large plastic deformation as in the HLVT Program. Using a compliance method, the crack extensions and the crack driving force (J-integral parameter) were calculated from the load displacement curve and related to the number of applied load cycles. Expressing the J-integral in units of kilogram force/millimeter, the crack growth rate, da/dN $(\mathrm{mm} / \mathrm{cycle})$ was determined as

$$
d a / d N=1.22 \times 10^{-4}(\Delta N)^{1.92}
$$

where $\Delta \mathbf{J}=\mathbf{J}_{\max }-\mathbf{J}_{\min }$. The corresponding relation in terms of the stress-intensity factor, $\mathrm{K}$, expressed in units of kilogram-force/(millimeter) ${ }^{3 / 2}$ is

$$
d a / d N=5.67 \times 10^{-13}(\Delta K)^{3.84}
$$

In order to confirm the above mentioned crack growth rates and establish additional material properties to characterize the cyclic deformation of the elbow material, a test program was instituted by the David Taylor Research Center (DTRC) (Reference 17). The tests conducted included monotonic and cyclic tensile tests to establish the stress-strain relationship of strain hardened specimens of the material, cyclic elastic and elastic-plastic fatigue crack growth rate tests and monotonic and cyclic J-R curve tests. For the fatigue crack growth tests two specimens were tested, one with the crack extending in the circumferential direction (L-C) and the other in the radial direction (L-R). The results of the tests indicated no significant differences between the L-C and L-R crack growth behaviors. Both low cycle as well as high cycle fatigue crack growth rate data were generated. The low cycle fatigue crack growth rate was obtained using the cyclic J-integral approach. The resulting crack growth rate in units of $\mathrm{mm} / \mathrm{cycle}$ was found as: where the stress-intensity factor is measured in units of $\mathrm{kgf} /(\mathrm{mm})^{3 / 2}$. In term of the fluctuation in the J-integral, Equation (5.2a) assumes the form

$$
d a \mid d N=14.08 \times 10^{-4}(\Delta J)^{1.625}
$$

These results (Equation 5.2) confirm Rolfe and Barsom's fatigue crack propagation data for austenitic stainless steels in air [Reference 2] and appear to differ from the Japanese data (Equation 5.1) by approximately one order of magnitude (Equation 5.2 predicts faster crack growth than Equation 5.1). An attempt was made to explain this difference based on the definition of the closure load in measuring $\Delta \mathrm{J}$ (or $\Delta \mathrm{K}$ ) for specimens subjected to compressive loading. The conclusion as explained in Reference 17 is that "The Japanese data for the HLVT Program appears to have been generated by assuming that the entire loading range (maximum tensile load to minimum compressive load) contributed to the crack driving force. This has the net effect of lowering the overall crack growth rate for a given driving force (Jintegral)." By recomputing $\Delta \mathrm{J}$ and then $\Delta \mathrm{K}$ using the minimum load for closure, the Japanese data represented by Equation (5.1) were regenerated very closely. Additional details are available in Reference 17.

A third propagation equation used in this study is the fatigue crack growth rate for austenitic piping materials recently developed by a working group under the sponsorship of the Pressure Vessel Research Committee and Metals Properties Council [Reference 18]. For stainless steels in air environment the equation in the present system of units appears as

$$
d a / d N=6207.8 \times 10^{-13}\left(1-0.5 R^{2}\right)^{-4}[\Delta K]^{3.3}
$$

Equation (5.3) was obtained by means of statistical correlation of all available data on austenitic stainless steels of various chemical compositions in air environment. The data base used for the derivation of Equation (5.3) includes data from tests conducted at various load ratios, cyclic frequencies, temperatures and neutron irradiation levels. In contrast with Equation (5.1) and (5.2), Equation (5.3) contains a multiplying correction factor which is a function of the stress ratio, $\mathbf{R}=$ $\sigma_{\min } / \sigma_{\max }$. Similar propagation equations are also available 


\subsection{Material Tests}

for PWR and BWR environments. Additional information may be found in Reference 19.

The variation of the fatigue crack growth rates given by Equations (5.1) through (5.3) are shown in Figure 5.1. It is clear from the figure that for a given crack driving force, in a wide range of values of $\Delta K$, the fatigue rate of Equation (5.2) yields crack growth faster than that of Equation (5.1) by about one order of magnitude. In addition, the growth rate of Equation (5.3), especially when the stress ratio, $R$, varies between $(0-0.5)$ generates faster crack growth than Equation (5.2) by more than one order of magnitude. The three fatigue crack growth rates will be used in Section 6.0 to analyze the crack growth behavior observed in the HLVT Program.

The monotonic $\mathrm{J}$-resistance curve of the material, obtained using deformation theory, was also developed in the DTRC test program. The ASTM validity regions of the J-integral parameters are also indicated in Reference 17. There is no appreciable difference between crack growth in the radial direction (L-R) from that in the circumferential direction (L-C). In order to obtain a representation of the entire curve, the lower bound data of the J-R curve was found to be best fitted by a power law of the form

$$
J_{\text {mat }}=64.72(\Delta a+0.0345)^{0.76}
$$

in which the crack extension, $\Delta a$, is measured in millimeters and $\mathbf{J}_{\text {mat }}$ in kilogram force/millimeter.

The material's true stress-strain behavior is shown in Figure 5.2 (Reference 1). Expressing this behavior in a Ramberg-Osgood format

$$
\varepsilon / \varepsilon_{y}=\sigma / \sigma_{y}+\alpha\left(\sigma / \sigma_{y}\right)^{n}
$$

where $\sigma_{y}$ is the yield stress of the material and $\epsilon_{y}=\sigma_{y} / E$. The strain hardening exponent $\mathrm{n}$, and the coefficient, $\alpha$, are obtained by fitting Equation (5.5) to the true stressstrain curve. It is found that $n=4$ and $\alpha=3.5$. 


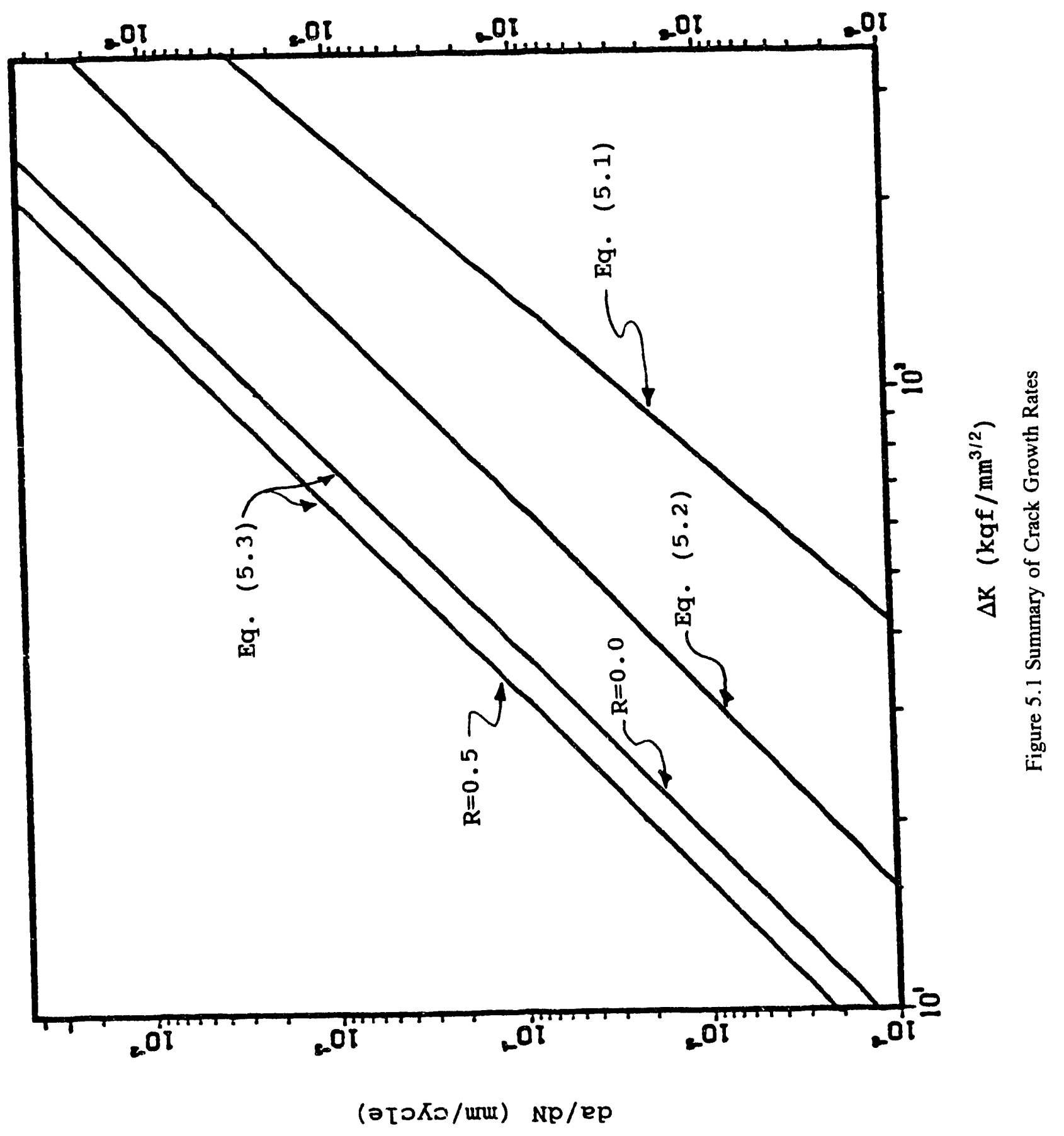


5.0 Material Tests

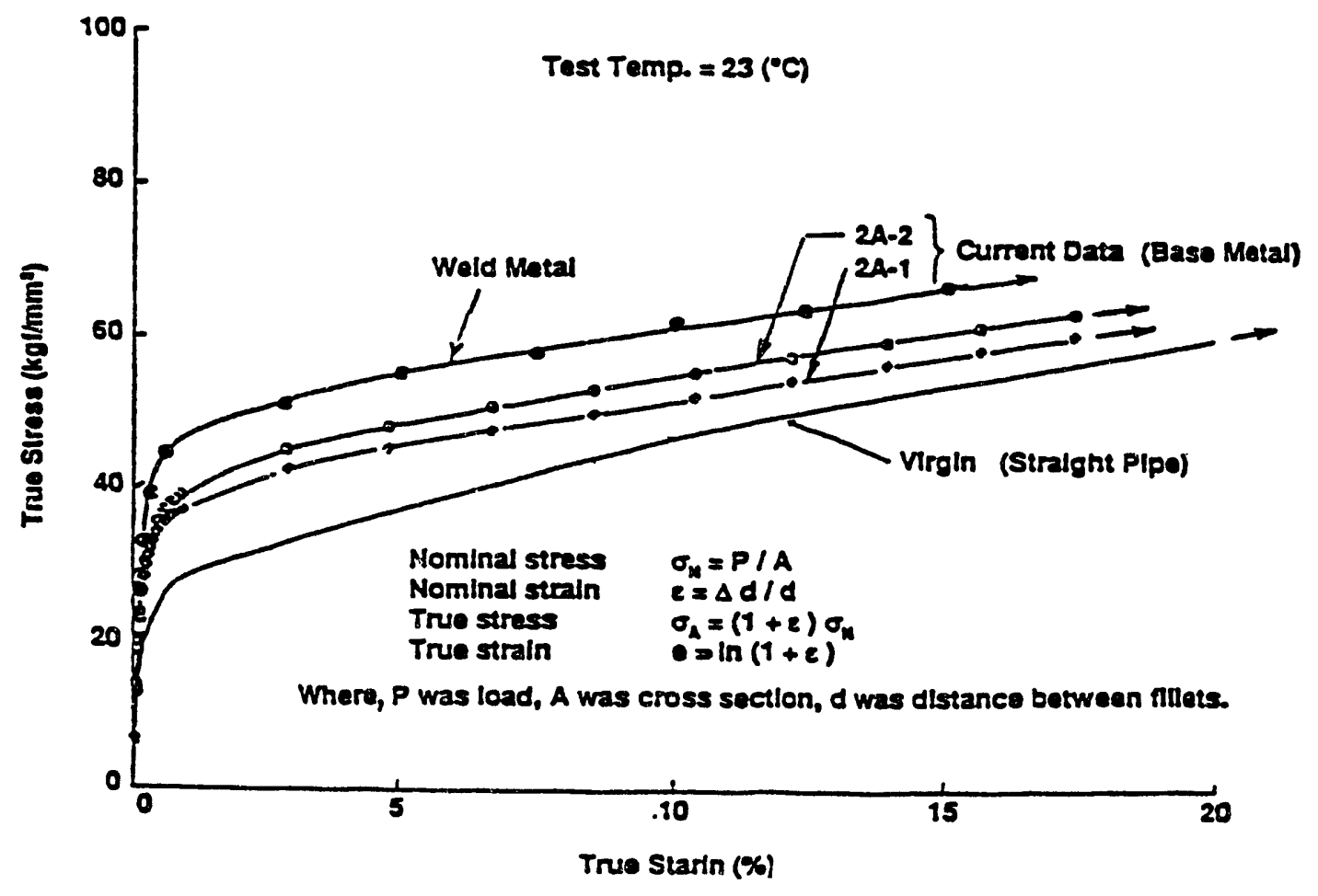

Figure 5.2 Stress-Strain Curve 


\section{0}

\section{METHODOLOGIES OF PREDICTING CRACK GROWTH}

This section presents the various methods used for predicting the crack growth behavior observed in the HLVT Program. From the viewpoint of fracture mechanics, crack growth behavior, and in particular fatigue crack propagation, have been studied extensively in the literature (see, e.g., References 2-4). Several methods have been proposed to predict the behavior of crack extensions in real structures. A widely used method of estimating the fatigue crack propagation is the $\Delta K$ methodology (Paris Law) in which the fatigue crack growth rate is expressed as a power function in $\Delta K$, the fluctuation in the stress-intensity factor. In applying this method, the limitations of Linear Elastic Fracture Mechanics (LEFM) are implied. For loads beyond the elastic limit the concept of the stress-intensity factor is not valid and other parameters are needed. One possibility which has been suggested in the literature is to use the range in the $J$-integral parameter $(\Delta J)$ to describe the crack driving force. Other methods which have been proposed to investigate crack growth behavior include linear summation of fatigue crack growth and ductile tearing (Reference 7 ), the use of cyclic J-R parameters (Reference 8 ) and the net-section stress range method (Reference 9).

In the following subsections three methods which are believed to be relevant to the present application are explored. These are: The $\Delta \mathrm{K}$ methodology, the use of the $\mathrm{J}$-integral parameter and the net section stress range method.

\section{1 $\Delta K$ Methodology}

A widely used method of estimating the inservice extension of cracks in structural components is the $\Delta \mathrm{K}$ methodology (Paris Law) in fracture mechanics. In this methodology, the change in crack depth, a, per fatigue cycle, $\mathrm{N}$, is related to the change in the stressintensity factor, $K$. Mathematically, the relation is expressed as $\mathrm{da} / \mathrm{dN}=\mathrm{C}(\Delta \mathrm{K})^{\mathrm{n}}$ where $\mathrm{C}$ and $\mathrm{n}$ are material constants obtained from an experimental data base and $\Delta \mathrm{K}\left(=\mathrm{K}_{\max }-\mathrm{K}_{\min }\right)$ is the fluctuation in the stress-intensity factor. The specific crack growth rates of the material are discussed in Section 5.0. Section XI of the ASME Boiler and Pressure Vessel Code allows the use of this technology to analyze stable crack growth and thus predict the extent of fatigue damage in structural components.
The purpose of this Section is to analyze the crack growth observed in the HLVT Program by the $\Delta K$ methodology. Each detected flaw is modeled by a semielliptical surface crack and the induced crack driving forces during Runs 12-14 are computed by using the formulas of the stress intensity factors given in Newman and Raju's work (References 20 and 21) and Section XI of the ASME Boiler and Pressure Vessel Code. An inhouse general-purpose fatigue crack growth computer program was used to compute the predicted dimensions of the extended cracks. Initially, a sensitivity study was carried out to find the influence of various parameters which could affect the prediction capability of this methodology. In the present application, the parameters affecting crack propagation include fatigue crack growth rates of the material, stress-intensity factor formulas, geometric modeling of the growth, influence of random loading and compressive stresses, retardation and acceleration models, interaction between adjoining cracks, etc. Three key parameters are found to influence the analysis and capability of predicting the growth pattern. These are: the experimental fatigue crack growth rates of the material, two-directional versus self-similar growth and the influence of compressive stresses on crack surfaces.

The fatigue crack growth rates used in the analysis are given in Equations (5.1) - (5.3). A second key parameter which is found to influence the results is the nature of the geometric modeling of the crack growth. Since the available formulas for calculating the stressintensity factors of cracks in solids are primarily for elliptical shaped flaws, it is natural to model the surface cracks observed in the HLVT Program by semi-elliptical shapes of semi-major and -minor axes, $a$ and $c$, respectively. The growth of such cracks may be modeled by either self-similar manner (one degree of freedom growth with constant aspect ratio $a / c$ ) or two-directional growth consisting of simultaneous and independent growths in the radial and circumferential directions. Note that, in a laboratory controlled test, a crack has a single degree of freedom while in the HLVT Program (as in any other realistic crack growth situation), the growth is more complex and is clearly a multidegree of freedom growth. Section XI of the ASME Boiler and Pressure Vessel Code allows the use of semi-elliptical surface cracks with different aspect ratios but only one value of the stressintensity factor is calculated and used in the growth formula. This means that the initial shape is maintained or the growth is self-similar with the same initial aspect ratio. To simulate the cracks observed in the HLVT 
Program, two degree of freedom growth is also used, i.e., crack growth is calculated at the deepest point in the radial direction as well as at the surface point in the circumferential direction. Each point has a different crack driving force (stress-intensity factor) and grows at its calculated rate according to the appropriate growth formula, and the aspect ratio changes continuously from one cycle of loading to the other. Both the two degree of freedom growth, as well as, the self-similar growth models are used in this study. For the self-similar growth (single degree of freedom growth), the crack growth is computed at both the deepest point in the throughthickness direction and at the surface point where the crack intersects the outside circumference of the pipe. The crack is then allowed to grow at the rate whichever location is growing faster while maintaining the initial aspect ratio between the major and minor semi-elliptical axes of the crack.

Since in the HLVT Program, the bending stresses change sign in many cycles of loading, the third parameter which was found to influence the accuracy of prediction is how to account for the compressive stresses on crack surfaces. The conventional approach is to use the actual values of the stress ratio, $R$, and neglect negative $\mathrm{K}$-values. Another approach is to set $\mathrm{R}=\mathbf{0}$ and include negative $K$ values in calculating $\Delta K$ in the growth formula (Reference 22). In this study both approaches are used.

In order to assess the influence of the previously mentioned parameters, the growth of the cracks observed after each of Runs 11 through 13 is considered separately.

\subsubsection{Growth of the Initial Cracks}

The initial configurations of the surface cracks detected in the hot leg of the model are indicated by the darkened areas, A, B, C, D, E and F, shown in Figure 4.1. These cracks were observed after loading Run 11 and individually may be modeled by a semi-elliptical profile of depth (a) and arc length (2c). The actual dimensions of the cracks are very small compared with the radius of the pipe. It follows that for this application the curvature of the pipe has no influence on the expression of the stress-intensity factor and the cracks can be regarded as edge cracks in a plate subjected to remote tension and bending loads. The expression of the stressintensity factor is obtained from Newman and Raju's equations of a semi-elliptical surface crack in a flat plate of finite thickness, $t$, subjected to an equivalent remote tensile stress, $\sigma$ (Reference 20 ). In the present application $\mathrm{a} / \mathrm{c}<1$ and it follows that

$$
\begin{aligned}
\mathrm{K}_{\max (\min )}= & \sigma_{\max (\min )}(\pi \mathrm{a} / \mathrm{Q})^{1 / 2} \\
& \times\left[\mathbf{M}_{1}+(\mathbf{a} / \mathrm{t})^{2} \mathbf{M}_{2}+(\mathbf{a} / \mathrm{t})^{4} \mathbf{M}_{3}\right] \mathrm{gf}_{\phi},
\end{aligned}
$$

in which $Q$ is the shape factor of an elliptical crack given by the empirical relation

$$
\mathrm{Q}=1+1.464(\mathrm{a} / \mathrm{c})^{1.65}
$$

and

$$
\begin{aligned}
& \mathrm{M}_{1}=1.13-0.09(\mathrm{a} / \mathrm{c}) \\
& \mathrm{M}_{2}=-0.54+0.89 /(0.2+\mathrm{a} / \mathrm{c}) \\
& \mathrm{M}_{3}=0.5-1 /(0.65+\mathrm{a} / \mathrm{c})+14(1-\mathrm{a} / \mathrm{c})^{24} \\
& \mathrm{~g}=1+(1-\sin \phi)^{2}\left[0.1+0.35(\mathrm{a} / \mathrm{t})^{2}\right] \\
& \mathrm{f}_{\phi}=\left[\sin ^{2} \phi+(\mathrm{a} / \mathrm{c})^{2} \cos ^{2} \phi\right]^{1 / 4}
\end{aligned}
$$

In Equations (6.2), $\phi$ represents a parametric coordinate describing points on the periphery of the crack, the deepest point of penetration is described by $\phi=\pi / 2$ and $\phi=0$ represents the free-surface edge point. In the limit, as a/c approaches zero, Equations (6.1) and (6.2) reduce to that of an edge crack in a plate. The maximum and minimum stresses, $\sigma_{\max }$ and $\sigma_{\min }$, in each cycle of loading are computed from the relations:

$$
\begin{aligned}
& \sigma_{\max }=\frac{F_{1}}{A}+\frac{M_{1}}{S} \\
& \sigma_{\text {min }}=\frac{F_{2}}{A}+\frac{M_{2}}{S}
\end{aligned}
$$

where $F_{i}$ and $M_{i}$ are the maximum $(i=1)$ and minimum $(i=2)$ member forces (axial force, $F$, and bending moment, M) of the hot leg pipe determined from the strain-time histories of the cross section near the crack location. Moreover, A stands for the cross sectional area of the pipe $\left(A=29.5 \times 10^{3} \mathrm{~mm}^{2}\right)$ and $\mathrm{S}$ is the section modulus $\left(\mathrm{S}=23.88 \times 10^{5} \mathrm{~mm}^{3}\right)$.

An alternative method of computing the stressintensity factor, $K$, is to make use of the formula recommended in Appendix A of Section XI of the ASME Boiler and Pressure Vessel Code. At the deepest point of penetration of the crack $(\phi=\pi / 2)$, the stress-intensity factor is given by 


$$
K=\left(\sigma_{m} M_{m}+\sigma_{b} M_{b}\right)(\pi a / Q)^{1 / 2}
$$

in which $a$ is the crack depth, $Q$ is the shape factor, which is defined in Equation (6.2a), and $\sigma_{m}\left(=F_{i} / A\right), M_{m}$ and $\sigma_{h}\left(=M_{i} / S\right), M_{b}$, are the axial and bending stresses and their corresponding free-surface correction factors, respectively. Graphical variations of the correction factors, $M_{m}$ and $M_{h}$, with the ratios $a / t$ and $a / c$ are available in Article A-3000 of the ASME code. Algebraic expressions of $M_{m}$ and $M_{h}$ which are more suitable for computer coding purposes are available in Reference 23. At the edge point of the crack $(\phi=0)$, an approximate value of the stress-intensity factor, suitable for the present application, may be obtained by multiplying the expressions in Equation (6.4) by the quantity $(a / c)^{1 / 2}$. Initial analysis by the authors revealed that in the present application practically the same crack growth is predicted whether the K-formula employed in the analysis is given by Equation (6.1) or Equation (6.4). Hence, in this study Equations (6.1-6.3) will be used to determine the crack driving forces for the surface cracks in a plate.

Utilizing Equations (6.1) through (6.3) in conjunction with the material's crack growth rates, the crack extensions after applying loading Run 12 were computed. The computation involves all the elements of the previously mentioned key parameters. For surface cracks $A, B, C, D, E$ and $F$ shown in Figure 4.1 , the predicted dimensions after Run 12 are given in Tables 6.1 to 6.6, respectively. For ease of comparison the tables contain the measured initial and final dimensions of the cracks.

The self-similar or one degree of freedom crack growth assumption (designated by 1 DOF in the tables of results) is achieved by maintaining the initial crack aspect ratio $(a / c)$ throughout the analysis. Here, the maximum stress-intensity factor, $K_{\max }$, along the crack front, is computed from expressions (6.1) - (6.3) at either $\phi=0$ or $\phi=\pi / 2$. For the cracks observed after loading Run 11, $K_{\max }$, invariably occurs at the deepest point of penetration $(\phi=\pi / 2)$. To account for the influence of compressive stresses on the growth behavior, first $\sigma_{\max }$ and $\sigma_{\min }$ are computed from Equations (6.3), and then two methods of evaluation are pursued. The first method consists of utilizing the actual values of the stress ratio, $R$, in each cycle of loading and using the tensile stesses to compute the crack growth. This is the logical and commonly used method of accounting for compressive loading on crack surfaces. The second approach used in this study involves setting $\mathbf{R}=\mathbf{0}$ and the inclusion of the contribution of negative stresses on the magnitude of $\Delta K$ throughout the cycles of loading (Reference 22). The predicted dimensions of the monitored cracks are given in Tables 6.1 - 6.6.

For the two-directional or two degree of freedom crack growth model (designated by 2 DOF in the tables of results), the crack driving forces are computed at $\phi=0$ (for growth in the circumferential direction) and $\phi=\pi / 2$ (for through-thickness growth). The crack growth is then allowed to occur simultaneously in both the radial and circumferential directions. In each cycle of loading, a new crack aspect ratio, $a / c$, and a shape factor, $Q$, are computed and used in the ensuing analysis. Typically, different material crack growth rates should also be used for the radial and circumferential crack growths. However, in the present application, identical data are used for both directions since the experimental evidence did not indicate otherwise. The results of the analysis of the 2 DOF crack growth model are given in the tables of results. In the remaining part of this section, a discussion on the results obtained in Tables $6.1-6.6$ and some conclusions concerning the influence of the parameters included in the analysis are provided. Note that in obtaining the results in Tables $6.1-6.6$, the interaction between neighboring cracks is neglected. In other words, each crack is allowed to grow on its own without the influence of the geometry of a neighboring crack. A recent study by lida, et al. (Reference 24 ) shows that the interaction can be neglected in the present application.

Consider crack "A" of Figure 4.1. The initial (actual) dimensions of the crack are: $a=1.74 \mathrm{~mm}(\mathrm{a} / \mathrm{t}$ $=6 \%$ ) and $2 \mathrm{c}=10 \mathrm{~mm}$. After experiencing loading Run 12 , the crack grew and its measured dimensions are: $\mathrm{a}=3.19 \mathrm{~mm}(\mathrm{a} / \mathrm{t}=11 \%)$ and $2 \mathrm{c}=22 \mathrm{~mm}$ (see Figure 4.2). Table 6.1 reveals the predicted dimensions of the crack. The growth in the radial direction, $a$, is best predicted by the ASME crack growth rate using either the self-similar or two-directional growth models. The assumption $\mathrm{R}=0$ predicts slightly smaller depth values than by allowing the ratio $R$ to vary between its negative and positive values. The error in predicting the depth varies between 3 to $37 \%$. The arc length of the crack, $2 c$, is best predicted by using the ASME rate assuming a self-similar crack growth model. Here the error in predicting the arc length varies between 19 to $23 \%$ while in the two directional crack growth model the error in predicting the value of $2 \mathrm{c}$ is about 51 to $54 \%$. Again, the assumption $\mathrm{R}=0$ predicts slightly smaller values of the 
Table 6.1 - Predicted Dimensions of Crack A after Loading Run 12 (depth $=a$, arc length $=2 c$ )

\begin{tabular}{|c|c|c|c|c|c|c|c|}
\hline \multirow{3}{*}{$\begin{array}{l}\text { Two-Directional } \\
(2 \text { DOF) versus } \\
\text { Self-Similar } \\
(1 \text { DOF) Growth }\end{array}$} & \multirow{3}{*}{$\begin{array}{c}\text { Influence of } \\
\text { Compressive } \\
\text { Loading }\end{array}$} & \multicolumn{6}{|c|}{$\begin{array}{l}\text { Fatigue Crack Growth Rates And } \\
\text { Crack Dimensions }\end{array}$} \\
\hline & & \multicolumn{2}{|c|}{$\begin{array}{l}\text { Japanese Data } \\
\text { (Eq. 5.1) }\end{array}$} & \multicolumn{2}{|c|}{$\begin{array}{l}\text { DTRC Data } \\
\text { (Eq. 5.2) }\end{array}$} & \multicolumn{2}{|c|}{$\begin{array}{l}\text { ASME Data } \\
\text { (Eq. 5.3) }\end{array}$} \\
\hline & & $\begin{array}{c}\mathrm{a} \\
(\mathrm{mm})\end{array}$ & $\begin{array}{c}2 \mathrm{c} \\
(\mathrm{mm})\end{array}$ & $\underset{(\mathrm{mm})}{\mathrm{a}}$ & $\begin{array}{c}2 c \\
(\mathrm{~mm})\end{array}$ & $\underset{(\mathrm{mm})}{\mathrm{a}}$ & $\begin{array}{c}2 \mathrm{c} \\
(\mathrm{mm})\end{array}$ \\
\hline \multirow[t]{2}{*}{$1 \mathrm{DOF}$} & $\mathrm{R}=\sigma_{\min } / \sigma_{\max }$ & 1.77 & 10.02 & 1.78 & 10.24 & 3.11 & 17.88 \\
\hline & $\mathrm{R}=0$ & 1.75 & 10.08 & 1.87 & 10.72 & 2.94 & 16.94 \\
\hline \multirow[t]{2}{*}{$2 \mathrm{DOF}$} & $\mathrm{R}=\sigma_{\min } / \sigma_{\max }$ & 1.77 & 10.01 & 1.78 & 10.02 & 2.86 & 10.80 \\
\hline & $R=0$ & 1.74 & 10.00 & 1.78 & 10.02 & 2.02 & 10.15 \\
\hline
\end{tabular}

NOTE: Measured dimensions of crack $A$

Initial dimensions (Figure 4.1): $\quad a=1.74 \mathrm{~mm}$ $2 \mathrm{c}=10.00 \mathrm{~mm}$

Final dimensions (Figure 4.2): $\quad a=3.19 \mathrm{~mm}$ $2 \mathrm{c}=22.00 \mathrm{~mm}$

arc length in both the self-similar and two-directional growth models. The fatigue crack growth rates given in Equations (5.1) and (5.2) predicted much slower crack growth for all assumed models of growth as indicated in Table 6.1. The growth rate given in Equation (5.2), predicted 1.78 to $1.87 \mathrm{~mm}$ for the deepest penetration of the crack while the measured value is a $=3.19 \mathrm{~mm}$. Clearly, the fatigue crack growth rates represented by Equation (5.1) and (5.2) do not predict the low cycle fatigue damage experienced in the HLVT Program.

Tables 6.2 through 6.6 give the predicted dimensions of cracks $B, C, D, E$ and $F$, respectively. Again the ASME crack growth rate predicts crack dimensions closest to the measured ones. The fatigue crack growth rates represented by Equations 5.1 and 5.2 predicted very slow crack growth compared to the actual growth observed after the application of loading Run 12. For cracks C (Table 6.3) and E (Table 6.5), the ASME rates predicted higher depths of penetration than the measured values using the self-similar crask growth model. The group of cracks A, B and C, wich had a combined arc length of about $32 \mathrm{~mm}$ initially, grew during the loading Run 12 and joined together to form a single crack of arc length $2 \mathrm{c}=55$ to $59 \mathrm{~mm}$ as shown in Figure 4.2. It is clear from Tables $6.1-6.3$ that the fatigue crack growth rate of Equation (5.3), in conjunction with the 1 DOF growth model, predicts a combined arc length of 57 to $60.5 \mathrm{~mm}$, while other growth parameters used in the analysis do not come close to what was observed in the actual test.

Based on the assumptions made in this study the following conclusions can be stated concerning the use of the $\Delta \mathrm{K}$ methodology to predict the crack growth behavior observed in the HLVT Program after the application of loading Run 12:

1. The small edge cracks observed after loading Run 11 can be modeled by semi-elliptical shapes. Since these cracks have a depth/pipe thickness ratio, $a / t$, less than 0.1 , the curvature of the pipe has no practical influence on the assessment of crack growth behavior, and the surface cracks may be considered to be situated in a flat plate of finite thickness subjected to remote axial and bending loads. 
Table 6.2 - Predicted Dimensions of Crack B after Loading Run 12 (depth $=a$, arc iength $=2 c)$

\begin{tabular}{|c|c|c|c|c|c|c|c|}
\hline \multirow{3}{*}{$\begin{array}{l}\text { Two-Directional } \\
\text { (2 DOF) versus } \\
\text { Self-Similar } \\
\text { (1 DOF) Growth }\end{array}$} & \multirow{3}{*}{$\begin{array}{l}\text { Influence of } \\
\text { Compressive } \\
\text { Loading }\end{array}$} & \multicolumn{6}{|c|}{$\begin{array}{c}\text { Fatigue Crack Growth Rates And } \\
\text { Crack Dimensions }\end{array}$} \\
\hline & & \multicolumn{2}{|c|}{$\begin{array}{c}\text { Japanese Data } \\
\text { (Eq. 'J.1) }\end{array}$} & \multicolumn{2}{|c|}{$\begin{array}{l}\text { DTRC Data } \\
\text { (Eq. 5.2) }\end{array}$} & \multicolumn{2}{|c|}{$\begin{array}{l}\text { ASME Data } \\
\text { (Eq. 5.3) }\end{array}$} \\
\hline & & $\underset{(\mathrm{mm})}{\mathrm{a}}$ & $\begin{array}{c}2 c \\
(\mathrm{~mm})\end{array}$ & $\underset{(\mathrm{mm})}{\mathrm{a}}$ & $\begin{array}{c}2 \varepsilon \\
(\mathrm{mm})\end{array}$ & $\underset{(\mathrm{mm})}{\mathbf{a}}$ & $\underset{(\mathrm{mm})}{2 \mathrm{c}}$ \\
\hline \multirow[t]{2}{*}{ I DOF } & $\mathrm{R}=\sigma_{\min } / \sigma_{\max }$ & 1.46 & 7.74 & 1.55 & 7.44 & 2.23 & 10.80 \\
\hline & $R=0$ & 1.46 & 7.04 & 1.53 & 7.38 & 2.15 & 10.38 \\
\hline \multirow[t]{2}{*}{2 DOF } & $\mathrm{R}=\sigma_{\min } / \boldsymbol{\sigma}_{\max }$ & 1.45 & $7 . \tilde{0} 1$ & 1.48 & 7.04 & 2.12 & 7.56 \\
\hline & $R=0$ & 1.46 & 7.01 & 1.53 & 7.06 & 2.04 & 7.48 \\
\hline
\end{tabular}

NOTE: Measured dimensions of crack $B$

Initial dimensions (Figure 4.1): $\quad a=1.45 \mathrm{~mm}$

$2 \mathrm{c}=7.00 \mathrm{~mm}$

Final dimensions (Figure 4.2): $\quad a=2.61 \mathrm{~mm}$

$2 \mathrm{c}=15.00 \mathrm{~mm}$

Table 6.3 - Predicted Dimensions of Crack C after Loading Run 12 (depth $=a_{\text {a }}$ arc length $=2 c$ )

\begin{tabular}{|c|c|c|c|c|c|c|c|}
\hline \multirow{3}{*}{$\begin{array}{l}\text { Two-Directional } \\
\text { (2 DOF) versus } \\
\text { Self-Similar } \\
\text { (1 DOF) Growth }\end{array}$} & \multirow{3}{*}{$\begin{array}{l}\text { influence of } \\
\text { Compressive } \\
\text { Loading }\end{array}$} & \multicolumn{6}{|c|}{$\begin{array}{c}\text { Fatigue Crack Growth Rates And } \\
\text { Crack Dimensions }\end{array}$} \\
\hline & & \multicolumn{2}{|c|}{$\begin{array}{c}\text { Japanese Data } \\
\text { (Eq. 5.1) }\end{array}$} & \multicolumn{2}{|c|}{$\begin{array}{l}\text { DTRC Data } \\
\text { (Eq. 5.2) }\end{array}$} & \multicolumn{2}{|c|}{$\begin{array}{c}\text { ASME Data } \\
\text { (Eq. 5.3) }\end{array}$} \\
\hline & & $\begin{array}{c}a \\
(\mathrm{~mm})\end{array}$ & $\begin{array}{c}2 \mathrm{c} \\
(\mathrm{mm})\end{array}$ & $\begin{array}{c}\mathrm{a} \\
(\mathrm{mm})\end{array}$ & $\begin{array}{c}2 \mathrm{c} \\
(\mathrm{mm})\end{array}$ & $\begin{array}{c}\mathrm{a} \\
(\mathrm{mm})\end{array}$ & $\begin{array}{c}2 c \\
(\mathrm{~mm})\end{array}$ \\
\hline \multirow[t]{2}{*}{1 DOF } & $\mathrm{R}=\sigma_{\min } / \sigma_{\max }$ & 1.75 & 15.04 & 1.79 & 15.44 & 3.68 & 31.82 \\
\hline & $R=0$ & 1.76 & 15.14 & 2.00 & 16.36 & 3.43 & 29.60 \\
\hline \multirow[t]{2}{*}{2 DOF } & $\mathrm{R}=\sigma_{\min } / \sigma_{\mathrm{mux}}$ & 1.75 & 15.02 & 1.79 & 15.02 & 3.31 & 15.68 \\
\hline & $R=$ ? & 1.76 & 15.01 & 1.90 & 15.04 & 3.11 & 15.58 \\
\hline
\end{tabular}

NOTE: Measured dimensions of crack $C$

Initial dimensions (Figure 4.1): $\quad a=1.74 \mathrm{~mm}$

$2 \mathrm{c}=15.00 \mathrm{~mm}$

Final dimensiors (Figure 4.2): $\quad a=3.19 \mathrm{~mm}$

$2 \mathrm{c}=22.00 \mathrm{~mm}$ 
Table 6.4 - Predicted Dimensions of Crack D after Loading Run 12 (depth $=a$, arc length $=2 c$ )

\begin{tabular}{|c|c|c|c|c|c|c|c|}
\hline \multirow{3}{*}{$\begin{array}{l}\text { Two-Directional } \\
\text { (2 DOF) versus } \\
\text { Self-Similar } \\
\text { (1 DOF) Growth }\end{array}$} & \multirow{3}{*}{$\begin{array}{c}\text { Influence of } \\
\text { Compressive } \\
\text { Loading }\end{array}$} & \multicolumn{6}{|c|}{$\begin{array}{c}\text { Fatigue Crack Growth Rates And } \\
\text { Crack Dimensions }\end{array}$} \\
\hline & & \multicolumn{2}{|c|}{$\begin{array}{l}\text { Japanese Data } \\
\text { (Eq. 5.1) }\end{array}$} & \multicolumn{2}{|c|}{$\begin{array}{l}\text { DTRC Data } \\
\text { (Eq. 5.2) }\end{array}$} & \multicolumn{2}{|c|}{$\begin{array}{l}\text { ASME Data } \\
\text { (Eq. 5.3) }\end{array}$} \\
\hline & & $\stackrel{a}{(\mathrm{~mm})}$ & $\begin{array}{c}2 c \\
(\mathrm{~mm})\end{array}$ & $\begin{array}{c}\mathrm{a} \\
(\mathrm{mm})\end{array}$ & $\begin{array}{c}2 \mathrm{c} \\
(\mathrm{mm})\end{array}$ & $\underset{(\mathrm{mm})}{\mathrm{a}}$ & $\begin{array}{c}2 \mathrm{c} \\
(\mathrm{mm})\end{array}$ \\
\hline \multirow[t]{2}{*}{$1 \mathrm{DOF}$} & $\mathrm{R}=\sigma_{\min } / \sigma_{\max }$ & 1.453 & 12.02 & 1.50 & 12.40 & 2.72 & 22.54 \\
\hline & $R=0$ & 1.46 & 12.10 & 1.56 & 12.96 & 2.57 & 21.22 \\
\hline \multirow[t]{2}{*}{2 DOF } & $\mathrm{R}=\sigma_{\min } / \sigma_{\max }$ & 1.453 & 12.00 & 1.49 & 12.01 & 2.52 & 12.48 \\
\hline & $R=0$ & 1.46 & 12.01 & 1.56 & 12.02 & 2.39 & 12.44 \\
\hline
\end{tabular}

NOTE: Measured dimensions of crack D

Initial dimensions (Figure 4.1): $\quad a=1.45 \mathrm{~mm}$

$$
2 \mathrm{c}=12.00 \mathrm{~mm}
$$

Final dimensions (Figure 4.2): $\quad \mathrm{a}=4.64 \mathrm{~mm}$

$2 \mathrm{c}=35.00 \mathrm{~mm}$

Table 6.5 - Predicted Dimensions of Crack E after Loading Run 12 (depth $=a$, arc length $=2 c$ )

\begin{tabular}{|c|c|c|c|c|c|c|c|}
\hline \multirow{3}{*}{$\begin{array}{c}\text { Two-Directional } \\
\text { (2 DOF) versus } \\
\text { Self-Similar } \\
\text { (1 DOF) Growth }\end{array}$} & \multirow{3}{*}{$\begin{array}{c}\text { Influence of } \\
\text { Compressive } \\
\text { Loading }\end{array}$} & \multicolumn{6}{|c|}{$\begin{array}{c}\text { Fatigue Crack Growth Rates And } \\
\text { Crack Dimensions }\end{array}$} \\
\hline & & \multicolumn{2}{|c|}{$\begin{array}{l}\text { Japanese Data } \\
\text { (Eq. 5.1) }\end{array}$} & \multicolumn{2}{|c|}{$\begin{array}{l}\text { DTRC Data } \\
\text { (Eq. 5.2) }\end{array}$} & \multicolumn{2}{|c|}{$\begin{array}{l}\text { ASME Data } \\
\text { (Eq. 5.3) }\end{array}$} \\
\hline & & $\begin{array}{c}\mathrm{a} \\
(\mathrm{mm})\end{array}$ & $\begin{array}{c}2 c \\
(\mathrm{~mm})\end{array}$ & $\underset{(\mathrm{mm})}{\mathrm{a}}$ & $\begin{array}{c}2 \mathrm{c} \\
(\mathrm{mm})\end{array}$ & $\stackrel{a}{(\mathrm{~mm})}$ & $\begin{array}{c}2 \mathrm{c} \\
(\mathrm{mm})\end{array}$ \\
\hline \multirow[t]{2}{*}{ I DOF } & $\mathrm{R}=\sigma_{\min } / \sigma_{\max }$ & 2.33 & 12.04 & 2.38 & 12.32 & 4.56 & 23.60 \\
\hline & $R=0$ & 2.34 & 12.12 & 2.51 & 13.00 & 4.28 & 22.12 \\
\hline \multirow[t]{2}{*}{2 DOF } & $\mathrm{R}=\sigma_{\min } / \sigma_{\max }$ & 2.32 & 12.01 & 2.38 & 12.04 & 4.03 & 13.48 \\
\hline & $R=0$ & 2.34 & 12.01 & 2.51 & 12.12 & 3.31 & 13.26 \\
\hline
\end{tabular}

NOTE: Measured dimensions of crack $E$

Initial dimensions (Figure 4.1): $\quad a=2.32 \mathrm{~mm}$ $2 \mathrm{c}=12 \mathrm{~mm}$

Final dimensions (Figure 4.2): $\quad \mathrm{a}=4.06 \mathrm{~mm}$ $2 \mathrm{c}=32 \mathrm{~mm}$ 
Table 6.6 - Predicted Dimensions of Crack F after Loading Run 12 (depth $=a$, arc length $=2 c$ )

\begin{tabular}{|c|c|c|c|c|c|c|c|}
\hline \multirow{3}{*}{$\begin{array}{l}\text { Two-Directional } \\
\text { (2 DOF) versus } \\
\text { Self-Similar } \\
\text { (1 DOF) Growth }\end{array}$} & \multirow{3}{*}{$\begin{array}{l}\text { Influence of } \\
\text { Compressive } \\
\text { Loading }\end{array}$} & \multicolumn{6}{|c|}{$\begin{array}{l}\text { Fatigue Crack Growth Rates And } \\
\text { Crack Dimensions }\end{array}$} \\
\hline & & \multicolumn{2}{|c|}{$\begin{array}{c}\text { Japanese Data } \\
\text { (Eq. 5.1) }\end{array}$} & \multicolumn{2}{|c|}{$\begin{array}{l}\text { DTRC Data } \\
\text { (Eq. 5.2) }\end{array}$} & \multicolumn{2}{|c|}{$\begin{array}{l}\text { ASME Data } \\
\text { (Eq. 5.3) }\end{array}$} \\
\hline & & $\underset{(\mathrm{mm})}{\mathrm{a}}$ & $\begin{array}{c}2 \mathrm{c} \\
(\mathrm{mm})\end{array}$ & $\begin{array}{c}a \\
(\mathrm{~mm})\end{array}$ & $\begin{array}{c}2 \mathrm{c} \\
(\mathrm{mm})\end{array}$ & $\begin{array}{c}a \\
(\mathrm{~mm})\end{array}$ & $\underset{(\mathrm{mm})}{2 \mathrm{c}}$ \\
\hline \multirow[t]{2}{*}{ I DOF } & $\mathrm{R}=\sigma_{\min } / \sigma_{\max }$ & 0.581 & 5.01 & 0.69 & 5.96 & 0.80 & 6.90 \\
\hline & $R=0$ & 0.582 & 5.01 & 0.61 & 5.22 & 0.78 & 6.70 \\
\hline \multirow[t]{2}{*}{2 DOF } & $\mathrm{R}=\sigma_{\min } / \sigma_{\max }$ & 0.581 & 5.01 & 0.59 & 5.02 & 0.79 & 5.06 \\
\hline & $\mathrm{R}=0$ & 0.582 & 5.01 & 0.61 & 5.02 & 0.77 & 5.06 \\
\hline
\end{tabular}

NOTE: Measured dimensions of crack $E$ Initial dimensions (Figure 4.1): $\quad a=0.58 \mathrm{~mm}$ $2 \mathrm{c}=5.00 \mathrm{~mm}$

Final dimensions (Figure 4.2): $\quad \mathrm{a}=1.45 \mathrm{~mm}$

$$
2 \mathrm{c}=10.00 \mathrm{~mm}
$$

2. The fatigue crack growth rates given in Equations 5.1 and 5.2 do not predict the low cycle fatigue crack growth behavior experienced in the HLVT Program. The crack growth rate represented by Equation 5.3, which was obtained by statistical correlation from a wide database, predicts crack dimensions closest to the measured ones. The deepest point of penetration of the crack can be predicted by assuming either self-similar (1 DOF) or two-directional (2 DOF) crack growth models. However, the arc length of the crack is best predicted by assuming the self-similar crack growth model.

3. In the presence of compressive loading across crack surfaces, the assumption $R=0$ and the inclusion of negative loading in the crack driving force yields practically the same result as in the conventional manner of utilizing the stress ratio $\mathrm{R}=\sigma_{\min } / \sigma_{\max }$. Slightly slower growth is predicted by utilizing the assumption $R=0$.

\subsubsection{Growth of the Cracks During Run 13}

The cracks observed after loading Run 12 are shown in Figure 4.2. They consist of three groups of surface cracks, group $A, B$ and $C$, group D and $E$ and Crack F. Cracks A, B and $C$ of Figure 4.1, joined together during Run 12 and formed one large crack of depth/thickness ratio $(a / t)=11 \%$ and arc length $2 c=54$ $\mathrm{mm}$. Similarly, cracks D and $E$ of Figure 4.1 joined with in between surface cracks and formed a larger crack with $a / t=15 \%$ and $2 c=67 \mathrm{~mm}$. Also, crack $F$ of Figure 4.1 grew during loading Run 12 and its dimensions appear in Figure 4.3. Each of these groups of cracks may also be modeled by a semi-elliptical surface crack in a flat plate of finite thickness and the growth encountered during loading Run 13 can be assessed in the same manner as done previously using Equations (6.1) through (6.3). After experiencing the loads of Run 13, the three groups of cracks grew and joined together to form a single large crack of dimensions $a / t=0.47$ at the deepest point of penetration and $2 \mathrm{c}=329 \mathrm{~mm}$ as shown in Figure 4.3. Figure 4.3 also shows the measured depth and arc length of each of the three groups of cracks mentioned previously. The predicted dimensions of the first group 
Table 6.7 - Predicted Dimensions of Layer Cracks A + B + C after Loading Run 13 (depth $=a$, arc length $=2 c$ )

\begin{tabular}{|c|c|c|c|c|c|c|c|}
\hline \multirow{3}{*}{$\begin{array}{l}\text { Two-Directional } \\
\text { (2 DOF) versus } \\
\text { Self-Similar } \\
\text { (1 DOF) Growth }\end{array}$} & \multirow{3}{*}{$\begin{array}{l}\text { Influence of } \\
\text { Compressive } \\
\text { Loading }\end{array}$} & \multicolumn{6}{|c|}{$\begin{array}{l}\text { Fatigue Crack Growth Rates And } \\
\text { Crack Dimensions }\end{array}$} \\
\hline & & \multicolumn{2}{|c|}{$\begin{array}{c}\text { Japanese Data } \\
\text { (Eq. 5.1) }\end{array}$} & \multicolumn{2}{|c|}{$\begin{array}{l}\text { DTRC Data } \\
\text { (Eq. 5.2) }\end{array}$} & \multicolumn{2}{|c|}{$\begin{array}{l}\text { ASME Data } \\
\text { (Eq. 5.3) }\end{array}$} \\
\hline & & $\begin{array}{c}a \\
(\mathrm{~mm})\end{array}$ & $\begin{array}{c}2 \mathrm{c} \\
(\mathrm{mm})\end{array}$ & $\stackrel{\mathrm{a}}{(\mathrm{mm})}$ & $\begin{array}{c}2 \mathrm{c} \\
(\mathrm{mm})\end{array}$ & $\underset{(\mathrm{mm})}{\mathbf{a}}$ & $\begin{array}{c}2 \mathrm{c} \\
(\mathrm{mm})\end{array}$ \\
\hline \multirow[t]{2}{*}{$1 \mathrm{DOF}$} & $\mathrm{R}=\sigma_{\min } / \sigma_{\max }$ & 3.21 & 54.32 & 3.37 & 57.10 & 5.80 & 98.30 \\
\hline & $R=0$ & 3.26 & 55.20 & 3.76 & 63.68 & 4.78 & 80.96 \\
\hline \multirow[t]{2}{*}{$2 \mathrm{DOF}$} & $\mathrm{R}=\sigma_{\min } / \sigma_{\max }$ & 3.21 & 54.01 & 3.37 & 54.04 & 5.77 & 60.60 \\
\hline & $\mathrm{R}=0$ & 3.26 & 54.01 & 3.75 & 54.06 & 4.69 & 54.16 \\
\hline
\end{tabular}

NOTE: Measured dimensions of crack $A+B+C$

$$
\text { Initial dimensions (Figure 4.2): } \quad \begin{aligned}
a & =3.19 \mathrm{~mm} \\
2 \mathrm{c} & =54 \mathrm{~mm} \\
\text { Final dimensions (Figure 4.3): } \quad \mathrm{a} & =6.67 \mathrm{~mm} \\
2 \mathrm{c} & =68.00 \mathrm{~mm}
\end{aligned}
$$

(crack $A+B+C$ ) appear in Table 6.7. In addition, the predicted dimensions of cracks $D+E$ and $F$ appear in Tables 6.8 and 6.9 , respectively. A critical assessment of the results leads to the same conclusions reached in the previous section concerning the cracks observed after Run 11. Briefly, the crack growth rates given in Equations (5.1) and (5.2) do not predict the observed growth behavior while the rate given in Equation 5.3 predicts reasonable results. Utilizing the latter rate, the maximum depth, a, may be predicted using either the self-similar or two-directional growth models while the arc length is best predicted in the self-similar growth model only. The analysis of cracks D + E using Equations (5.1) and (5.2) underpredicted the maximum penetration by about 53 to $62 \%$ while Equation (5.3) produced values larger than the pipe's thickness. The latter values are eliminated from Table 6.8 as being physically unacceptable. It is interesting to note that the initial aspect ratio of cracks $D$ $+E$ is very small $(a / c=0.13)$ indicating that it is acting as an edge crack (rather than a circumferential surface crack) in a plate. An edge crack propagates faster than a thumb nail surface crack subjected to identical loading. So far, the analysis has focused on modeling the circumferential cracks in the elbow as surface cracks in a plate and the influence of curvature of the elbow on the crack growth behavior is ignored.

In order to find out the role of curvature of the elbow on the crack growth behavior, the stress intensity factor of a semi-elliptical surface crack in a pipe needs to be used in the analysis instead of Equations 6.1 through 6.3. For a semi-elliptical crack situated in a plane normal to the axis of a pipe of radius $=R$, thickness $=t$, Raju and Newman (Reference 21 ) calculated the stress-intensity factor by a three-dimensional finite element analysis. The formulation is valid for crack depth to wall thickness ratio $(\mathrm{a} / \mathrm{t})$ from 0.2 to 0.8 , aspect ratio $(\mathrm{a} / \mathrm{c})$ from 0.6 to 1.0 and internal radius to wall thickness ratio $(R / t)$ from 1 to 10. In addition, the crack front is assumed to intersect the free surface of the pipe at right angles. The formula of the stress-intensity factor for remote tensile and bending loads is given by

$$
K=(\pi a / Q)^{1 / 2}\left[\frac{F_{1}}{A} C_{t}+\frac{M_{1}}{S} C_{b}\right]
$$


Table 6.8 - Predicted Dimensions of Layer Cracks D + E after Loading Run 13 (depth $=a$, arc length $=2 c$ )

\begin{tabular}{|c|c|c|c|c|c|c|c|}
\hline \multirow{3}{*}{$\begin{array}{l}\text { Two-Directional } \\
\text { (2 DOF) versus } \\
\text { Self-Similar } \\
\text { (1 DOF) Growth }\end{array}$} & \multirow{3}{*}{$\begin{array}{l}\text { Influence of } \\
\text { Compressive } \\
\text { Loading }\end{array}$} & \multicolumn{6}{|c|}{$\begin{array}{c}\text { Fatigue Crack Growth Rates And } \\
\text { Crack Dimensions }\end{array}$} \\
\hline & & \multicolumn{2}{|c|}{$\begin{array}{c}\text { Japanese Data } \\
\text { (Eq. 5.1) }\end{array}$} & \multicolumn{2}{|c|}{$\begin{array}{l}\text { DTRC Data } \\
\text { (Eq. 5.2) }\end{array}$} & \multicolumn{2}{|c|}{$\begin{array}{l}\text { ASME Data } \\
\text { (Eq. 5.3) }\end{array}$} \\
\hline & & $\begin{array}{c}a \\
(\mathrm{~mm})\end{array}$ & $\begin{array}{c}2 \mathrm{c} \\
(\mathrm{mm})\end{array}$ & $\begin{array}{c}a \\
(\mathrm{~mm}) \\
\end{array}$ & $\begin{array}{c}2 \mathrm{c} \\
(\mathrm{mm})\end{array}$ & $\begin{array}{c}\mathrm{a} \\
(\mathrm{mm})\end{array}$ & $\begin{array}{c}2 \mathrm{c} \\
(\mathrm{mm})\end{array}$ \\
\hline \multirow[t]{2}{*}{$1 \mathrm{DOF}$} & $\mathrm{R}=\sigma_{\min } / \sigma_{\max }$ & 4.39 & 67.58 & 4.66 & 71.84 & $*_{-}$ & - \\
\hline & $R=0$ & 4.49 & 67.18 & 5.40 & 83.18 & - & - \\
\hline \multirow[t]{2}{*}{2 DOF } & $\mathrm{R}=\sigma_{\min } / \sigma_{\max }$ & 4.39 & 67.00 & 4.67 & 6704 & - & - \\
\hline & $R=0$ & 4.49 & 67.01 & 5.37 & 67.12 & - & - \\
\hline
\end{tabular}

NOTE: Measured dimensions of crack $\mathrm{D}+\mathrm{E}$

Initial dimensions (Figure 4.2): $\quad a=4.35 \mathrm{~mm}$

$$
2 \mathrm{c}=67 \mathrm{~mm}
$$

Final dimensions (Figure 4.3): $\quad a=11.60 \mathrm{~mm}$

$$
2 \mathrm{c}=(92-110) \mathrm{mm}
$$

* The analysis predicted values greater than $29 \mathrm{~mm}$.

Table 6.9 - Predicted Dimensions of Crack F after

\begin{tabular}{|c|c|c|c|c|c|c|c|}
\hline \multirow{3}{*}{$\begin{array}{l}\text { Two-Directional } \\
\text { (2 DOF) versus } \\
\text { Self-Similar } \\
\text { (1 } \text { DOF) Growth }\end{array}$} & \multirow{3}{*}{$\begin{array}{l}\text { Influence of } \\
\text { Compressive } \\
\text { Loading }\end{array}$} & \multicolumn{6}{|c|}{$\begin{array}{l}\text { Fatigue Crack Growth Rates And } \\
\text { Crack Dimensions }\end{array}$} \\
\hline & & \multicolumn{2}{|c|}{$\begin{array}{l}\text { Japanese Data } \\
\text { (Eq. 5.1) }\end{array}$} & \multicolumn{2}{|c|}{$\begin{array}{l}\text { DTRC Data } \\
\text { (Eq. 5.2) }\end{array}$} & \multicolumn{2}{|c|}{$\begin{array}{l}\text { ASME Data } \\
\text { (Eq. 5.3) }\end{array}$} \\
\hline & & $\underset{(\mathrm{mm})}{\mathrm{a}}$ & $\begin{array}{c}2 \mathrm{c} \\
(\mathrm{mm})\end{array}$ & $\begin{array}{c}\mathrm{a} \\
(\mathrm{mm})\end{array}$ & $\begin{array}{c}2 \mathrm{c} \\
(\mathrm{mm})\end{array}$ & $\begin{array}{c}\mathrm{a} \\
(\mathrm{mm})\end{array}$ & $\begin{array}{c}2 \mathrm{c} \\
(\mathrm{mm})\end{array}$ \\
\hline \multirow[t]{2}{*}{$1 \mathrm{DOF}$} & $\mathrm{R}=\sigma_{\min } / \sigma_{\max }$ & 1.453 & 10.02 & 1.49 & 10.24 & 2.56 & 17.68 \\
\hline & $R=0$ & 1.46 & 10.08 & 1.56 & 10.72 & 2.43 & 16.76 \\
\hline \multirow[t]{2}{*}{$2 \mathrm{DOF}$} & $R=\sigma_{\min } / \sigma_{\max }$ & 1.453 & 10.00 & 1.49 & 10.00 & 2.38 & 10.50 \\
\hline & $R=0$ & 1.46 & 10.01 & 1.55 & 10.04 & 2.27 & 10.42 \\
\hline
\end{tabular}
Loading Run 13 (depth $=a$, arc length $=2 \mathrm{c}$ )

NOTE: Measured dimensions of crack $F$

Initial dimensions (Figure 4.2): $\quad a=1.45 \mathrm{~mm}$

$$
2 c=10.00 \mathrm{~mm}
$$

Final dimensions (Figure 4.3): $\quad a=3.77 \mathrm{~mm}$

$$
2 \mathrm{c}=20.00 \mathrm{~mm}
$$


Table 6.10 - Boundary Correction Factors $C_{1}$ and $C_{b}$ appearing in Equation (6.5)

\begin{tabular}{||l|l|l|l|l||}
\hline \multirow{2}{*}{$\mathrm{a} / \mathrm{t}$} & \multicolumn{2}{|c|}{$\mathrm{C}_{\mathrm{t}}$} & \multicolumn{2}{c|}{$\mathrm{C}_{\mathrm{b}}$} \\
\cline { 2 - 5 } & \multicolumn{1}{|c|}{$\phi=\pi / 2$} & \multicolumn{1}{|c|}{$\phi=0$} & \multicolumn{1}{c|}{$\phi=\pi / 2$} & \multicolumn{1}{c|}{$\phi=0$} \\
\hline 0.2 & 1.100 & 0.932 & 1.067 & 0.915 \\
\hline 0.5 & 1.174 & 1.071 & 1.111 & 1.043 \\
\hline 0.8 & 1.272 & 1.287 & 1.166 & 1.232 \\
\hline
\end{tabular}

where the shape factor, $\mathrm{Q}$, is defined in Equation (6.2a) and $F_{i}, M_{i}, A$ and $S$ are defined in Equation (6.3). The boundary-correction factors, $C_{t}$ and $C_{b}$, associated with remote tension and bending loads, respectively, are obtained from Reference 21 for $R / t=6, a / c=0.6, \phi=$ $\pi / 2$ (deepest point of penetration) and $\phi=0$ (free-surface edge) and the results are listed in Table 6.10.

As an example to illustrate the use of Equation (6.5), the dimensions of the second group (cracks D and E) are modified. The crack depth/thickness ratio is changed from $15 \%$ to $20 \%$ and a crack aspect ratio of a/c $=0.6$ is assumed. This gives the dimensions of the modified crack as a $=5.8 \mathrm{~mm}$ and $2 \mathrm{c}=19.34 \mathrm{~mm}$ (instead of $\mathrm{a}=4.35 \mathrm{~mm}$ and $2 \mathrm{c}=67 \mathrm{~mm}$ for the original cracks). The modification is necessary so that one can utilize Equation (6.5) for the crack driving force and assess the influence of curvature of the elbow on the crack growth behavior experienced during Run 13 .

For the modified cracks, the results of assessment based on the model of a surface crack in a plate is given in Table 6.11. The corresponding results assuming a surface crack in a pipe are given in Table 6.12. A glance at these results indicates the following: The model of an edge crack in a plate (Table 6.11) yields faster crack growth than that of an identical crack in a pipe (Table 6.12). This is true whether the crack is assumed to extend in a self-similar manner or in two directional orientations. This leads to the conclusion that for a pipe with circumferential thumb nail cracks having crack depth/pipe thickness ratio, $\mathrm{a} / \mathrm{t}=0.2$, aspect ratio, $\mathrm{a} / \mathrm{c}=$ 0.6 and $R / t=6$, the curvature of the pipe reduces the crack driving force(s) compared to identical cracks in a flat plate subjected to the same loading.

In order to assess the results of the growth analysis presented in Table 6.12 , an estimate must be made of the final dimensions of crack $D+E$ (modified) based on the actual measurement observed in the HLVT Program. The actual dimensions of crack D $+E$ after the application of loading Run 13 are obtained from Figure 4.3 as: a (average) $=0.4 \times 29=11.6 \mathrm{~mm}$ and $2 \mathrm{c}=92 \mathrm{~mm}$. Assuming a linear correlation between the actual and modified dimensions of the crack, the "expected" dimensions after experiencing Run 13 are: a $=5.8 / 4.34 \times 11.6=15.47 \mathrm{~mm}$ and $2 \mathrm{c}=19.34167 \times 92$ $=26.56 \mathrm{~mm}$. The depth $\mathrm{a}$, is best predicted by assuming self-similar crack growth and using the growth rate of Equation (5.3). This yields $\mathrm{a}=12.80$, i.e., an underprediction with an error of $17 \%$. The arc length is reasonably predicted using the same growth rate and assuming a two directional growth model which gives $2 \mathrm{c}$ $=25.78$, i.e., an error of about $3 \%$. Note that the twodirectional growth model (2 DOF) underpredicts the depth (a) by an error of about $30 \%$ while the self-similar growth model (1 DOF) overpredicts the arc length (2c) by an error of about $58 \%$. As discussed previously, the fatigue crack growth rates represented by Equations (5.1) and (5.2) generated very small crack growth compared to the actual behavior observed in the test program. The growth of the other two groups of cracks, i.e., crack A + B + $C$ and crack $F$, can also be analyzed by using Equation (5.3) for the crack driving forces. The results have similar trends as those presented in Table 6.12 for group $D+E$ and are excluded from this study.

The following conclusions can be stated concerning the application of the $\Delta \mathrm{K}$ methodology for predicting the crack growth behavior observed in the HLVT Program after loading Run 13:

1. Because of the relatively large size of the surface cracks, the magnitude(s) of the crack driving force(s) is influenced by the curvature of the pipe (ratio $R / t$ ) as well as by the ratios $a / c$ and $a / t$. 
Table 6.11 - Predicted Dimensions of Modified Cracks D + E after Loading Run 13 - Surface Crack in a Plate (depth $=a$, arc length $=2 c$ )

\begin{tabular}{|c|c|c|c|c|c|c|c|}
\hline \multirow{3}{*}{$\begin{array}{l}\text { Two-Directional } \\
\text { (2 DOF) versus } \\
\text { Self-Similar } \\
\text { (1 DOF) Growth }\end{array}$} & \multirow{3}{*}{$\begin{array}{l}\text { Influence of } \\
\text { Compressive } \\
\text { Loading }\end{array}$} & \multicolumn{6}{|c|}{$\begin{array}{l}\text { Fatigue Crack Growth Rates And } \\
\text { Crack Dimensions }\end{array}$} \\
\hline & & \multicolumn{2}{|c|}{$\begin{array}{c}\text { Japanese Data } \\
(\text { Eq. 5.1) }\end{array}$} & \multicolumn{2}{|c|}{$\begin{array}{l}\text { DTRC Data } \\
\text { (Eq. 5.2) }\end{array}$} & \multicolumn{2}{|c|}{$\begin{array}{c}\text { ASME Data } \\
\text { (Eq. 5.3) }\end{array}$} \\
\hline & & $\underset{(\mathrm{mm})}{\mathrm{a}}$ & $\begin{array}{c}2 \mathrm{c} \\
(\mathrm{mm})\end{array}$ & $\underset{(\mathrm{mm})}{\mathrm{a}}$ & $\begin{array}{c}2 \mathrm{c} \\
(\mathrm{mm})\end{array}$ & $\underset{(\mathrm{mm})}{\mathrm{a}}$ & $\underset{(\mathrm{mm})}{2 \mathrm{c}}$ \\
\hline \multirow[t]{2}{*}{$1 \mathrm{DOF}$} & $\mathrm{R}=\sigma_{\min } / \sigma_{\max }$ & 5.82 & 19.40 & 6.00 & 20.00 & 15.42 & 51.44 \\
\hline & $R=0$ & 5.88 & 19.60 & 6.40 & 21.34 & 13.89 & 46.32 \\
\hline \multirow[t]{2}{*}{$2 \mathrm{DOF}$} & $\mathrm{R}=\sigma_{\min } / \sigma_{\max }$ & 5.82 & 19.36 & 5.99 & 18.58 & 11.92 & 30.08 \\
\hline & $R=0$ & 5.88 & 19.44 & 6.38 & 20.08 & 11.03 & 28.60 \\
\hline
\end{tabular}

NOTE: Measured dimensions of modified crack $D+E$

Initial dimensions:

$$
\begin{array}{rlrl} 
& \text { Initial dimensions: } & \mathrm{a} & =5.8 \mathrm{~mm} \\
& \text { Final dimensions (estimate): } & \mathrm{c} & =19.33 \mathrm{~mm} \\
\mathrm{a} & =15.47 \mathrm{~mm} \\
2 \mathrm{c} & =26.56 \mathrm{~mm}
\end{array}
$$

\begin{tabular}{|c|c|c|c|c|c|c|c|}
\hline \multirow{3}{*}{$\begin{array}{l}\text { Two-Directional } \\
\text { (2 DOF) versus } \\
\text { Self-Similar } \\
\text { (1 DOF) Growth }\end{array}$} & \multirow{3}{*}{$\begin{array}{l}\text { Influence of } \\
\text { Compressive } \\
\text { Loading }\end{array}$} & \multicolumn{6}{|c|}{$\begin{array}{c}\text { Fatigue Crack Growth Rates And } \\
\text { Crack Dimensions }\end{array}$} \\
\hline & & \multicolumn{2}{|c|}{$\begin{array}{c}\text { Japanese Data } \\
\text { (Eq. 5.1) }\end{array}$} & \multicolumn{2}{|c|}{$\begin{array}{c}\text { DTRC Data } \\
\text { (Eq. 5.2) }\end{array}$} & \multicolumn{2}{|c|}{$\begin{array}{l}\text { ASME Data } \\
\text { (Eq. 5.3) }\end{array}$} \\
\hline & & $\underset{(\mathrm{mm})}{\mathrm{a}}$ & $\begin{array}{c}2 \mathrm{c} \\
(\mathrm{mm})\end{array}$ & $\underset{(\mathrm{mm})}{\mathrm{a}}$ & $\begin{array}{c}2 \mathrm{c} \\
(\mathrm{mm})\end{array}$ & $\underset{(\mathrm{mm})}{\mathrm{a}}$ & $\begin{array}{c}2 \mathrm{c} \\
(\mathrm{mm})\end{array}$ \\
\hline \multirow[t]{2}{*}{ I DOF } & $\mathrm{R}=\sigma_{\min } / \sigma_{\max }$ & 5.82 & 19.40 & 5.97 & 19.90 & 12.80 & 42.60 \\
\hline & $R=0$ & 5.81 & 19.60 & 5.98 & 19.94 & 12.82 & 43.00 \\
\hline \multirow[t]{2}{*}{2 DOF } & $\mathrm{R}=\sigma_{\min } / \sigma_{\max }$ & 5.82 & 19.36 & 5.96 & 19.54 & 10.84 & 25.78 \\
\hline & $\mathrm{R}=0$ & 5.88 & 19.42 & 6.35 & 20.00 & 10.73 & 25.64 \\
\hline
\end{tabular}

Table 6.12 - Predicted Dimensions of Modified Cracks D + E After Loading Run 13 - Surface Crack in a Pipe $($ depth $=a$, arc length $=2 c)$

NOTE: Measured dimensions of modified crack $D+E$

Initial dimensions:

Final dimensions (estimate): $\mathrm{a}=5.8 \mathrm{~mm}$

$2 \mathrm{c}=19.33 \mathrm{~mm}$

$\mathrm{a}=15.47 \mathrm{~mm}$

$2 \mathrm{c}=26.56 \mathrm{~mm}$ 
2. The fatigue crack growth rates of the material represented by Equation (5.1) and (5.2) do not predict the growth behavior observed after applying ioading Run 13. The rate given in Equation (5.3) generated a reasonably acceptable growth pattern compared to the measured data. In particular, the results in Table 6.12 indicate excellent prediction for the arc length of the crack using the 2 DOF (two-directional or two degree of freedom) growth model and reasonable prediction for the depth, a, using the 1 DOF (self-similar) growth model.

3. By neglecting the stress ratio $(R=0)$ and including the effect of negative stresses on the crack driving force, the analysis is simplified and slightly slower growth is predicted.

\subsubsection{Growth of a Part Through Crack During Run 14}

After experiencing loading Run 13, the three groups of surface cracks shown in Figure 4.2, i.e., group $A+B+C$, group $D+E$ and group $F$, joined together and formed a single surface crack which is shown covering the darkened areas in Figure 4.3. The deepest point of penetration of this crack is a $=0.47 \times 29=$ $13.63 \mathrm{~mm}$ and its arc length is $2 \mathrm{c}=329 \mathrm{~mm}$. When subjected to loading Run 14, which consisted of only one of the four segments of strong motion included in Runs $11-13$, the crack grew and penetrated almost $94 \%$ of the wall thickness before the test was terminated. Figure 4.4 displays the crack configuration at the termination of the test program. In this figure, $a=27.26 \mathrm{~mm}$ and the arc length is approximately given by $2 \mathrm{c}=341 \mathrm{~mm}$.

In order to assess the crack growth behavior experienced during loading Run 14, two models of the crack configuration are considered. The first consists of a semi-elliptical surface crack in a plate with $a=13.63$ $\mathrm{mm}, \mathrm{c}=164.5 \mathrm{~mm}$ and the second is a crack in a pipe with $\mathrm{a}=13.63 \mathrm{~mm}$ and $\mathrm{c}=22.72 \mathrm{~mm}$. Since the actual aspect ratio of the crack is $a / c=13.63 / 164.50=0.08$, the crack is essentially an edge crack in a plate and the second model is obviously not reliable. Subjecting both models to the appropriate loading cycles of Run 14 , i.e., input motion lasting 8-10 seconds, it is found that for the model of a crack in a pipe a 1 DOF crack growth with $R$ $=0$, the growth rate of Equation (5.3) predicts $\mathrm{a}=$ $24.37 \mathrm{~mm}$ and Equation (5.2) predicts $\mathrm{a}=16.65 \mathrm{~mm}$ while the actual maximum penetration is $\mathrm{a}=27.26 \mathrm{~mm}$.
Table 6.13 presents the predicted dimensions of the crack in a plate. In contrast, with previous observations, the rate given in Equation (5.1) predicts reasonable results while Equation (5.2) and (5.3) predicted physically impossible results which are eliminated from the table. The deepest penetration is best predicted by assuming $\mathbf{R}=\mathbf{0}$ and either self-similar or two-directional crack growth. The arc length, however, is best predicted by using multi-degree of freedom crack growth assumption.

In conclusion, the tools required to perform a $\Delta K$ analysis to predict the crack growth behavior of the HLVT Program are well established and a comprehensive study of the role of the key parameters influencing the growth can be carried out. The drawback is that some of the cyclic loading induced stresses higher than the yield strength which would invalidate the assumption of the methodology. Based on the assumptions made in this work the following conclusions can be stated:

1. The experimental fatigue crack growth rates given by Equations (5.1) and (5.2) do not predict the low cycle fatigue crack growth behavior observed in the HLVT program. However, the fatigue rate represented by Equation (5.3), which is obtained by means of statistical correlation from a wide range experimental data base. predicts from the engineering viewpoint reasonable growth patterns compared to what was actually observed in the vibration test program. The remaining comments are based on using Equation (5.3) for the growth rate of the material.

2. For circumferential surface cracks with a crack depth/pipe thickness ratio, $a / t<0.2$, the curvature of the pipe has no influence on the crack growth behavior and for all intents and purposes the crack can be assumed to be situated in a plate of the same thickness as the pipe. For cracks with $\mathrm{a} / \mathrm{t}>0.2$, the pipe's curvature affects the crack growth behavior and should be incl ided in the analysis. However, the available formulas of the stress intensity factors are valid for crack depth/arc length ratios, $a / c$, between 0.6 and 1.0 and $a / t=0.2$ to 0.8 which, in some cases, necessitates correlation between the actual crack dimensions and the dimensions used in the analysis. 
Table 6.13 - Predicted Dimensions after Loading Run 14 -

Surface Crack in a Plate (depth $=a$, arc length $=2 c$ )

\begin{tabular}{|c|c|c|c|c|c|c|c|}
\hline \multirow{3}{*}{$\begin{array}{l}\text { Two-Directional } \\
\text { (2 DOF) versus } \\
\text { Self-Similar } \\
\text { (1 } \text { DOF) Growth }\end{array}$} & \multirow{3}{*}{$\begin{array}{l}\text { Influence of } \\
\text { Compressive } \\
\text { Loading }\end{array}$} & \multicolumn{6}{|c|}{$\begin{array}{l}\text { Fatigue Crack Growth Rates And } \\
\text { Crack Dimensions }\end{array}$} \\
\hline & & \multicolumn{2}{|c|}{$\begin{array}{c}\text { Japanese Data } \\
\text { (Eq. 5.1) }\end{array}$} & \multicolumn{2}{|c|}{$\begin{array}{l}\text { DTRC Data } \\
\text { (Eq. 5.2) }\end{array}$} & \multicolumn{2}{|c|}{$\begin{array}{l}\text { ASME Data } \\
\text { (Eq. 5.3) }\end{array}$} \\
\hline & & $\begin{array}{c}\mathrm{a} \\
(\mathrm{mm})\end{array}$ & $\begin{array}{c}2 \mathrm{c} \\
(\mathrm{mm})\end{array}$ & $\begin{array}{c}\mathrm{a} \\
(\mathrm{mm})\end{array}$ & $\begin{array}{c}2 \mathrm{c} \\
(\mathrm{mm}) \\
\end{array}$ & $\begin{array}{c}\mathrm{a} \\
(\mathrm{mm}) \\
\end{array}$ & $\begin{array}{c}2 \mathrm{c} \\
(\mathrm{mm})\end{array}$ \\
\hline \multirow[t]{2}{*}{$1 \mathrm{DOF}$} & $\mathrm{R}=\sigma_{\min } / \sigma_{\max }$ & 16.8 & 404.0 & - & - & - & - \\
\hline & $\mathrm{R}=0$ & 17.6 & 425.0 & - & - & - & - \\
\hline \multirow[t]{2}{*}{2 DOF } & $\mathrm{R}=\sigma_{\min } / \sigma_{\max }$ & 16.9 & 329.0 & - & - & - & - \\
\hline & $\mathrm{R}=0$ & 17.0 & 329.0 & - & - & - & - \\
\hline
\end{tabular}

NOTE: Measured dimensions of modified crack

Initial dimensions (Figure 4.3): $\quad a=13.63 \mathrm{~mm}$

$2 \mathrm{c}=329 \mathrm{~mm}$

Final dimensions (Figure 4.4): $\quad a=27.76 \mathrm{~mm}$

$2 \mathrm{c}=341 \mathrm{~mm}$

3. For a semi-elliptical crack in a plate, the deepest point of penetration may be predicted by assuming either a self-similar or two-directional crack growth model. However, the arc length of the crack along the outside surface of the pipe is best predicted by assuming a self-similar growth model.

4. For a semi-elliptical crack in a pipe, the growth behavior is best predicted by using a two directional growth model. However, since the available stress intensity factor formulas are restricted to ratios $a / c=0.6$ to 1.0 and some of the cracks observed in the HLVT program have aspect ratios outside this range, this conclusion is based on linear interpolation between the results of the analysis and the actual crack dimensions.

5. For semi-elliptical surface cracks with $a / c<$ 0.2 , the crack's model is essentially that of an edge crack in a plate of the same finite thickness. Accordingly, the corresponding stress intensity factor formula can be used for the crack driving force.

6. In the presence of compressive stresses, the stress ratio, $\mathrm{R}=\sigma_{\min } / \sigma_{\max }$, can be assumed to be zero provided that the contribution of the negative stresses are included in the computation of the stress intensity factors. From the engineering viewpoint, practically identical results are obtained by setting $R=0$ compared to the conventional manner of accounting for compressive stresses across crack surfaces.

\subsection{USE OF J-INTEGRAL PARAMETERS}

Since some of the cyclic loading in the HLVT Program induced stresses larger than the yield strength, the use of $\Delta \mathrm{K}$ methodology in predicting the crack growth behavior is at best approximate and certainly open to questions. This is because the concept of the stress intensity factor is based on linear elastic analysis and is not valid when there is gross plastic deformation. This section explores the use of $\mathrm{J}$-integral concepts in predicting the crack growth behavior (References 25-26). The appropriate material crack growth rates are expressed in Equations (5.1a) and (5.2b). In order to use these 


\subsection{Methodologies}

equations the crack driving force, specifically the range in the J-parameter, $\Delta \mathrm{J}$, must be determined for each cycle of loading. Since the available engineering estimates of the $\mathrm{J}$-parameter are based on deformation theory of plasticity, their use in the present application is not strictly valid. This is because equations $(5.1 \mathrm{a})$ and $(5.2 \mathrm{~b})$ were developed from laboratory tests on compact tension specimens where the value of the $\mathrm{J}$-integral is computed by summing the area under the load-displacement curve generated in the tests. In the case of cyclic loading with negative stress ratio $R$, part (or all) of the compressive load-displacement area is used in the computation of the $\mathrm{J}$-parameter (see Section 5.0) while the tabulated J-values, usually obtained by finite element analysis or engineering estimates, are based on deformation theory of plasticity in which unloading is not permissible.

It was mentioned in previous sections that the crack growth behavior observed in the HLVT Program can be assessed by modeling the growth of an external circumferential crack in a pipe. The shape of the circumferential crack is conveniently assumed as a semielliptical of semi-axes a and c. The crack driving force consists of the J-integral as a function of the applied normal and bending loads.

An engineering estimate of the J-integral parameter can be obtained by writing (Reference 27):

$$
J=J_{e}\left(a_{e}\right)+J_{p}(a, n)
$$

where $J_{e}$ is the elastic contribution and $J_{p}$ is the fully plastic part. The elastic part is, $\mathrm{J}_{\mathrm{c}}=\mathrm{K}_{\mathrm{i}}^{2} / \mathrm{E}^{\circ}$, where $\mathrm{K}_{1}$ is the stress intensity factor, and $\mathrm{E}^{\prime}=\mathrm{E}$ for plane stress and $E /\left(1-\nu^{2}\right)$ for plane strain. In order to include the effects of small-scale yielding, the elastic part is usually computed by using the effective crack length, $a_{e}$, which is greater than the actual length by a correction factor to account for strain hardening of the material (Reference 3 ). However, in order to simplify the analysis, the actual crack length, $a$, is used in the following discussion. The fully plastic part, $J_{p}$, is strongly influenced by the Ramberg-Osgood material constants which were found in Section 5.0, namely, $\alpha=3.5$ and $n=4$. The crack growth is evaluated in the next section.

\subsubsection{Growth of a Surface Crack in a Pipe}

Consider a surface-cracked pipe subjected to the general loading condition as shown in Figure 6.1. The pipe's mean, external and internal radii are denoted by $R$, $R_{o}$ and $R_{i}$, respectively. The crack dimensions are defined by the depth $\mathrm{a}(\theta)$ and the angle $\theta$ with the maximum crack depth, a, at $\theta=0$. A self-similar or 1 DOF crack growth is assumed, i.e., a semi-elliptical surface crack grows into a larger semi-ellipse with the same aspect ratio. The engineering estimate of the $J$ integral was obtained from a recently published work by Zahoor (Reference 28). At the deepest point of penetration $(\theta=0)$, the $\mathrm{J}$-parameter is given by

$$
J=\left(t \sigma^{2} / E\right)\left[\pi\left(1-v^{2}\right) f_{t}+\alpha H_{1}\left(\sigma / \sigma_{0}\right)^{n-1}\right]
$$

where $\sigma$ is the applied tensile stress, $\sigma_{0}$ is a reference stress, $\alpha$ and $\mathrm{n}$ are the material constants in the RambergOsgood true stress-strain relation and

$$
f_{t}=\left[0.25+0.5298 \eta+0.3835 \eta^{2}\right]^{2}, \text { for } \eta \geq 0.25
$$

or

$$
\begin{array}{r}
f_{t}=\left[3.72 \eta-13.475 \eta^{2}+19.988 \eta^{3}\right]^{2}, \\
\text { for } \eta<0.25
\end{array}
$$

The dimensionless parameter, $\eta$, appearing in equations $(6.8)$ is given by

$$
\eta=\left(0.25+\frac{a}{c}\right)^{-0.58}\left[\frac{a}{t}+\left(F_{t}^{2} / 6\right)\left(\frac{n-1}{n+1}\right)\left(B_{0}+\left(\sigma_{0} / \sigma\right)^{2}\right\}\right]
$$

in which

$$
\begin{aligned}
& B_{0}=\left[2 R t /\left(R_{0}^{2}-R_{c}^{2}+(1-\theta / \pi)\left(R_{C}^{2}-R_{i}^{2}\right) \mid\right]^{2}\right. \\
& R_{C}=R_{i}+a \\
& \theta=\pi c /\left(4 R_{i}\right)
\end{aligned}
$$

and 


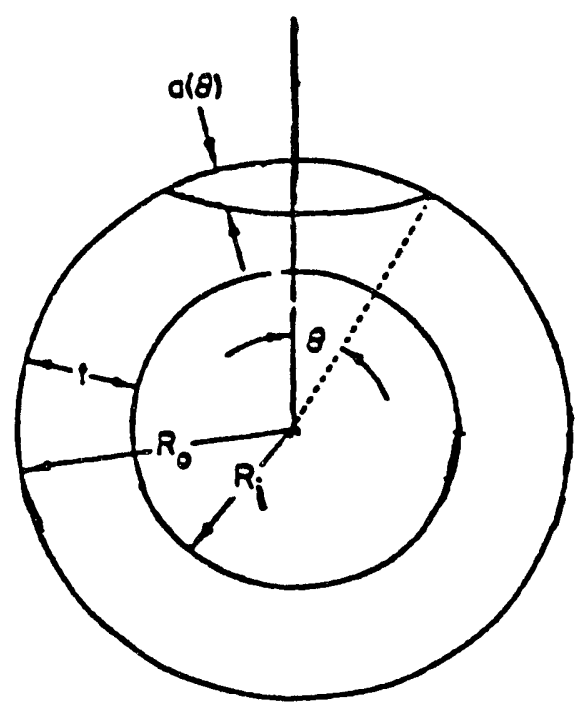

(a) Geometry of the Surface Crack

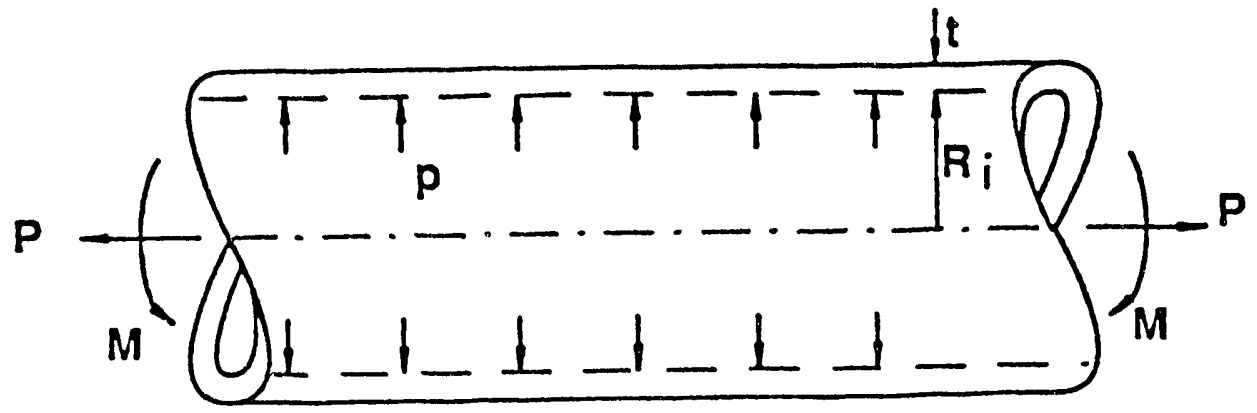

(b) Surface-Cracked Pipe Under General Loading

Figure 6.1 External Surface Crack in a Pipe 


$$
\begin{array}{r}
F_{t}=0.25+0.5298 \zeta+0.3835 \zeta^{2}, \\
\text { for } \zeta \geq 0.25
\end{array}
$$

or

$$
\begin{array}{r}
F_{t}=3.72 \zeta-13.475 \zeta^{2}+19.988 \zeta^{2}, \\
\text { for } \zeta<0.25
\end{array}
$$

where

$$
\zeta=(0.25+a / c)^{-0.58}(a / t)
$$

The function, $H_{1}$, in Equation (6.7) depends on $\theta / \pi, \mathbf{a} / \mathrm{t}, \mathbf{n}$ and $\mathbf{R} / \mathrm{t}$. Reference 28 lists tabulated values of $H_{1}$ for $R / t=10$ and $n=1,2,5$ and 10 . In developing these tables, a plane strain crack-tip condition was assumed for the part-through crack, and limited finite element results were used.

Table 6.14 below gives the values of the function, $H_{1}$, for $n=4$ and the relevant crack dimensions for the present application. These values were obtained by linear interpolation from tables listed in Reference 28 and should be regarded as approximate since the referenced tables are applicable to pipes with $R / t=10$ while in the HLVT case the ratio $R / t$ is about 6 .

An alternative evaluation of the J-integral was also obtained from a computer code developed by Battelle (Reference 29). The code requires input loading in terms of internal pressure. The pressure was obtained from the applied axial stress by the relation $p=2(t / R) \sigma$. Since a spot check of the results confirmed the evaluation made by using Equations (6.7) through (6.11), the crack growth analysis was carried out using the latter estimation for the J-integral. It should also be mentioned that the engineering estimate of the J-integral, based on the deformation theory of plasticity, was not adjusted to correspond to the cyclic operational J-values in Equations (5.1a) and (5.2b).

Utilizing the growth rates in Equations (5.1a) and (5.2b) and assuming self-similar crack growth, the cracks appearing after loading Run 12 were analyzed and the predicted dimensions appear in Table 6.15.
Comparing the results in Table 6.15 with the corresponding results predicted by the $\Delta \mathrm{K}$ methodology (See Tables 6.1 through 6.6), it is clear that the application of the $\Delta \mathrm{J}$ concept has improved the prediction capability of the crack growth by about 15 to $20 \%$. As expected, Equation (5.2b) provides a faster crack growth than Equation (5.1a). Based on the assumption and formulation used in the analysis, the application of the $\Delta \mathbf{J}$ concepts to the cracks considered in Table 6.15 resulted in an underprediction of the actual crack growth by about 29 to $58 \%$.

The $\Delta \mathrm{J}$ methodology and the J-integral estimation given in Equations (6.7) through (6.11) were also used to assess the crack growth observed during loading Run 13. As in the previous case, self-similar crack growth (1 DOF) is maintained, i.e., the crack aspect ratio, a/c, remains constant throughout the analysis. The results of the crack growth are displayed in Table 6.16.

For these crack dimensions, the prediction is much better. For the group of cracks designated as A + $B+C$, the prediction by Equation (5.2b) for the maximum crack penetration is practically perfect while the depth for the crack group $D+E$ is underpredicted by about $26 \%$ which is reasonable from an engineering viewpoint. An attempt was also made to predict the growth of the crack appearing after loading Run 14 (See Table 6.13). However, the methodology predicted a crack depth larger than the pipe's thickness which is physically impossible. It should also be mentioned that the J-estimation given in Equations (6.7) through (6.11) does not allow two-dimensional modeling of the crack growth as was discussed in previous sections and, accordingly, such an analysis was not attempted.

\subsection{NET-SECTION STRESS RANGE}

The third method used to investigate the crack growth behavior is based on the net-section limit load failure criterion. The method involves computing a netsection stress range for the cracked pipe and determining the corresponding number of loading cycles required to drive the crack through the pipe's thickness. The relation between the net-section stress range and the number of loading cycles is based on experimental data. In a recent test program (Reference 9), specimens of circumferentially cracked pipes made from 304 stainless steel and STS $\mathbf{4 2}$ carbon steel were subjected to sinusoidal loading applied at the natural frequency of the test model. The experimental results have indicated a relationship 
Table 6.14 - Values of $H_{1}$ for a Semi-Elliptical Crack in Tension $(n=4)$

\begin{tabular}{||c|c|c|c||}
\hline \multirow{2}{*}{$\frac{\mathrm{a}}{\mathrm{t}}$} & 0.05 & 0.10 & 0.15 \\
\cline { 2 - 4 } & 0.395 & 0.421 & 0.473 \\
0.100 & 0.494 & 0.528 & 0.619 \\
0.125 & 0.603 & 0.653 & 0.762 \\
0.150 & 0.824 & 0.914 & 1.077 \\
0.200 & 1.048 & 1.225 & 1.473 \\
0.250 & 1.289 & 1.617 & 2.061 \\
0.300 & 1.599 & 2.217 & 2.993 \\
0.350 & 1.919 & 2.914 & 4.307 \\
0.400 & 2.250 & 3.714 & 5.683 \\
0.450 & 2.580 & 4.593 & 7.310 \\
0.500 & & & \\
\hline
\end{tabular}

Table 6.15 - Predicted Dimensions of Cracks Appearing After Run 12

\begin{tabular}{|c|c|c|c|c|c|c|}
\hline \multirow{3}{*}{ Crack } & \multicolumn{4}{|c|}{ Measured Crack Dimensions } & \multicolumn{2}{|c|}{$\begin{array}{l}\text { Predicted Maximum } \\
\text { Depth }(\mathrm{mm})\end{array}$} \\
\hline & \multicolumn{2}{|c|}{ Initial } & \multicolumn{2}{|c|}{ Final } & \multirow{2}{*}{$\begin{array}{l}\text { Eq. } \\
(5.1 a)\end{array}$} & \multirow{2}{*}{$\begin{array}{l}\text { Eq. } \\
(5.2 b)\end{array}$} \\
\hline & $a(\mathrm{~mm})$ & $\mathrm{c}(\mathrm{mm})$ & $\mathrm{a}(\mathrm{mm})$ & $\mathrm{c}(\mathrm{mm})$ & & \\
\hline A & 1.74 & 5.00 & 3.19 & 11.00 & 1.78 & 2.03 \\
\hline B & 1.45 & 3.50 & 2.61 & 7.50 & 1.47 & 1.65 \\
\hline C & 1.74 & 7.50 & 3.19 & 11.00 & 1.80 & 2.13 \\
\hline D & 1.45 & 6.00 & 4.64 & 17.50 & 1.50 & 1.92 \\
\hline $\mathrm{E}$ & 2.32 & 6.00 & 4.06 & 16.00 & 2.40 & 2.88 \\
\hline $\mathrm{F}$ & 0.58 & 2.50 & 1.45 & 5.00 & 0.59 & 0.65 \\
\hline
\end{tabular}

Table 6.16 - Predicted Dimensions of the Cracks Appearing After Run 13

\begin{tabular}{|c|c|c|c|c|c|c|}
\hline \multirow{3}{*}{ Crack } & \multicolumn{4}{|c|}{ Measured Crack Dimensions } & \multicolumn{2}{|c|}{$\begin{array}{l}\text { Predicted Maximum } \\
\text { Depth }(\mathrm{mm})\end{array}$} \\
\hline & \multicolumn{2}{|c|}{ Initial } & \multicolumn{2}{|c|}{ Final } & \multirow{2}{*}{$\begin{array}{l}\text { Eq. } \\
(5.1 \mathrm{a})\end{array}$} & \multirow{2}{*}{$\begin{array}{l}\text { Eq. } \\
(5.2 b)\end{array}$} \\
\hline & $\mathrm{a}(\mathrm{mm})$ & $\mathrm{c}(\mathrm{mm})$ & $a(\mathrm{~mm})$ & $c(\mathrm{~mm})$ & & \\
\hline$A+B+C$ & 3.19 & 27.00 & 6.67 & 34.00 & 3.84 & 6.53 \\
\hline$D+E$ & 4.35 & 33.50 & 11.60 & $(46-55)$ & 5.21 & 8.60 \\
\hline
\end{tabular}




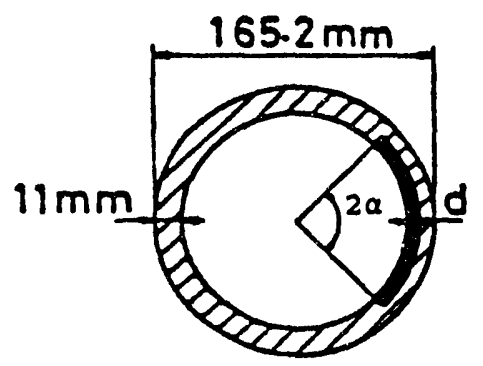

$2 \alpha=90^{\circ}$

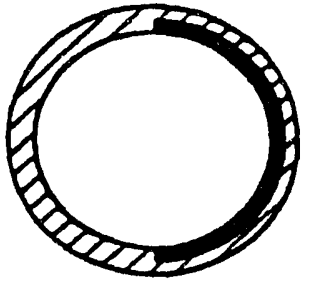

$2 \alpha=180^{\circ}$

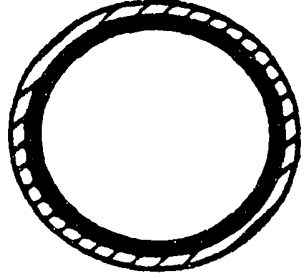

$2 \alpha=360^{\circ}$

Figure 6.2 Geometry of Test Specimens

between the net-section stress range $\left(\Delta \sigma_{\text {nec }}\right)$ acting on the cracked section and the number of cycles required for complete penetration of the cracks. The stainless steel material has strength properties equivalent to the material of the hot leg in the HLVT Program. Results of other dynamic tests performed on cracked pipes under similar test conditions are available in References 30 and 31 .

The test specimens of Reference 9 consisted of pipes, $200 \mathrm{~cm}$ ( 6 feet 8 -inches) long, fabricated from $16.52 \mathrm{~cm}$ (6-inch diameter) schedule 80 type 304 stainless steel and STS 42 carbon steel. The nominal yield stress of both materials is $28 \mathrm{kgf} / \mathrm{mm}^{2}$ ( $40 \mathrm{ksi}$ ). Various partthrough circumferential cracks were artificially introduced at the mid-span of the pipes by electric dis-charge machining. Figure 6.2 shows the geometry of the cracked pipes. The vibration tests were performed with and without an inner pressure of $0.7 \mathrm{kgf} / \mathrm{mm}^{2}(1 \mathrm{ksi})$ at room temperature. For type 304 stainless steel pipes, the initial crack depth-to-thickness ratio $(d / t)$, crack angles $(2 \alpha)$ and internal pressures are indicated in Table 6.17. The pressurization of the test specimens was achieved by using Argon gas. The test specimens were mounted on a $3 \mathrm{~m} \mathrm{x}$ $3 \mathrm{~m}$ shake table and dynamically loaded in four-point bending until through-thickness crack penetration occurred.

The vibratory testing consisted of a constant amplitude sine wave applied at the pre-determined natural frequency of the specimens. The fundamental natural frequency of the specimens was adjusted to simulate a typical field installed piping system, i.e, about 11.5$12 \mathrm{~Hz}$. The crack depths were monitored and measured by ultrasonic devices until complete penetration took place. During the vibration testing, strain gauges were placed at the mid-span of the pipes (i.e., near the cracked

Table 6.17 - Crack Geometry for Type 304 Stainless Steei Test Specimens

\begin{tabular}{|c|c|c|c|}
\hline \multirow{2}{*}{$\begin{array}{c}\text { Crack } \\
\text { depth/thickness } \\
\mathrm{d} / \mathrm{t}\end{array}$} & 90 & 180 & 360 \\
\cline { 2 - 4 } & 0 & 0 & 0 \\
\hline 0.10 & 0 & 0 & \\
\hline 0.25 & & 0 & \\
\hline 0.50 & & 0 & \\
\hline 0.90 & & 0 & 0 \\
\hline
\end{tabular}

- Inner pressure $0 \mathrm{kgf} / \mathrm{mm}^{2}(0 \mathrm{psi})$

- Inner pressure $0.7 \mathrm{kgf} / \mathrm{mm}^{2}$ (1000 psi) 
ser:tion) and the rerorded strains enabled the applied rending stresses (and equivalent bending moments) to be computed. In all cases considered, crack penetration was observed to be caused by rapid fatigue crack growth.

A net-section collapse failure criterion has heen developed to predict the static collapse of a cracked, ipe (Reference 32). This criterion is based on the st -ss distribution shown in Figure 6.3 where a uniform stress, $\sigma_{r}$, is assumed to operate in the tension as well as the compression side of the cracked pipe. The stress, $\sigma_{f}$, is the flow stress of the material, usually taken as the arithmetic mean of the yield and ultimate strengths. When a pipe is subjected to cyclically changing moments. a uniform stress. $\sigma_{\text {nel. }}$. higher than the yield strer.gth, can also bi assumed to operate in the cross section (such a stress would have a distribution identical to the one shown in Figure 6.3). Based on this concept, a net-section stress range criterion has recently been postulated in Reference 9 to predict crack growth behavior. The expressions for the net-section stres: range are as follows:

For $\beta \leq \pi-\alpha$

$$
\begin{aligned}
& \left.\Delta \sigma_{r=1}=\Delta \mathrm{M}_{\Delta p T^{\prime}} / 2 \mathrm{R}^{\prime} \mathrm{t}(2 \sin \beta-(\mathrm{d} / \mathrm{t}) \sin \alpha)\right] . \\
& \beta=(\pi / 2)\left(1-\mathrm{d} \alpha / \mathrm{t} \pi-\mathrm{PR} / 2 \mathrm{t} \sigma_{1}\right) .
\end{aligned}
$$

while for $\beta>\pi-\alpha$

$$
\begin{aligned}
& \Delta \sigma_{n=1}=\Delta M_{\alpha i p} /\left[2 R^{\prime} t(2(1-d / t) \sin \beta\right. \\
& \quad+(d / t) \sin \alpha)] . \\
& \beta=\pi+[\pi / 2(1-d / t)]\left(d \alpha / t \pi-1-P R / 2 t \sigma_{f}\right) .
\end{aligned}
$$

where $R$ is the mean radius of the pipe, $t$ is the thickness, $p$ is the internal nressure. $\beta$ is the angle of the neutral axis and $\alpha$ is the crack angle (Figure 6.3). In Equations (6.12) and (6.13), $\Delta M_{\Delta p}=\left(\Delta \sigma_{h} \pi R^{2} t\right)$, is the applied bending moment range where $\Delta \sigma_{\mathrm{h}}$ stands for the applied bending stress range.

The exp srimental data obtained in Reference 9 indicate a linear relationship between $\Delta \sigma_{n e 1}$ and $\log N_{p}$ where $N_{n}$ is the number of cycles to crack penetration. For type 304 stainless steel the linear variation is reproduced from the cited reference and shown in Figure 6.4. The top line gives the results without inner pressure and indicates a good correlation for all initial crack configurations. The bottom line gives the results for pipes with an internal pressure of $0.7 \mathrm{kgf} / \mathrm{mm}^{2}(1 \mathrm{ksi})$. For the latter case, there are only two data points and a straight line parallel to the case without inner pressure is assumed between them. The corresponding membrane stress in the pipe is given by $p R / 2 t$, i.e., $2.46 \mathrm{kgf} / \mathrm{mm}^{2}$. The linear relationship can be expressed as:

$$
\Delta \sigma_{n=1}=a+b \log N_{n}
$$

where $\mathrm{a}$ and $\mathrm{b}$ are constants and determined from Figure 6.4 as $a=660-665 \mathrm{MPa}$ and $\mathrm{b}=-100 \mathrm{MPa}$. The strength properties of the type 304 stainless steel piping are $\sigma_{y}=275 \mathrm{MPa}(40 \mathrm{ksi})$ and $\sigma_{u}=598 \mathrm{MPa}(87 \mathrm{ksi})$. At these values of the net-section stress range, the corresponding number of loading cycles required for crack penetration are found from equation (6.14) as $N_{y}=$ 7079 to 7943 cycles and $N_{u}=4$ cycles. Note that if $\Delta \sigma_{\text {ret }}$ is measured in units of $\mathrm{kgf} / \mathrm{mm}^{2}$, then Equation (6.14) assumes the form $\log N_{p}=(1 / 10)\left(68-\Delta \sigma_{n+1}\right)$.

The cracked pipe in the HLVT Program is made of Japanese cast stainless steel which is almost equivalent to ASME designation SA-351 CF8. It has a $0.2 \%$ offset yield strength of $24 \mathrm{kgf} / \mathrm{mm}^{2}(35 \mathrm{ksi})$ and in ultimate stress of $55 \mathrm{kgf} / \mathrm{mm}^{2}(78 \mathrm{ksi})$. During the dynamic test, the pipe was subjected to an internal pre sure of 157 $\mathrm{kgf} / \mathrm{cm}^{2}(2.23 \mathrm{ksi})$ and high level dynamic excitations. The mean radius of the pipe is $161.1 \mathrm{~mm}$ and its thickness $=29 \mathrm{~mm}$. Accordingly, the meınbrane stress is about $4.38 \mathrm{kgf} / \mathrm{mm}^{2}$.

In order to develop a net-section stress range criterion, applicable to the HLVT Program, Equation (6.14) is written as:

$$
\begin{aligned}
& a+b \log N_{y}=\Delta \sigma_{y}, \\
& a+b \log N_{u}=\Delta \sigma_{u},
\end{aligned}
$$

where $N_{y}$ and $N_{u}$ denote the number of loading cycles required for crack penetration when the net-section stress ranges are given by $\Delta \sigma_{\mathrm{y}}$ and $\Delta \sigma_{\mathrm{u}}$, respectively. Here, $\sigma_{\mathrm{y}}$ and $\sigma_{u}$ stand for the yield and ultimate strengths of the material. Utilizing the strength properties of the HLVT material and postulating that the number of loading cycles required for crack penetration in the HLVT Program is similar to that found in the data of Figure 6.4, i.e., $N_{y} \approx$ 7500 and $N_{4} \approx 1-5$ cycles, it follows that the constants a and $b$ in Equation (6.15) which are applicable to the HLVT Program are found as 55 and $-8 \mathrm{kgf} / \mathrm{mm}^{2}$. respectively. It follows then that the number of cycles. $N$, required for complete penetration of the surface crack 


\subsection{Methodologies}

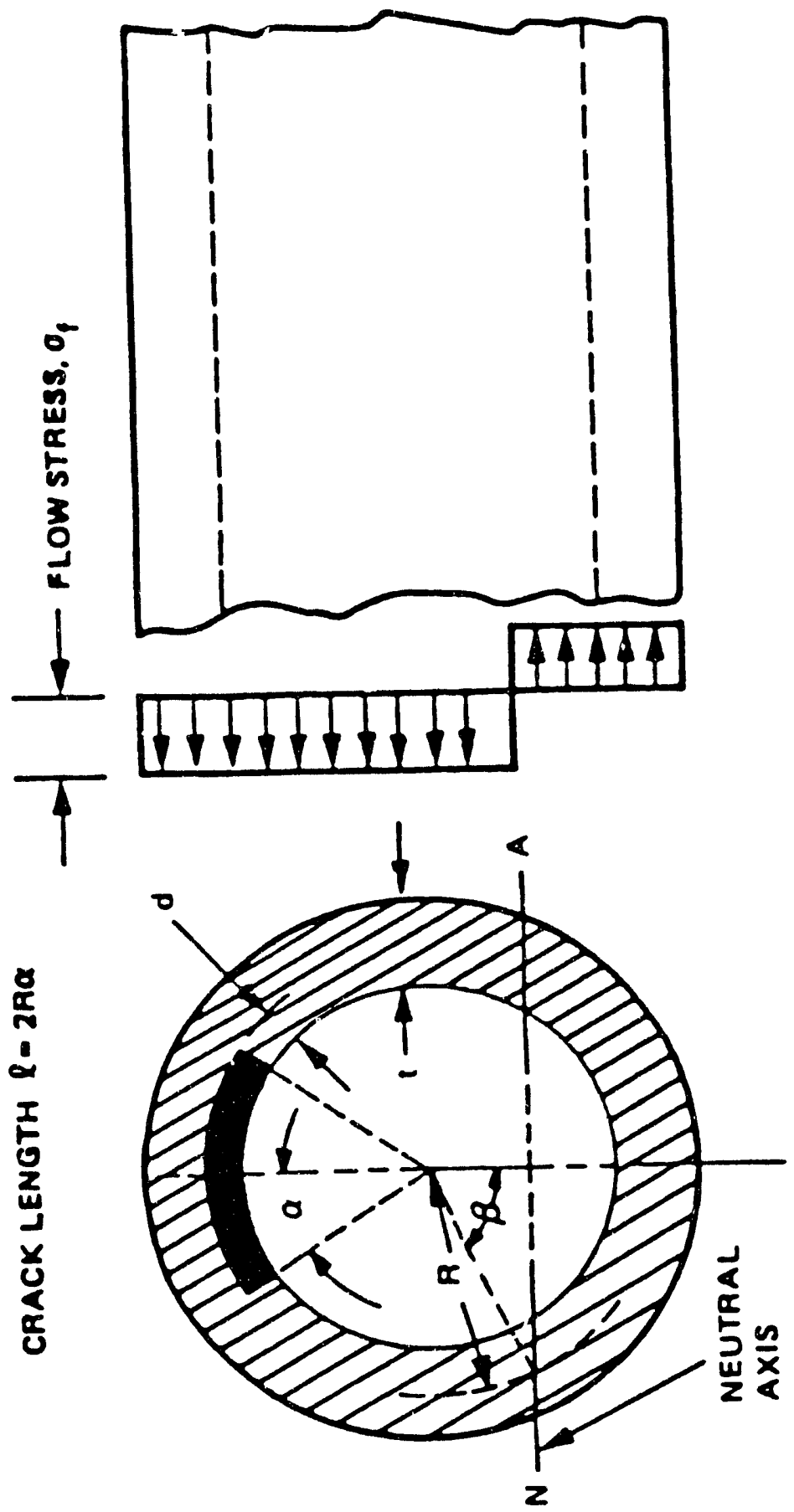

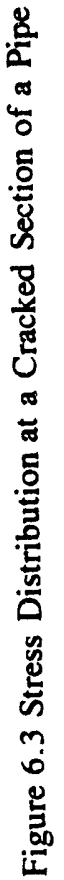




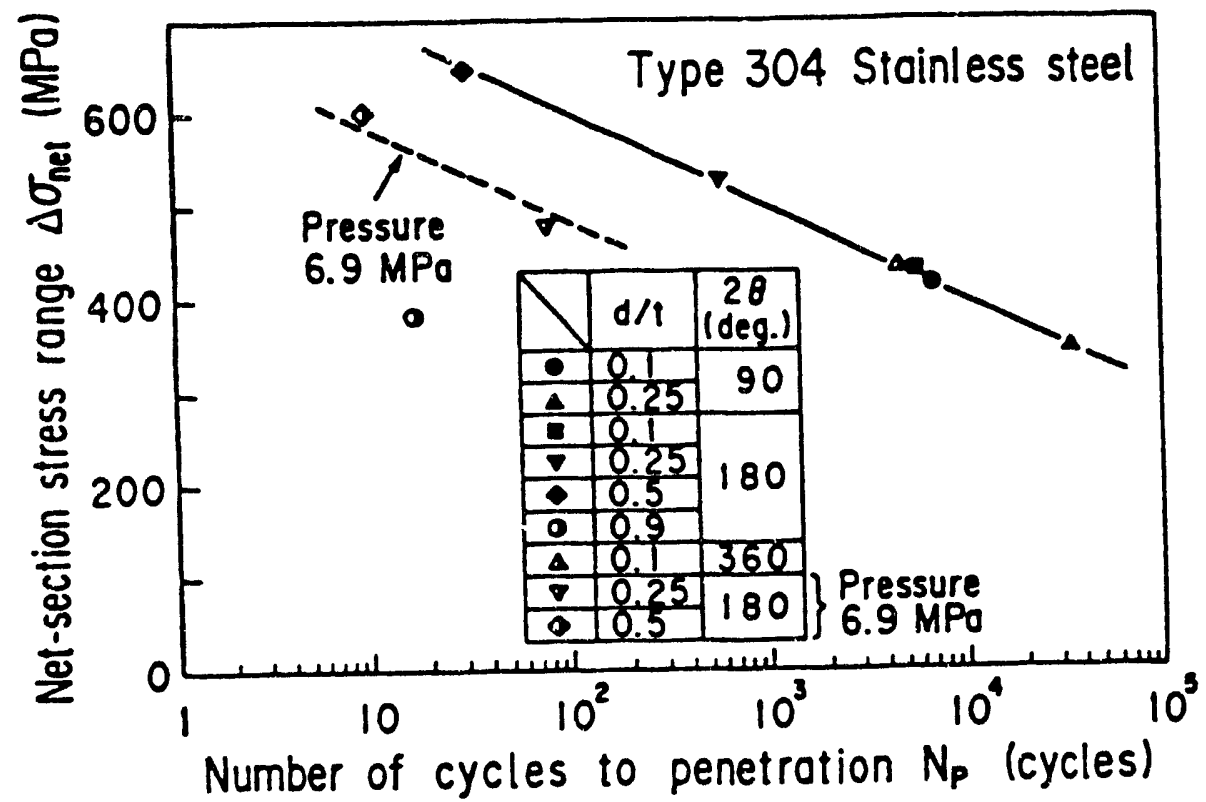

Figure 6.4 Relation Between Net-Section Stress Range and Number of Cycles to Crack Penetration (Reference 9)

in the HLVT Program may be estimated from the relation,

$$
\log N=(1 / 8)\left(55-\Delta \sigma_{\text {net }}\right)
$$

Utilizing Equation (6.16), the number of loading cycles, $\mathrm{N}$, corresponding to a few values of the net section stress range are shown in Table 6.18.

In order to apply Equation (6.16) to predict crack growth behavior in the HLVT Program, the expression of the static collapse moment in Equations (6.12) and (6.13) must be corrected to suit the particular crack crnfigura- tions observed in the HLVT data. For this purpose, consider a flawed cross section of a pipe with the stress distribution shown in Figure 6.5. The length of the crack along the circumference is $\ell=2 R \alpha$ and its thickness ratio, $h(\theta) / t$, is expressed as a power degree polynomial in the angle $\theta$, namely, $h(\theta) / t=\left(h_{0} / t\right)\left[1-(\theta / \alpha)^{2}\right]$. Here, $2 \alpha$, denotes the crack angle and $h_{v}$ is the maximum crack depth. Equilibrium of the longitudinal forces on the cross section requires

$$
\begin{aligned}
& 2(\pi-\beta) R t \sigma_{f}+2 \beta R t\left(-\sigma_{f}\right) \\
& \quad-\int_{-\alpha}^{\alpha} h(\theta) R \sigma_{f} d \theta=(2 \pi R t) \sigma_{m},
\end{aligned}
$$

\begin{tabular}{|c|c|c|}
\hline \multicolumn{2}{|c|}{$\begin{array}{c}\Delta \sigma_{\mathrm{nel}} \text { in units of } \\
\mathrm{kgf} / \mathrm{mm}^{2}(\mathrm{ksi})\end{array}$} & \multirow{2}{*}{$\frac{N}{7,500}$} \\
\hline 24 & (35) & \\
\hline 30 & (43) & 1,334 \\
\hline 35 & (50) & 317 \\
\hline 40 & (57) & 75 \\
\hline 45 & (64) & 18 \\
\hline 50 & (71) & 5 \\
\hline 55 & (78) & 1 \\
\hline
\end{tabular}

Table 6.18 Number of Loading Cycles Computed from Equation (6.16) 


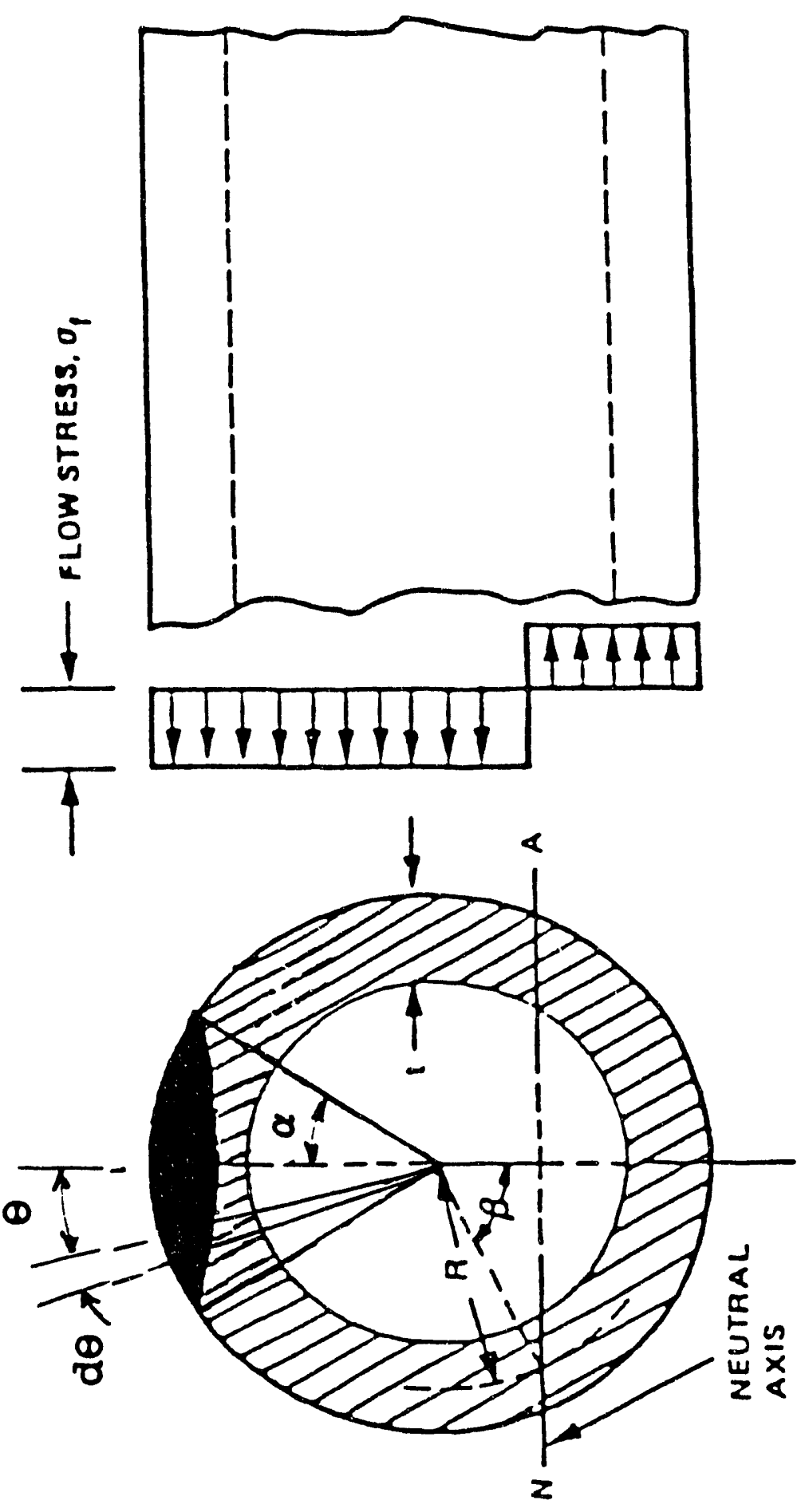


Table 6.19 - Values of Angles $\beta$ and Ratios $M_{c} / M_{o}$ for the Cracks Appearing in the HLVT Program

\begin{tabular}{|l|l|l|l|l||}
\hline & $\begin{array}{l}\text { After Run } \\
\text { No. 11 }\end{array}$ & $\begin{array}{l}\text { After Run } \\
\text { No. 12 }\end{array}$ & $\begin{array}{l}\text { After Run } \\
\text { No. 13 }\end{array}$ & $\begin{array}{l}\text { After Run } \\
\text { No. 14 }\end{array}$ \\
\hline Crack Angle $(2 \alpha)$ & $90^{\circ}$ & $108^{\circ}$ & $112^{\circ}$ & $116^{\circ}$ \\
\hline $\begin{array}{l}\text { Max. Crack } \\
\text { Depth/Thickness Ratio } \\
\left.\mathrm{h}_{\mathrm{o}} / \mathrm{t}\right)\end{array}$ & 0.08 & & & 0.47 \\
\hline $\begin{array}{l}\text { Angle of Neutral } \\
\text { axis }(\beta)\end{array}$ & $78.8^{\circ}$ & 0.16 & $71.2^{\circ}$ & $61.8^{\circ}$ \\
\hline $\mathrm{M}_{\mathrm{c}} / \mathrm{M}_{\mathrm{c}}$ & 0.961 & 0.929 & 0.808 & 0.595 \\
\hline
\end{tabular}

in which, $\sigma_{\mathrm{m}}$, stands for the longitudinal stress in the uncracked section of the pipe, $\beta$ is the angle that defines location of the neutral axis and $\sigma_{\mathrm{f}}$ is the flow stress of the material. Equation (6.17) simplifies to

$$
\begin{array}{r}
\beta=(\pi / 2)\left[1-(2 / 3)\left(h_{\mathrm{v}} / \mathrm{t}\right)(\alpha / \pi)-\sigma_{\mathrm{m}} / \sigma_{\mathrm{f}}\right], \\
(\beta \leq \pi-\alpha)
\end{array}
$$

Similarly, taking moments of the longitudinal forces about the centroidal axis leads to the following equation for the collapse moment.

$$
\begin{aligned}
M_{c} / 2= & \int_{0}^{\pi-\beta} \sigma_{f} l R^{2} \cos \theta d \theta+\int_{0}^{\beta} \sigma_{f} t R^{2} \cos \theta d \theta \\
& -\int_{0}^{\alpha} \sigma_{f} h(\theta) R^{2} \cos \theta d \theta
\end{aligned}
$$

which can be simplified into:

$$
M_{c}=\left[\sin \beta+\left(h_{\mathrm{c}} / t\right)\left(\alpha^{-1} \cos \alpha-\alpha^{-2} \sin \alpha\right)\right] \mathrm{M}_{\mathrm{o}}
$$

Where $M_{v}=4 R^{2} t \sigma_{f}$ is the static collapse moment of an uncracked section of the pipe.

In the HLVT Program, external circumferential surface cracks were observed in the elbow region after loading Run No. 11 and progressed through loading Runs 12,13 and 14 in the manner indicated in Figures 4.1 through 4.4. Utilizing the values $\sigma_{\mathrm{f}}=39.5 \mathrm{kgf} / \mathrm{mm}^{2}$ $(56 \mathrm{ksi})$ and $\sigma_{\mathrm{m}}=4.38 \mathrm{kgf} / \mathrm{mm}^{2}(6.23 \mathrm{ksi})$, Equations (6.18) and (6.20) are used to compute the locations of the neutral axis (angle $\beta$ ) and the ratios $M_{c} / M_{c}$ for the cracks appearing after loading Run Nos. $11-14$ and the results appear in Table 6.19.

Guided by the limit load result obtained in Equation (6.20), an expression of the net-section stress range, $\Delta \sigma_{n:}$, to be used in Equation (6.16) is postulated as

$$
\begin{aligned}
\Delta \sigma_{\mathrm{n}: \mathrm{t}}= & {\left[\Delta \mathrm{F}_{\mathrm{app}} / \mathrm{A}+\Delta \mathrm{M}_{\mathrm{app}} / \pi \mathrm{R}^{2} \mathrm{t}\right] } \\
& \times\left[\sin \beta+h_{\mathrm{v}} / \mathrm{t}\left(\alpha^{-1} \cos \alpha-\alpha^{-2} \sin \alpha\right)\right]^{-1}
\end{aligned}
$$

in which $\Delta \mathrm{F}_{\mathrm{\alpha pp}}$ and $\Delta \mathrm{M}_{\mathrm{app}}$ are, respectively, the applied axial force and bending moment ranges across the cracked section of the pipe and $A$ is the cross sectional area of the pipe. In the HLVT Program, the loading during each of Run Nos. 11-14 (which affected crack growth) was identical. The loading for Runs 11-13 consisted of four segments of random table motion over a thirty-six (36) second time period. As noted earlier, the loading for Run 14 consisted of one segment of random table motion which lasted approximately 9 seconds. The time histories of the estimated values of the axial force $(F)$ and bending moment (M) across the crack plane are computed in Section 2. For the purpose of comiputing the net-section stress range appearing in Equation (6.21), the root mean square (R.M.S.) values of $\Delta F_{a p p}$ and $\Delta M_{a p p}$ over all cycles of loading in each run (about 180 cycles) were used. These were found as,

$$
\text { R.M.S. of } \Delta F_{\text {app }}=445.70 \times 10^{9} \mathrm{kgf} \text { (983kips) }
$$

R.M.S. of $\Delta M_{\text {app }}=420.32 \times 10^{5} \mathrm{kgf}-\mathrm{mm}$ (3649kip-in) 
Table 6.20 Net Section Stress Range Values and the Predicted Number of Loading Cycles for Complete Penetration of the Cracks

\begin{tabular}{||l|c|c|c|c||}
\hline & After Run 11 & After Run 12 & After Run 13 & After Run 14 \\
\hline$\Delta \sigma_{\mathrm{n} t}\left(\mathrm{kgf} / \mathrm{mm}^{2}\right)$ & 34.04 & 35.21 & 40.48 & 54.90 \\
\hline $\begin{array}{l}\text { Predicted No. of } \\
\text { Cycles }\end{array}$ & 417 & 298 & 65 & 1 \\
\hline $\begin{array}{l}\text { Actual No. of } \\
\text { Loading Cycles (test } \\
\text { data) }\end{array}$ & 405 & 225 & 45 & $3-4$ \\
\hline
\end{tabular}

Note that the root mean square value of a randomly varying quantity $F_{i}(i=1 \ldots n)$, is defined as,

$$
\text { R.M.S. }=\left[\frac{1}{n} \sum_{i=1}^{n} F_{i}^{2}\right]^{1 / 2}
$$

Utilizing the geometric parameters of the cracked cross section of the pipe in Table 6.19 and the R.M.S. values in Equation (6.22), the net-section stress range is computed for each loading run from Equation (6.21) and the results appear in Table 6.20. The predicted number of loading cycles required for through-thickness penetration of the surface cracks can then be computed from Equation (6.16) and are given in Table 6.20. The number of actual loading cycles observed in the HLVT Program are also shown in Table 6.20. The predicted number of loading cycles appearing in Table 6.20 compare with the actual growth pattern observed in the HLVT Program. The surface cracks were observed after loading Run No. 11 and joined together and formed one large surface crack during Run No. 13. The crack continued to grow and penetrated to about $94 \%$ of the pipe thickness after applying a one-quarter segment of loading Run No. 14. It is estimated that had the HLVT testing continued during loading Run No. 14, it would have required only a few* more large loading cycles to drive the crack depth/thickness ratio from 0.94 (when the testing was stopped) to 1.0 (i.e., complete penetration).

*The actual number of loading cycles required for complete penetration after Run 14 is not known. An estimate based on the data of Run 13 can be made as $(! ! .94-1)(45-50)$ or $3-4$ cycles.
Since each loading run consisted of about 180 large strain cycles, the observed number of loading cycles after Run No. 11 is about 405 cycles while the predicted number is 417 cycles. Similarly after loading Run No. 12, the actual number of loading cycles is about 225 while the predicted is found to be 298. After Run No. 13, the predicted number of cycles for crack penetration is 65 while the actual is 45 .

A final consideration concerning the application of the net-section stress range method to predict the crack growth behavior of circumferentially cracked pipes is the influence of pipe ovalization ( $R / t$-factor) on the methodology. The theoretical failure load of a circumferentially cracked pipe predicted by the net-section collapse method is independent of the ovalization effects of the pipe's cross section which takes place during bending to failure (Reference 32). Reference 33, however, presents experimental data which indicate that pipe ovalization affects the failure load of circumferentially cracked pipes. As the pipe's $R / t$ - ratio increases the pipe becomes more flexible and has a tendency to flatten (ovalize) and consequently its resistance to bending decreases. The ratio of the experimental failure stress to the net-section collapse stress will decrease with an increase in the R/t-ratio. In order to correlate the theoretical and experimental failure loads, an analytical assessment was carried out in Reference 33 and correction factors (the so called $R / t$ factor which is a function of the pipe's radius " $R$ ", thickness " $t$," axial membrane stress and bending stress) are determined for this purpose. In the present application, it turns out that the correction factors applicable to the cracked pipes used to generate the experimental data base (Reference 9) vary between 15.2 
to $15.9 \%$ while the correction factors applicable to the cracked pipe in the HLVT Program are in the range of 14.0 to $15.4 \%$. The bending stresses used to generate these factors vary between the yield and ultimate strengths of the material. Thus, any modification to the net-section stress range methodology presented in this study to account for ovalization effects will not influence the results.

In conclusion, a good correlation is obtained between the predicted and observed numbers of loading cycles required for crack growth and through-thickness penetration of the surface crack. Based on this study, it can be concluded that the net-section stress range criterion postulated to predict low-cycle fatigue crack growth in nuclear piping subjected to high level dynamic loading is promising and warrants further study. The following recommendations are suggested to improve this new methodology of predicting crack growth behavior:

Develop additional test data in which the test specimens are subjected to cyclic as well as randomly varying dynamic loading and various internal pressures. It is believed that the magnitude of the internal pressure significantly influences the crack growth behavior especially when combined with high level dynamic loading leading to inelastic response of the cracked pipe. Influence of variations in the initial crack depth and geometry should also be explored as well as different pipe size and material.

(2) In order to refine the computational phase of the methodology and because of the nature of the randomly applied loading, better estimates of the equivalent axial force and bending moments driving the crack are required. This necessitates more accurate measurement of the strains in the inelastic range and perhaps a more refined approach to include the influence of the randomness of the loading.

(3) Explore the influence of mixed mode loading on the crack growth behavior in cracked pipe sections. In a complex loading situation, the cracked section of a pipe is subjected to a form of loading which includes twisting moment in addition to axial force and bending moment. This results in a mixed mode crack growth behavior and requires the inclusion of all loadings acting on the cracked section which are responsible for extending the crack in the crack growth criterion. 
The object of this work is to use the data from the High Level Vibration Test at Tadotsu to assess the accuracy and usefulness of existing state-of-the-art methodologies for predicting crack initiation and growth under complex, large amplitude loading.

Fatigue crack initiation was analyzed by applying the design curve of Section III of the ASME Boiler and Pressure Vessel Code and a fatigue equation based on a local strain approach. Based on the concept that crack initiation occurs when the accumulated usage factor is unity, the design curve of the code provided conservative results while the local strain approach predicted a usage factor close to unity. An alternative study of the crack initiation phenomenon requires the use of finite element analysis in conjunction with postulates of modern damage theories (Reference 16). A brief outline of such an approach was discussed in Section 3.0. In the present application, it is believed that such an approach to investigate crack initiation is feasible and would yield fruitful results.

Three state-of-the-art fracture mechanics methods were applied in this work to analyze the crack growth behavior in the HLVT Program. These methods are: the $\Delta \mathrm{K}$ methodology (Paris law), J-integral concepts and the net-section stress range method. Based on our investigation and analysis the following are our conclusions concerning the use of each of the methodologies:

\section{$\Delta \mathrm{K}$ methodology}

(a) This approach is commonly used in the industry to predict low cycle as well as high cycle crack growth behavior in complex structures subjected to various loading conditions.

(b) The tools required for application of the methodology (modeling of realistic cracks, stress-intensity factor formulas, material characteristics, etc.) have been adequately developed and can be used in complex models of surface cracks and structural components subjected to random cyclic loading.

(c) The method yields good results for loads within the elastic limit. The method, from the theoretical viewpoint is not valid for loads

beyond the limitation of linear elastic fracture mechanics.

(d) In the present application the experimental crack growth rates of the material underpredicted the low cycle crack propagation behavior observed in the HLVT Program even when it was used beyond the limitation of LEFM. However, the use of the ASME bounding formula for austenitic stainless steel in air yielded faster growth, and from the engineering viewpoint, better results. This can be attributed to the presence of the Rfactor in the coefficient of the ASME formula.

\section{J-Integral Concepts}

(a) In principle, the method used in this study is similar to the $\Delta \mathrm{K}$ methodology. Instead of the stress-intensity factor, the J-integral parameter is used as the crack driving force which is more appropriate for components loaded beyond the yield stress.

(b) The tools required for the application of the methodology are limited. For surface cracks in pipes, few engineering estimates are available for the crack driving forces. Moreover, these estimates of the J-integral parameters are based on deformation theory of plasticity and require some adjustment to correlate with the $J$ parameters obtained in a laboratory test on a specimen of the material (see Section 6.2). However, they can be used in an engineering manner to assess the crack growth.

(c) In the present application the methodology provided much better results than the $\Delta K$ methodology.

\section{Net-Section Stress Range Method}

(a) This method is based on a limit load fracture criterion. It can be used for large amplitude loading. It is a simple method to use.

(b) The available experimental data base for stainless steel material is limited. It predicts the number of loading cycles required for through thickness penetration of the circumferential cracks. 


\subsection{Conclusions}

(c) In the present application the correlation between the measured crack growth data and the postulated criterion is promising.

Recommendations:

The following recommendations are provided in an effort to improve the methods of investigating crack initiation and growth behavior in stainless steel piping material:

1. The crack initiation phenomenon in the HLVT Program may be addressed via a local damage approach (Reference 16).

2. Explore alternative methods of accounting for the variable amplitude loading in applying the $\Delta \mathrm{K}$ methodology to predict crack growth behavior.

3. Improve the J-estimation schemes of computing the crack driving force to better comply with the experimentally determined $\Delta \mathrm{J}$-values. Estimate the J-parameter for circumferentially cracked pipes to allow 2 DOF crack growth.

4. The limit load criterion used in the current study requires additional data to establish the relation between the net-section stress range and the number of loading cycles required for throughthickness crack penetration 
1. Y.J. Park, J.R. Curreri and C.H. Hofmayer, "The High Level Vibration Test Program," Final Report, NUREG/CR-5585, May 1991.

2. J.M. Barsom and S.T. Rolfe, Fracture and Fatigue Control in Structures, second edition, Prentice-Hall, Inc., Englewood Cliffs, 1987.

3. M.F. Kanninen and C.H. Poplar, Advanced Fracture Mechanics, Oxford University Press, New York, 1985.

4. D. Broek, The Practical Use of Fracture Mechanics, Kluwer Academic Publishers, The Netherlands, 1989.

5. American Society of Mechanical Engineers, ASME Boiler and Pressure Vessel Code, Section III.

6. N.E. Dowling and J.A. Begley, "Fatigue Crack Growth During Gross Plasticity and the JIntegral," Mechanics of Crack Growth, ASTM STP 590, American Society for Testing and Materials, 1976, pp. 82-103.

7. K.J. Nix, et al., "An Investigation of the Interaction Between Ductile Tearing and Fatigue in a Low Alloy Steel," Advances in Fracture and Fatigue for the 1990's, Volume I, Edited by G.M. Wilkowski and H. Kobayashi, ASME PVP-Volume 166, 1989, pp. 33-39.

8. K. Mogami, et al., "Elastic-Plastic Cyclic J-R Curve and Tearing Instability Characteristics Under Cyclic Load," Advances in Fracture and Fatigue for the 1990's, Volume I, Edited by G.M. Wilkowski and H. Kobayashi, ASME PVP-Volume 166, 1989, pp. 71-76.

9. E. Murakami, et al., "Crack Growth Behavior of Nuclear Piping Under Dynamic Loading," Advances in Fracture and Fatigue for the 1990's, Volume II, ASME PVP-Volume 167, Edited by G. Yagawa and G.M. Wilkowski, 1989, pp. $115-120$

10. M.R. Mitchell, "Fundamentals of Modern Fatigue Analysis for Design," Fatigue and
Microstructure, Metals Park, Ohio, American Society for Metals, 1979, pp. 385-437.

11. F.A. McClintock, "A Criteria for Ductile Fracture by the Growth of Holes," Journal of Applied Mechanics, ASME, 1968, pp. 363-371.

12. J.W. Hancock and A.C. Mackenzie, "On the Mechanisms of Ductile Failure in High-Strength Steels Subjected to Multi-Axial Stress-States," Journal of the Mechanics and Physics of Solids, Volume 24, 1976, pp. 147-169.

13. J.R. Rice and D. Tracey, "On Ductile Enlargement of Voids in Triaxial Stress Field." Journal of Mechanics and Physics of Solids, Volume 17, 1969.

14. R.D. Thomsom and J.W. Hancock, "Ductile Failure by Void Nucleation, Growth and Coalenscense, "International Journal of Fracture. Volume 26, 1984, pp. 99-112.

15. J. Lamaitre, "Micro-Mechanics of Crack Initiation," International Journal of Fracture, Volume 42, 1990, pp. 87-00.

16. J. Lamaitre, A Course on Damage Mechanics, Springer-Verlag, New York, 1992

17. J.A. Joyce, E.M. Hackett and C. Roe, "ElasticPlastic Characterization of a Cast Stainless Steel Pipe Elbow Material", NUREG/CR-5774, January 1992.

18. Section XI Task Group for Piping Flaw Evaluation - ASME Code, "Evaluation of Flaws in Austenitic Steel Piping," Journal of Pressure Vessel Technology, Volume 108, 1986, pp. 352366.

19. J.A. James and D.P. Jones, "Fatigue Crack Growth Correlations for Austenitic Stainless Steels in Air, Predictive Capabilities in Environmentally Assisted Cracking," PVP Volume 99, ASME, 1985, pp. 363-4I4.

20. J.C. Newman and I.S. Raju, "Stress-Intensity Factor Equations for Cracks in ThreeDimensional Finite Bodies," ASTM STP 791, 
Edited by J.C. Lewis and G. Sines, Volume I, 1983, pp. 238-265.

21. I.S. Raju and J.C. Newman, "Stress-Intensity Factors for Circumferential Surface Cracks in Pipes and Rods Under Tension and Bending Loads," ASTM STP 905, Edited by J.M. Underwood et al, 1986, pp. 789-805.

22. J.L. Hechmer, "An Assessment of Crack Growth Technology for the Design of Pressure Vessels, " Advances in Fracture and Fatigue for 1990's, Volume 1, Edited by G.M. Wilkowski and H. Hobayashi, PVP Volume 166, ASME, 1989, pp. 99-106.

2.3. R.C. Cipolla, "Computational Method to Perform the Flaw Evaluation Procedure as Specified in the ASME Code, Section XI, Appendix A." EPRI NP-1181, 1979.

24. K. lida, K. Ando and Y. Hirata, "An Evaluation Technique for Fatigue Life of Multiple Surface Cracks," Journal of the Society of Naval Architects of Japan, Vol. 148, December 1980 and Vol. 153, June 1983, English Version.

25. J.R. Rice, "A Path Independent Integral and the Approximate Analysis of Strain Concentrations by Notches and Cracks," Journal of Applied Mechanics, Volume 35, 1968, pp. 379-386.

26. J.A. Begley and J.D. Landes, "The J-Integral as a Fracture Criterion," Fracture Toughness, Part II, ASTM STP 514, 1972, pp. 1-20.

27. V. Kumar, M.D. German and C.F. Shih, "An Engineering Approach for Elastic-Plastic Fracture Analysis," EPRI Report NP-1931, July 1981.

28. A. Zahoor, Ductile Fracture Handbook, Volume 2, EPRI NP-6301-D, (Volumes 1-3), January 1991.

29. Wilkowski, G., et al., "Short Cracks in Piping and Piping Welds - Second Semi-Annual Report, October 1990 - March 1991," NUREG/CR-4559, Vol. 1, No. 2, May 1992.
30. M.F. Kanninen et al., "Instability Predictions for Circumferentially Cracked Type-304 Stainless Pipes Under Dynamic Loading, "EPRI NP-2347, 1982.

31. D.A. Hale, et al., "Dynamic Tests of Cracked Pipe Components," Journal of Pressure Vessel Technologies, Volume 106, 1984, pp. 37-46.

32. M.F. Kanninen, et al., "Towards an Elastic Plastic Fracture Mechanics Predictive Capability for Reactor Piping," Nuclear Engineering and Design, Volume 48, 1976, pp. 117-134.

33. M. Scott and J. Ahmad, "Experimental and Analytical Assessment of Circumferentially Surface-Cracked Pipes Under Bending." NUREG/CR-4872, 1987. 


\section{APPENDIX}

This appendix contains the numerical listing of the peak values of the member forces, F and M, appearing in Figures 2.11 and 2.12 . 
Table A.1

Peak Values of the Member Forces (F)

$\begin{array}{ccccc}\text { No of cycles } & \text { Time } & \text { Forcel } & \text { Force2 } & \text { Force-Rarge } \\ & (\mathrm{sec}) & (\mathrm{kg}) & (\mathrm{kg}) & (\mathrm{kg})\end{array}$

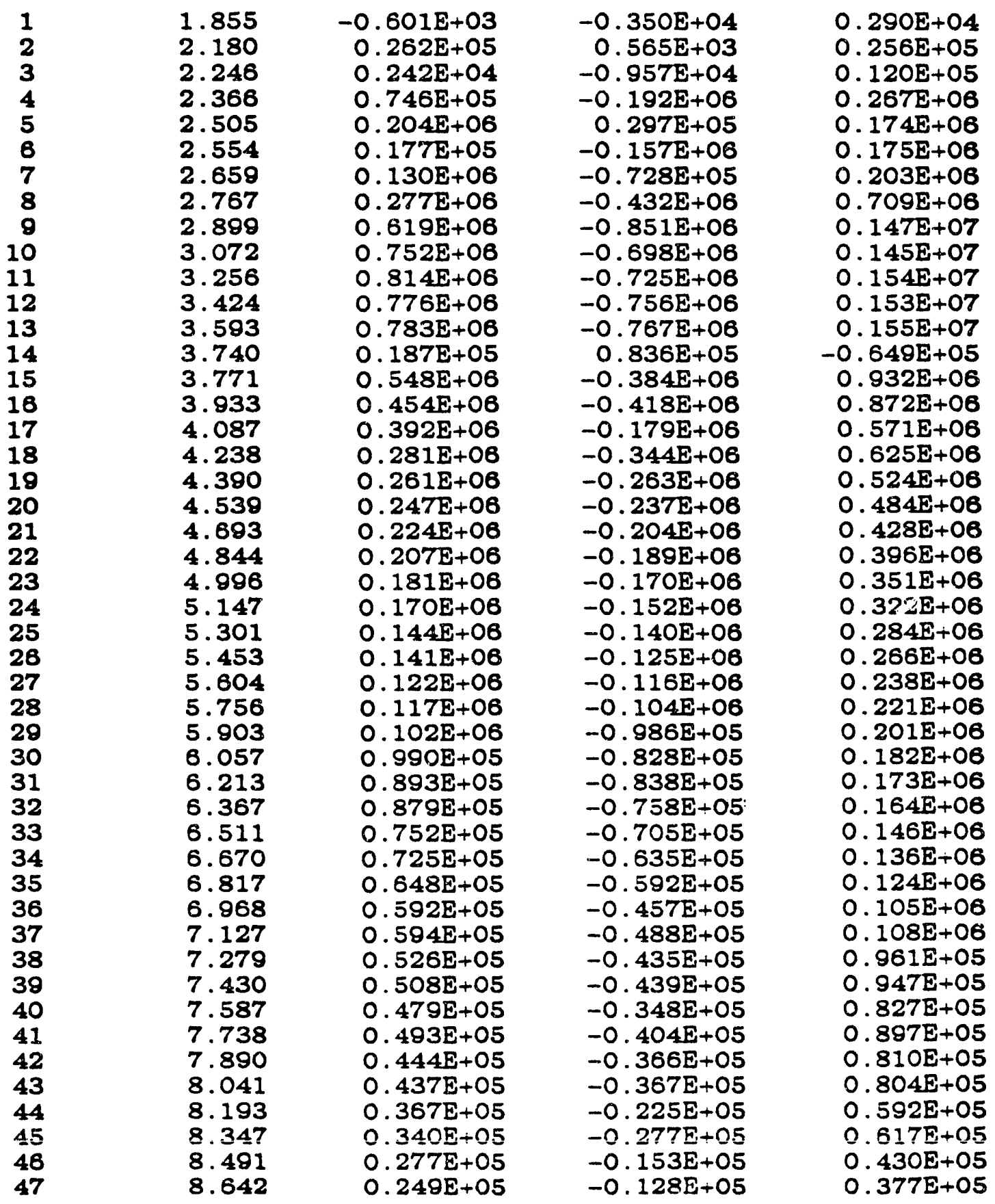




\begin{tabular}{|c|c|}
\hline $\begin{array}{l}48 \\
49 \\
50 \\
51 \\
52 \\
53 \\
54 \\
55 \\
56 \\
57 \\
58 \\
59 \\
60 \\
61 \\
62 \\
63 \\
64 \\
65 \\
66 \\
67 \\
68 \\
69 \\
70 \\
71 \\
72 \\
73 \\
74 \\
75 \\
76 \\
77 \\
78 \\
79 \\
80 \\
81 \\
82 \\
83 \\
84 \\
85 \\
86 \\
87 \\
88 \\
89 \\
90 \\
91 \\
92 \\
83 \\
94 \\
85 \\
86 \\
87 \\
98 \\
89 \\
100 \\
101 \\
102 \\
103 \\
104 \\
105 \\
106 \\
107\end{array}$ & $\begin{array}{r}8.792 \\
8.941 \\
9.095 \\
10.023 \\
10.163 \\
10.544 \\
10.691 \\
10.842 \\
10.952 \\
11.089 \\
11.226 \\
11.267 \\
11.453 \\
11.632 \\
11.769 \\
11.810 \\
12.001 \\
12.150 \\
12.323 \\
12.455 \\
12.587 \\
12.768 \\
12.927 \\
13.081 \\
13.230 \\
14.951 \\
15.269 \\
15.418 \\
15.564 \\
15.730 \\
15.882 \\
16.034 \\
16.175 \\
16.334 \\
16.483 \\
16.637 \\
18.685 \\
18.874 \\
19.015 \\
19.169 \\
18.279 \\
19.419 \\
19.551 \\
19.600 \\
19.783 \\
19.988 \\
20.174 \\
20.318 \\
20.453 \\
20.624 \\
20.773 \\
20.917 \\
21.064 \\
21.232 \\
21.389 \\
21.530 \\
21.677 \\
21.838 \\
21.890 \\
22.144\end{array}$ \\
\hline
\end{tabular}

$0.248 \mathrm{E}+05$

$0.221 E+05$

$0.211 E+05$

$0.187 \mathrm{E}+05$

$0.205 E+05$

$0.615 E+05$

$0.193 E+06$

$0.119 \mathrm{E}+06$

$0.287 \mathrm{E}+06$

$0.654 \mathrm{E}+08$

$0.260 \mathrm{E}+06$

$0.765 \mathrm{E}+06$

$0.789 \mathrm{E}+06$

$0.774 \mathrm{E}+06$

$0.739 \mathrm{E}+05$

$0.798 \mathrm{E}+06$

$0.295 \mathrm{E}+06$

$0.205 E+06$

$0.188 \mathrm{E}+06$

$0.229 E+06$

$0.481 \mathrm{E}+05$

$0.369 \mathrm{E}+05$

$0.383 E+05$

$0.336 \mathrm{E}+05$

$0.277 \mathrm{E}+05$

$0.168 \mathrm{E}+05$

$0.256 \mathrm{E}+05$

$0.275 \mathrm{E}+05$

$0.241 E+05$

$0.308 \mathrm{E}+05$

$0.281 \mathrm{E}+05$

$0.273 E+05$

$0.237 \mathrm{E}+05$

$0.238 \mathrm{E}+05$

$0.242 \mathrm{E}+05$

$0.204 E+05$

$0.127 \mathrm{E}+05$

$0.768 E+05$

$0.188 \mathrm{E}+06$

$0.871 \mathrm{E}+05$

$0.228 \mathrm{E}+08$

$0.633 \mathrm{E}+08$

$0.242 \mathrm{E}+06$

$0.82 \supset E+06$

$0.710 \mathrm{E}+06$

$0.290 E+06$

$0.548 \mathrm{E}+06$

$0.626 \mathrm{E}+04$

$0.876 \mathrm{E}+05$

$0.137 \mathrm{E}+06$

$0.260 \mathrm{E}+06$

$0.234 \mathrm{E}+06$

$0.509 \mathrm{E}+05$

$0.439 \mathrm{E}+05$

$0.444 \mathrm{E}+05$

$0.537 \mathrm{E}+05$

$0.431 E+05$

$0.554 \mathrm{E}+05$

$0.518 \mathrm{E}+05$

$0.503 E+05$
$-0.238 \mathrm{E}+05$

$-0.262 \mathrm{E}+05$

$-0.238 \mathrm{E}+05$

$-0.205 E+05$

$-0.219 \mathrm{E}+05$

$-0.180 \mathrm{E}+\mathrm{OE}$

$-0.146 E+06$

$-0.665 E+05$

$-0.414 \mathrm{E}+06$

$-0.852 \mathrm{E}+06$

$0.372 \mathrm{E}+06$

$-0.686 \mathrm{E}+06$

$-0.630 \mathrm{E}+06$

$-0.719 \mathrm{E}+06$

$0.146 \mathrm{E}+06$

$-0.559 \mathrm{E}+06$

$-0.324 \mathrm{E}+06$

$-0.185 E+06$

$-0.110 E+06$

$-0.124 \mathrm{E}+06$

$-0.691 \mathrm{E}+05$

$-0.413 E+05$

$-0.270 \mathrm{E}+05$

$-0.265 \mathrm{E}+05$

$-0.237 \mathrm{E}+05$

$-0.223 \mathrm{E}+05$

$-0.251 \mathrm{E}+05$

$-0.222 E+05$

$-0.165 \mathrm{E}+05$

$-0.269 \mathrm{E}+05$

$-0.258 \mathrm{E}+05$

$-0.219 \mathrm{E}+05$

$-0.219 \mathrm{E}+05$

$-0.237 \mathrm{E}+05$

$-0.237 \mathrm{E}+05$

$-0.178 \mathrm{E}+05$

$-0.246 \mathrm{E}+05$

$-0.193 \mathrm{E}+06$

$-0.186 E+06$

$-0.105 E+06$

$-0.453 E+08$

$-0.740 \mathrm{E}+06$

$0.339 \mathrm{E}+06$

$-0.571 E+06$

$-0.426 \mathrm{E}+06$

$-0.543 E+06$

$-0.213 E+06$

$-0.833 \mathrm{E}+05$

$-0.760 E+05$

$-0.235 E+06$

$-0.123 E+06$

$-0.140 \mathrm{E}+08$

$-0.685 E+05$

$-0.476 E+05$

$-0.428 E+05$

$-0.422 \mathrm{E}+05$

$-0.487 \mathrm{E}+05$

$-0.420 \mathrm{E}+05$

$-0.471 E+05$

$-0.456 \mathrm{E}+05$
$0.486 \mathrm{E}+05$

$0.483 \mathrm{E}+05$

$0.449 \mathrm{E}+05$

$0.402 E+05$

$0.424 E+05$

$0.242 \mathrm{E}+06$

$0.339 E+06$

$0.186 \mathrm{E}+06$

$0.711 E+06$

$0.151 \mathrm{E}+07$

$-0.112 \mathrm{E}+06$

$0.145 \mathrm{E}+07$

0. $142 \mathrm{E}+07$

$0.149 \mathrm{E}+07$

$-0.721 \mathrm{E}+05$

$0.136 \mathrm{E}+07$

$0.619 E+06$

$0.390 E+06$

C. $298 \mathrm{E}+06$

$0.353 E+06$

$0.117 \mathrm{E}+06$

$0.782 \mathrm{E}+05$

$0.653 \mathrm{E}+05$

$0.601 E+05$

$0.514 \mathrm{E}+05$

$0.382 \mathrm{E}+05$

$0.507 \mathrm{E}+05$

$0.497 \mathrm{E}+05$

$0.406 \mathrm{E}+05$

$0.577 \mathrm{E}+05$

$0.548 \mathrm{E}+05$

$0.492 \mathrm{E}+05$

$0.456 \mathrm{E}+05$

$0.475 \mathrm{E}+05$

$0.479 \mathrm{E}+05$

$0.382 \mathrm{E}+05$

$0.373 E+05$

$0.270 \mathrm{E}+06$

$0.374 \mathrm{E}+06$

$0.182 \mathrm{E}+06$

$0.681 \mathrm{E}+06$

$0.137 \mathrm{E}+07$

$-0.970 \mathrm{E}+05$

$0.140 \mathrm{E}+07$

$0.114 E+07$

$0.833 E+06$

$0.761 \mathrm{E}+06$

$0.896 \mathrm{E}+05$

$0.174 \mathrm{E}+06$

$0.372 E+06$

$0.283 \mathrm{E}+06$

$0.374 E+06$

$0.119 \mathrm{E}+06$

$0.915 \mathrm{E}+05$

$0.872 \mathrm{E}+05$

$0.958 \mathrm{E}+05$

$0.918 \mathrm{E}+05$

$0.874 E+05$

$0.988 \mathrm{E}+05$

$0.959 \mathrm{~F}+05$ 


\begin{tabular}{|c|c|}
\hline $\begin{array}{l}108 \\
108 \\
110 \\
111 \\
112 \\
113 \\
114 \\
115 \\
116 \\
117 \\
118 \\
119 \\
120 \\
121 \\
122 \\
123 \\
124 \\
125 \\
126 \\
127 \\
128 \\
129 \\
130 \\
131 \\
132 \\
133 \\
134 \\
135 \\
136 \\
137 \\
138 \\
139 \\
140 \\
141 \\
142 \\
143 \\
144 \\
145 \\
146 \\
147 \\
148 \\
149 \\
150 \\
151 \\
152 \\
153 \\
154 \\
155 \\
158 \\
157 \\
158 \\
158 \\
160 \\
161 \\
162 \\
163 \\
164 \\
165 \\
166 \\
167\end{array}$ & $\begin{array}{l}22.293 \\
22.149 \\
22.599 \\
22.755 \\
22.906 \\
23.051 \\
23.212 \\
23.366 \\
23.510 \\
23.662 \\
23.811 \\
23.965 \\
24.119 \\
24.270 \\
21.424 \\
1.568 \\
24.722 \\
25.026 \\
27.345 \\
27.487 \\
27.638 \\
27.748 \\
27.888 \\
28.020 \\
28.551 \\
28.492 \\
29.5 .11 \\
28.589 \\
28.836 \\
28.980 \\
29.129 \\
29.327 \\
29.459 \\
29.808 \\
29.755 \\
29.908 \\
30.060 \\
30.214 \\
30.368 \\
30.513 \\
30.667 \\
30.823 \\
30.975 \\
31.131 \\
31.278 \\
31.434 \\
31.586 \\
31.735 \\
31.891 \\
32.040 \\
32.197 \\
32.343 \\
32.500 \\
32.649 \\
32.805 \\
32.957 \\
33.111 \\
33.265 \\
33.421 \\
33.573\end{array}$ \\
\hline
\end{tabular}

$0.488 \mathrm{E}+05$

$0.466 \mathrm{E}+05$

$0.484 E+05$

$0.448 E+05$

$0.480 E+05$

$0.363 E+05$

$0.485 \mathrm{E}+05$

$0.399 E+05$

$0.436 \mathrm{E}+05$

$0.397 \mathrm{E}+05$

$0.383 E+05$

$0.367 \mathrm{E}+05$

$0.361 \mathrm{E}+05$

$0.349 E+05$

$0.334 E+05$

$0.282 \mathrm{E}+05$

$0.264 E+05$

$0.226 E+05$

$\cap .664 \mathrm{E}+05$

U. $194 \mathrm{E}+06$

$0.108 \mathrm{E}+06$

$0.295 E+06$

u. $615 \mathrm{E}+06$

$0.149 \mathrm{E}+08$

$0.761 \mathrm{E}+06$

$0.377 \mathrm{E}+06$

$0.340 E+06$

$0.611 \mathrm{E}+06$

$0.107 \mathrm{E}+08$

$0.243 E+06$

$0.110 \mathrm{E}+08$

$0.153 E+06$

$0.271 E+06$

$0.174 \mathrm{E}+08$

$0.229 \mathrm{E}+06$

$0.234 E+06$

$0.233 E+06$

$0.200 E+06$

$0.182 \mathrm{E}+06$

$0.169 \mathrm{E}+06$

$0.168 \mathrm{E}+06$

$0.152 \mathrm{E}+06$

$0.148 \mathrm{E}+08$

$0.128 \mathrm{E}+06$

$0.129 \mathrm{E}+06$

$0.118 \mathrm{E}+08$

$0.116 \mathrm{E}+06$

$0.105 \mathrm{E}+06$

$0.103 E+06$

$0.973 E+05$

$0.924 \mathrm{E}+05$

$0.890 \mathrm{E}+05$

$0.837 \mathrm{E}+05$

$0.815 E+05$

$0.749 \mathrm{E}+05$

$0.770 \mathrm{E}+05$

$0.696 \mathrm{E}+05$

$0.717 \mathrm{E}+05$

$0.682 \mathrm{E}+05$

$0.682 \mathrm{E}+05$
$-0.433 . \overline{\mathrm{u}}+05$

$-0.43 .3 \mathrm{E}+05$

$-0.429 \mathrm{E}+05$

$-0.380 \mathrm{E}+05$

$-0.430 \mathrm{E}+05$

$-0.365 E+05$

$-0.389 \mathrm{E}+05$

$-0.409 \mathrm{E}+05$

$-0.379 \mathrm{E}+05$

$-0.376 \mathrm{E}+05$

$-0.354 \mathrm{E}+05$

$-0.355 E+05$

. $0.339 \mathrm{E}+05$

$-0.335 E+05$

$-0.274 \mathrm{E}+05$

$-0.281 E+05$

$-0.243 E+05$

$-0.179 \mathrm{E}+05$

$-0.175 E+06$

$-0.145 E+06$

$-0.774 \mathrm{E}+05$

$-0.424 \mathrm{E}+06$

$-0.764 \mathrm{E}+06$

$0.341 \mathrm{E}+06$

$-0.505 E+06$

$-0.265 E+06$

$-0.620 \mathrm{E}+06$

$-0.173 \mathrm{E}+\mathrm{C} \mathrm{B}$

$-0.227 \mathrm{E}+06$

$-0.175 E+06$

$-0.873 E+05$

$-0.132 \mathrm{E}+06$

$-0.134 E+06$

$-0.261 E+06$

$-0.260 \mathrm{E}+06$

$-0.224 E+06$

$-0.205 E+0 B$

-.0.193E+06

$-0.175 E+06$

$-0.167 \mathrm{E}+06$

$-0.153 E+06$

$-0.143 E+06$

$-0.131 E+06$

$-0.125 \mathrm{E}+06$

$-0.115 E+06$

$-0.113 \mathrm{E}+06$

$-0.102 \mathrm{E}+06$

$-0.980 E+05$

$-0.906 \mathrm{E}+05$

$-0.887 \mathrm{E}+05$

$-0.801 E+05$

$-0.797 E+05$

$-0.743 E+05$

$-0.746 E+05$

$-0.655 \mathrm{E}+05$

$-0.6402+05$

$-0.637 \mathrm{E}+05$

$-0.605 \mathrm{E}+05$

$-0.617 \mathrm{E}+05$

$-0.557 \mathrm{E}+05$
$0.931 E+05$

$0.898 \mathrm{E}+05$

$0.913 \mathrm{E}+05$

$0.828 \mathrm{E}+05$

$0.910 \mathrm{E}+05$

$0.728 \mathrm{E}+05$

$0.874 \mathrm{E}+05$

$0.808 \mathrm{E}+05$

$0.815 \mathrm{E}+05$

$0.773 \mathrm{E}+05$

$0.737 \mathrm{E}+05$

$0.722 \mathrm{E}+05$

$0.700 \mathrm{E}+05$

$0.684 \mathrm{E}+05$

$0.608 \mathrm{E}+05$

$0.563 E+05$

$0.507 \mathrm{E}+05$

$0.405 E+05$

$0.241 E+06$

$0.339 E+06$

$0.185 E+06$

$0.719 \mathrm{E}+06$

$0.138 \mathrm{E}+07$

$-0.192 \mathrm{E}+06$

$0.127 \mathrm{E}+07$

$0.642 \mathrm{E}+06$

$0.960 \mathrm{E}+06$

$0.784 E+06$

$0.334 E+06$

$0.418 \mathrm{E}+06$

$0.197 \mathrm{E}+06$

$0.285 \mathrm{E}+06$

$0.405 E+06$

$0.435 \mathrm{E}+06$

$0.489 \mathrm{E}+06$

$0.458 \mathrm{E}+06$

$0.438 \mathrm{E}+06$

$0.383 E+06$

$0.367 \mathrm{E}+06$

$0.336 \mathrm{E}+06$

$0.321 E+06$

$0.295 E+06$

$0.279 E+06$

$0.254 \mathrm{E}+06$

$0.244 \mathrm{E}+06$

$0.231 \mathrm{E}+06$

$0.218 \mathrm{E}+06$

$0.203 E+06$

0. $194 \mathrm{E}+06$

0. $186 E+06$

$0.173 E+06$

$0.168 \mathrm{E}+06$

$0.158 \mathrm{E}+06$

$0.156 \mathrm{E}+06$

$0.140 E+06$

$0.141 \mathrm{E}+06$

$0.133 \mathrm{E}+06$

$0.132 \mathrm{E}+06$

$0.130 E+06$

$0.124 E+06$ 


$\begin{array}{lllll}1.68 & 33.724 & 0.846 \mathrm{E}+05 & -0.518 \mathrm{E}+05 & 0.116 \mathrm{E}+06 \\ 169 & 33.878 & 0.616 \mathrm{E}+05 & -0.513 \mathrm{E}+05 & 0.113 \mathrm{E}+06 \\ 170 & 34.11 .15 & 0.596 \mathrm{E}+05 & -0.513 \mathrm{E}+05 & 0.111 \mathrm{E}+06 \\ 171 & 34.151 & 0.544 \mathrm{E}+05 & -0.498 \mathrm{E}+05 & 0.104 \mathrm{E}+06 \\ 172 & 34.23 .10 & 0.581 \mathrm{E}+05 & -0.463 \mathrm{E}+05 & 0.104 \mathrm{E}+06 \\ 173 & 34.494 & 0.526 \mathrm{E}+05 & -0.375 \mathrm{E}+05 & 0.801 \mathrm{E}+05 \\ 174 & 34.643 & 0.497 \mathrm{E}+05 & -0.426 \mathrm{E}+05 & 0.923 \mathrm{E}+05 \\ 175 & 34.795 & 0.440 \mathrm{E}+05 & -0.403 \mathrm{E}+05 & 0.843 \mathrm{E}+05 \\ 176 & 34.927 & 0.227 \mathrm{E}+05 & -0.368 \mathrm{E}+05 & 0.595 \mathrm{E}+05 \\ 177 & 35.095 & 0.368 \mathrm{E}+05 & -0.157 \mathrm{E}+05 & 0.525 \mathrm{E}+05 \\ 178 & 35.244 & 0.351 \mathrm{E}+05 & -0.299 \mathrm{E}+05 & 0.650 \mathrm{E}+05 \\ 178 & 35.540 & 0.248 \mathrm{E}+05 & -0.243 \mathrm{E}+05 & 0.492 \mathrm{E}+05 \\ 180 & 35.699 & 0.251 \mathrm{E}+05 & -0.172 \mathrm{E}+05 & 0.423 \mathrm{E}+05\end{array}$


Table A.2

Peak Values of the Member Moments (M)

$\begin{array}{ccccc}\text { No of cycles } & \text { Time } & \text { Yoml } & \text { Mom2 } & \text { Mom-Range } \\ & (\mathrm{sec}) & (\mathrm{kg}-\mathrm{mm}) & (\mathrm{kg}-\mathrm{mm}) & (\mathrm{kg}-\mathrm{mm})\end{array}$

\begin{tabular}{|c|c|c|c|c|}
\hline $\begin{array}{r}1 \\
2 \\
3 \\
4 \\
5 \\
6 \\
7 \\
8 \\
9 \\
10 \\
11 \\
12 \\
13 \\
14 \\
15 \\
16 \\
17 \\
18 \\
19 \\
20 \\
21 \\
22 \\
23 \\
24 \\
25 \\
26 \\
27 \\
28 \\
28 \\
30 \\
31 \\
32 \\
33 \\
34 \\
35 \\
36 \\
37 \\
38 \\
39 \\
40 \\
41 \\
12 \\
43 \\
44\end{array}$ & $\begin{array}{l}1.855 \\
2.180 \\
2.246 \\
2.366 \\
2.505 \\
2.554 \\
2.659 \\
2.767 \\
2.898 \\
3.072 \\
3.256 \\
3.424 \\
3.593 \\
3.740 \\
3.771 \\
3.933 \\
4.087 \\
4.238 \\
4.390 \\
4.539 \\
4.693 \\
4.844 \\
4.996 \\
5.147 \\
5.301 \\
5.453 \\
5.604 \\
5.756 \\
5.903 \\
6.057 \\
6.213 \\
6.367 \\
6.511 \\
6.670 \\
6.817 \\
6.968 \\
7.127 \\
7.279 \\
7.430 \\
7.587 \\
7.738 \\
7.890 \\
8.041 \\
8.183 \\
8.347 \\
8.491\end{array}$ & $\begin{array}{l}0.796 \mathrm{E}+05 \\
0.233 \mathrm{E}+07 \\
0.208 \mathrm{E}+06 \\
0.694 \mathrm{E}+07 \\
0.179 \mathrm{E}+08 \\
0.152 \mathrm{E}+07 \\
0.974 \mathrm{E}+07 \\
0.232 \mathrm{E}+08 \\
0.562 \mathrm{E}+08 \\
0.716 \mathrm{E}+08 \\
0.757 \mathrm{E}+08 \\
0.726 \mathrm{E}+08 \\
0.721 \mathrm{E}+08 \\
0.741 \mathrm{E}+08 \\
0.556 \mathrm{E}+08 \\
0.434 \mathrm{E}+08 \\
0.369 \mathrm{E}+08 \\
0.253 \mathrm{E}+08 \\
0.244 \mathrm{E}+08 \\
0.218 \mathrm{E}+08 \\
0.208 \mathrm{E}+08 \\
0.184 \mathrm{E}+08 \\
0.166 \mathrm{E}+08 \\
0.148 \mathrm{E}+08 \\
0.136 \mathrm{E}+08 \\
0.123 \mathrm{E}+08 \\
0.114 \mathrm{E}+08 \\
0.104 \mathrm{E}+08 \\
0.817 \mathrm{E}+07 \\
0.862 \mathrm{E}+07 \\
0.838 \mathrm{E}+07 \\
0.763 \mathrm{E}+07 \\
0.678 \mathrm{E}+07 \\
0.661 \mathrm{E}+07 \\
0.595 \mathrm{E}+07 \\
0.539 \mathrm{E}+07 \\
0.521 \mathrm{E}+07 \\
0.503 \mathrm{E}+07 \\
0.455 \mathrm{E}+07 \\
0.457 \mathrm{E}+07 \\
0.409 \mathrm{E}+07 \\
0.412 \mathrm{E}+07 \\
0.373 \mathrm{E}+07 \\
0.355 \mathrm{E}+07 \\
0.315 \mathrm{E}+07 \\
0.247 \mathrm{E}+07\end{array}$ & $\begin{array}{r}-0.131 \mathrm{E}+06 \\
0.783 \mathrm{E}+05 \\
-0.637 \mathrm{E}+06 \\
-0.170 \mathrm{E}+08 \\
0.273 \mathrm{E}+07 \\
-0.151 \mathrm{E}+08 \\
-0.735 \mathrm{E}+07 \\
-0.426 \mathrm{E}+08 \\
-0.794 \mathrm{E}+08 \\
-0.872 \mathrm{E}+08 \\
-0.686 \mathrm{E}+08 \\
-0.726 \mathrm{E}+08 \\
-0.740 \mathrm{E}+08 \\
0.802 \mathrm{E}+07 \\
-0.345 \mathrm{E}+08 \\
-0.382 \mathrm{E}+08 \\
-0.158 \mathrm{E}+08 \\
-0.318 \mathrm{E}+08 \\
-0.242 \mathrm{E}+08 \\
-0.217 \mathrm{E}+08 \\
-0.187 \mathrm{E}+08 \\
-0.169 \mathrm{E}+08 \\
-0.155 \mathrm{E}+08 \\
-0.134 \mathrm{E}+08 \\
-0.125 \mathrm{E}+08 \\
-0.115 \mathrm{E}+08 \\
-0.105 \mathrm{E}+08 \\
-0.964 \mathrm{E}+07 \\
-0.882 \mathrm{E}+07 \\
-0.789 \mathrm{E}+07 \\
-0.739 \mathrm{E}+07 \\
-0.711 \mathrm{E}+07 \\
-0.642 \mathrm{E}+07 \\
-0.613 \mathrm{E}+07 \\
-0.525 \mathrm{E}+07 \\
-0.458 \mathrm{E}+07 \\
-0.457 \mathrm{E}+07 \\
-0.437 \mathrm{E}+07 \\
-0.418 \mathrm{E}+07 \\
-0.331 \mathrm{E}+07 \\
-0.389 \mathrm{E}+07 \\
-0.351 \mathrm{E}+07 \\
-0.351 \mathrm{E}+07 \\
-0.226 \mathrm{E}+07 \\
-0.261 \mathrm{E}+07 \\
-0.120 \mathrm{E}+07\end{array}$ & $\begin{array}{r}0.211 \mathrm{E}+06 \\
0.225 \mathrm{E}+07 \\
0.845 \mathrm{E}+06 \\
0.239 \mathrm{E}+08 \\
0.152 \mathrm{E}+08 \\
0.166 \mathrm{E}+08 \\
0.171 \mathrm{E}+08 \\
0.658 \mathrm{E}+08 \\
0.136 \mathrm{E}+08 \\
0.139 \mathrm{E}+08 \\
0.144 \mathrm{E}+08 \\
0.145 \mathrm{E}+08 \\
0.146 \mathrm{E}+08 \\
-0.728 \mathrm{E}+07 \\
0.901 \mathrm{E}+08 \\
0.816 \mathrm{E}+08 \\
0.527 \mathrm{E}+08 \\
0.571 \mathrm{E}+08 \\
0.486 \mathrm{E}+08 \\
0.435 \mathrm{E}+08 \\
0.395 \mathrm{E}+08 \\
0.353 \mathrm{E}+08 \\
0.321 \mathrm{E}+08 \\
0.282 \mathrm{E}+08 \\
0.261 \mathrm{E}+08 \\
0.238 \mathrm{E}+08 \\
0.219 \mathrm{E}+08 \\
0.200 \mathrm{E}+08 \\
0.180 \mathrm{E}+08 \\
0.165 \mathrm{E}+08 \\
0.158 \mathrm{E}+08 \\
0.147 \mathrm{E}+08 \\
0.132 \mathrm{E}+08 \\
0.127 \mathrm{E}+08 \\
0.112 \mathrm{E}+08 \\
0.997 \mathrm{E}+07 \\
0.978 \mathrm{E}+07 \\
0.940 \mathrm{E}+07 \\
0.873 \mathrm{E}+07 \\
0.788 \mathrm{E}+07 \\
0.798 \mathrm{E}+07 \\
0.763 \mathrm{E}+07 \\
0.724 \mathrm{E}+07 \\
0.581 \mathrm{E}+07 \\
0.576 \mathrm{E}+07 \\
0.367 \mathrm{E}+07\end{array}$ \\
\hline
\end{tabular}




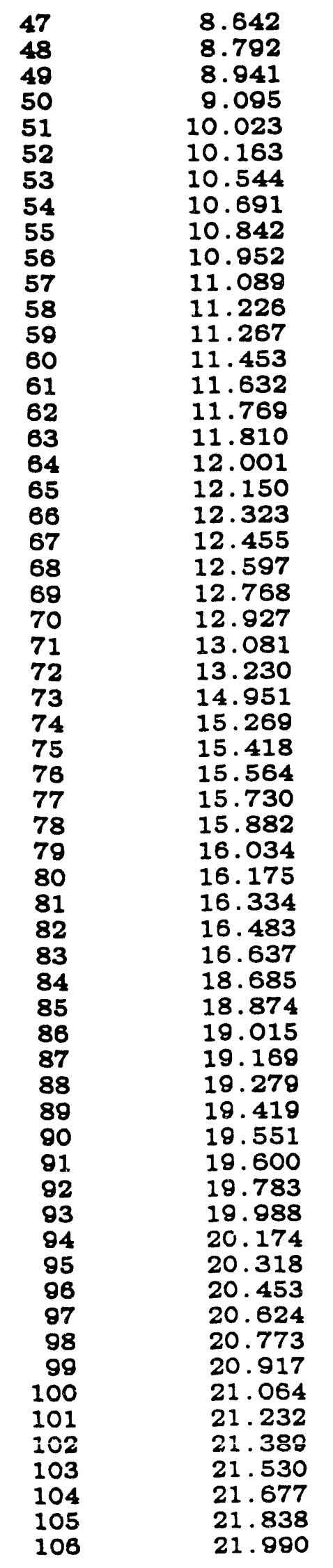

$0.230 E+07$

$0.223 E+07$

$0.226 \mathrm{E}+07$

$0.185 \mathrm{E}+07$

$0.173 E+07$

$0.200 E+07$

$0.558 \mathrm{E}+07$

$0.175 E+08$

$0.981 \mathrm{E}+07$

$0.268 \mathrm{E}+08$

$0.600 E+08$

$0.351 \mathrm{E}+08$

$0.723 E+08$

$0.755 \mathrm{E}+08$

$0.740 E+08$

$0.730 \mathrm{E}+07$

$0.773 E+08$

$0.271 E+08$

$0.181 E+08$

$0.168 \mathrm{E}+08$

$0.201 E+08$

$0.466 \mathrm{E}+07$

$0.355 \mathrm{E}+07$

$0.336 \mathrm{E}+07$

$0.330 E+07$

$0.233 E+07$

$0.186 \mathrm{E}+07$

$0.246 E+07$

$0.240 E+07$

$0.230 \mathrm{E}+07$

$0.255 E+07$

$0.263 E+07$

$0.250 \mathrm{E}+07$

$0.201 \mathrm{E}+07$

$0.219 \mathrm{E}+07$

$0.207 \mathrm{E}+07$

$0.208 \mathrm{E}+07$

$0.134 \mathrm{E}+07$

$0.706 \mathrm{E}+07$

$0.163 \mathrm{E}+08$

$0.584 \mathrm{E}+07$

$0.192 E+08$

$0.606 \mathrm{E}+08$

$0.312 E+08$

$0.792 \mathrm{E}+08$

$0.696 \mathrm{E}+08$

$0.240 \mathrm{E}+08$

$0.527 \mathrm{E}+08$

$0.126 \mathrm{E}+07$

$0.101 E+08$

$0.117 \mathrm{E}+08$

$0.235 \mathrm{E}+08$

$0.204 \mathrm{E}+08$

$0.508 \mathrm{E}+07$

$0.373 \mathrm{E}+07$

0. $448 \mathrm{E}+0$ ?

$0.464 \mathrm{E}+07$

$0.423 E+07$

$0.471 \mathrm{E}+07$

$0.463 E+07$
$-0.150 E+07$

$-0.208 \mathrm{E}+07$

$-0.275 E+07$

$-0.225 E+07$

$-0.218 \mathrm{E}+07$

$-0.178 \mathrm{E}+07$

$-0.163 E+08$

$-0.135 E+08$

$-0.582 E+07$

$-0.396 \mathrm{E}+08$

$-0.795 E+08$

$0.473 E+08$

$-0.668 E+08$

$-0.603 E+08$

$-0.690 \mathrm{E}+08$

$0.154 \mathrm{E}+08$

$-0.543 E+08$

$-0.301 E+08$

$-0.171 \mathrm{E}+08$

$-0.949 \mathrm{E}+07$

$-0.113 \mathrm{E}+08$

$-0.615 \mathrm{E}+07$

$-0.425 \mathrm{E}+07$

$-0.225 E+07$

$-0.257 \mathrm{E}+07$

$-0.199 \mathrm{E}+07$

$-0.198 \mathrm{E}+07$

$-0.213 E+07$

$-0.219 E+07$

$-0.150 E+07$

$-0.259 \mathrm{E}+07$

$-0.233 E+07$

$-0.238 E+07$

$-0.188 \mathrm{E}+07$

$-0.237 \mathrm{E}+07$

$-0.217 \mathrm{E}+07$

$-0.172 \mathrm{E}+07$

$-0.253 E+07$

$-0.175 \mathrm{E}+08$

$-0.180 E+08$

$-0.108 \mathrm{E}+08$

$-0.447 \mathrm{E}+08$

$-0.674 \mathrm{E}+08$

$0.425 E+08$

$-0.549 \mathrm{E}+08$

$-0.411 E+08$

$-0.533 E+08$

$-0.190 E+08$

$-0.693 E+07$

$-0.666 \mathrm{E}+07$

$-0.210 E+08$

$-0.108 \mathrm{E}+08$

$-0.126 \mathrm{E}+08$

$-0.616 E+07$

$-0.452 \mathrm{E}+07$

$-0.374 E+07$

$-0.431 E+07$

$-0.444 E+07$

$-0.426 E+07$

$-0.424 \mathrm{E}+07$
$0.380 E+07$

$0.431 E+07$

$0.501 \mathrm{E}+07$

$0.410 \mathrm{E}+07$

$0.391 E+07$

$0.378 \mathrm{E}+07$

$0.219 \mathrm{E}+08$

$0.310 \mathrm{E}+08$

$0.157 \mathrm{E}+08$

$0.664 \mathrm{E}+08$

$0.140 \mathrm{E}+09$

$-0.122 \mathrm{E}+08$

$0.139 \mathrm{E}+09$

$0.136 E+09$

$0.143 \mathrm{E}+09$

$-0.810 E+07$

$0.132 \mathrm{E}+09$

$0.572 \mathrm{E}+08$

$0.352 \mathrm{E}+08$

$0.263 E+08$

$0.314 \mathrm{E}+08$

$0.108 \mathrm{E}+08$

$0.780 \mathrm{E}+07$

$0.561 \mathrm{E}+07$

$0.587 \mathrm{E}+07$

$0.432 E+07$

$0.384 \mathrm{E}+07$

$0.459 \mathrm{E}+07$

$0.459 \mathrm{E}+07$

$0.380 \mathrm{E}+07$

$0.514 \mathrm{E}+07$

$0.496 \mathrm{E}+07$

$0.488 \mathrm{E}+07$

$0.389 \mathrm{E}+07$

$0.456 \mathrm{E}+07$

$0.424 \mathrm{E}+07$

$0.380 E+07$

$0.387 \mathrm{E}+07$

$0.246 E+08$

$0.343 E+08$

$0.166 \mathrm{E}+08$

$0.639 \mathrm{E}+08$

$0.128 \mathrm{E}+09$

$-0.113 E+08$

$0.134 \mathrm{E}+09$

$0.111 \mathrm{E}+08$

$0.773 E+08$

$0.717 \mathrm{E}+08$

$0.819 E+07$

$0.158 \mathrm{E}+08$

$0.327 \mathrm{E}+08$

$0.343 E+08$

$0.330 E+08$

$0.112 E+08$

$0.825 E+07$

$0.822 \mathrm{E}+07$

$0.895 \mathrm{E}+07$

$0.867 \mathrm{E}+07$

$0.897 \mathrm{E}+07$

$0.887 \mathrm{E}+07$ 


\begin{tabular}{|c|c|}
\hline $\begin{array}{l}107 \\
108 \\
109 \\
110 \\
111 \\
112 \\
113 \\
114 \\
115 \\
116 \\
117 \\
118 \\
119 \\
120 \\
121 \\
122 \\
123 \\
124 \\
125 \\
126 \\
127 \\
128 \\
129 \\
130 \\
131 \\
132 \\
133 \\
134 \\
135 \\
136 \\
137 \\
138 \\
139 \\
140 \\
141 \\
142 \\
143 \\
144 \\
145 \\
146 \\
147 \\
148 \\
149 \\
150 \\
151 \\
152 \\
153 \\
154 \\
155 \\
156 \\
157 \\
158 \\
159 \\
160 \\
161 \\
162 \\
163 \\
164 \\
165 \\
166\end{array}$ & $\begin{array}{l}22.144 \\
22.293 \\
22.448 \\
22.599 \\
22.755 \\
22.906 \\
23.051 \\
23.212 \\
23.366 \\
23.510 \\
23.662 \\
23.811 \\
23.965 \\
24.119 \\
24.270 \\
24.424 \\
24.568 \\
24.722 \\
25.026 \\
27.345 \\
27.487 \\
27.638 \\
27.748 \\
27.888 \\
28.020 \\
28.051 \\
28.262 \\
28.521 \\
28.689 \\
28.836 \\
28.980 \\
29.129 \\
29.327 \\
29.459 \\
29.608 \\
29.755 \\
29.909 \\
30.060 \\
30.214 \\
30.368 \\
30.513 \\
30.687 \\
30.823 \\
30.875 \\
31.131 \\
31.278 \\
31.434 \\
31.586 \\
31.735 \\
31.891 \\
32.040 \\
32.197 \\
32.343 \\
32.500 \\
32.649 \\
32.805 \\
32.957 \\
33.111 \\
33.265 \\
33.421\end{array}$ \\
\hline
\end{tabular}

$\begin{array}{ll}0.463 \mathrm{E}+07 & -0.452 \mathrm{E}+07 \\ 0.435 \mathrm{E}+07 & -0.384 \mathrm{E}+07 \\ 0.445 \mathrm{E}+07 & -0.421 \mathrm{E}+07 \\ 0.407 \mathrm{E}+07 & -0.381 \mathrm{E}+07 \\ 0.427 \mathrm{E}+07 & -0.372 \mathrm{E}+07 \\ 0.409 \mathrm{E}+07 & -0.400 \mathrm{E}+07 \\ 0.372 \mathrm{E}+07 & -0.341 \mathrm{E}+07 \\ 0.401 \mathrm{E}+07 & -0.340 \mathrm{E}+07 \\ 0.412 \mathrm{E}+07 & -0.359 \mathrm{E}+07 \\ 0.355 \mathrm{E}+07 & -0.358 \mathrm{E}+07 \\ 0.357 \mathrm{E}+07 & -0.339 \mathrm{E}+07 \\ 0.318 \mathrm{E}+07 & -0.330 \mathrm{E}+07 \\ 0.349 \mathrm{E}+07 & -0.309 \mathrm{E}+07 \\ 0.319 \mathrm{E}+07 & -0.338 \mathrm{E}+07 \\ 0.311 \mathrm{E}+07 & -0.298 \mathrm{E}+07 \\ 0.311 \mathrm{E}+07 & -0.280 \mathrm{E}+07 \\ 0.244 \mathrm{E}+07 & -0.232 \mathrm{E}+07 \\ 0.254 \mathrm{E}+07 & -0.212 \mathrm{E}+07 \\ 0.216 \mathrm{E}+07 & -0.136 \mathrm{E}+07 \\ 0.626 \mathrm{E}+07 & -0.159 \mathrm{E}+08 \\ 0.176 \mathrm{E}+08 & -0.132 \mathrm{E}+08 \\ 0.941 \mathrm{E}+07 & -0.691 \mathrm{E}+07 \\ 0.266 \mathrm{E}+08 & -0.413 \mathrm{E}+08 \\ 0.582 \mathrm{E}+08 & -0.741 \mathrm{E}+08 \\ 0.187 \mathrm{E}+08 & 0.408 \mathrm{E}+08 \\ 0.739 \mathrm{E}+08 & -0.499 \mathrm{E}+08 \\ 0.339 \mathrm{E}+08 & -0.247 \mathrm{E}+08 \\ 0.292 \mathrm{E}+08 & -0.603 \mathrm{E}+08 \\ 0.597 \mathrm{E}+08 & -0.142 \mathrm{E}+08 \\ 0.114 \mathrm{E}+08 & -0.192 \mathrm{E}+08 \\ 0.228 \mathrm{E}+08 & -0.158 \mathrm{E}+08 \\ 0.897 \mathrm{E}+07 & -0.760 \mathrm{E}+07 \\ 0.141 \mathrm{E}+08 & -0.120 \mathrm{E}+08 \\ 0.236 \mathrm{E}+08 & -0.116 \mathrm{E}+08 \\ 0.161 \mathrm{E}+08 & -0.239 \mathrm{E}+08 \\ 0.193 \mathrm{E}+08 & -0.236 \mathrm{E}+08 \\ 0.214 \mathrm{E}+08 & -0.206 \mathrm{E}+08 \\ 0.202 \mathrm{E}+08 & -0.186 \mathrm{E}+08 \\ 0.185 \mathrm{E}+08 & -0.173 \mathrm{E}+08 \\ 0.169 \mathrm{E}+08 & -0.160 \mathrm{E}+08 \\ 0.147 \mathrm{E}+08 & -0.147 \mathrm{E}+08 \\ 0.141 \mathrm{E}+08 & -0.138 \mathrm{E}+08 \\ 0.135 \mathrm{E}+08 & -0.127 \mathrm{E}+08 \\ 0.127 \mathrm{E}+08 & -0.119 \mathrm{E}+08 \\ 0.120 \mathrm{E}+08 & -0.112 \mathrm{E}+08 \\ 0.113 \mathrm{E}+08 & -0.106 \mathrm{E}+08 \\ 0.106 \mathrm{E}+08 & -0.991 \mathrm{E}+07 \\ 0.101 \mathrm{E}+08 & -0.942 \mathrm{E}+07 \\ 0.961 \mathrm{E}+07 & -0.893 \mathrm{E}+07 \\ 0.914 \mathrm{E}+07 & -0.844 \mathrm{E}+07 \\ 0.858 \mathrm{E}+07 & -0.805 \mathrm{E}+07 \\ 0.86107 \mathrm{E} & -0.766 \mathrm{E}+07 \\ 0.785 \mathrm{E}+07 & -0.738 \mathrm{E}+07 \\ 0.766 \mathrm{E}+07 & -0.689 \mathrm{E}+07 \\ 0.627 \mathrm{E}+07 & -0.689 \mathrm{E}+07 \\ 0.619 \mathrm{E}+07 & -0.511 \mathrm{E}+07 \\ 0.700 \mathrm{E}+07 & -0.610 \mathrm{E}+07 \\ 0.581 & -0.592 \mathrm{E}+07 \\ 0.573 \mathrm{E}+07\end{array}$

$0.915 E+07$

$0.819 \mathrm{E}+07$

$0.866 \mathrm{E}+07$

$0.788 \mathrm{E}+07$

$0.799 E+07$

$0.809 E+07$

$0.713 E+07$

$0.741 \mathrm{E}+07$

$0.771 \mathrm{E}+07$

$0.713 \mathrm{E}+07$

$0.696 \mathrm{E}+07$

$0.648 \mathrm{E}+07$

$0.658 \mathrm{E}+07$

$0.657 \mathrm{E}+07$

$0.610 \mathrm{E}+07$

$0.591 \mathrm{E}+07$

$0.476 \mathrm{E}+07$

$0.466 \mathrm{E}+07$

$0.352 \mathrm{E}+07$

$0.222 \mathrm{E}+08$

$0.308 \mathrm{E}+08$

$0.163 \mathrm{E}+08$

$0.679 \mathrm{E}+08$

$0.132 \mathrm{E}+09$

$-0.221 \mathrm{E}+08$

$0.124 \mathrm{E}+09$

$0.586 \mathrm{E}+08$

$0.885 \mathrm{E}+08$

$0.739 E+08$

$0.306 \mathrm{E}+08$

$0.386 \mathrm{E}+08$

$0.166 \mathrm{E}+08$

$0.261 \mathrm{E}+08$

$0.352 \mathrm{E}+08$

$0.400 \mathrm{E}+08$

$0.429 \mathrm{E}+08$

$0.420 \mathrm{E}+08$

$0.388 \mathrm{E}+08$

$0.358 \mathrm{E}+08$

$0.329 \mathrm{E}+08$

$0.294 E+08$

$0.279 \mathrm{E}+08$

0. $262 \mathrm{E}+08$

$0.246 \mathrm{E}+08$

$0.232 \mathrm{E}+08$

$0.219 \mathrm{E}+08$

$0.205 E+08$

$0.185 E+08$

$0.185 E+08$

$0.176 \mathrm{E}+08$

$0.166 \mathrm{E}+08$

$0.161 \mathrm{E}+08$

$0.152 \mathrm{E}+08$

0. 146E+08

$0.139 E+08$

$0.131 E+08$

$0.127 \mathrm{E}+08$

0. $122 \mathrm{E}+08$

$0.122 \mathrm{E}+08$

$0.119 \mathrm{E}+08$ 


$\begin{array}{lllll}167 & 33.573 & 0.601 \mathrm{E}+07 & -0.554 \mathrm{E}+07 & 0.116 \mathrm{E}+08 \\ 168 & 33.724 & 0.582 \mathrm{E}+07 & -0.486 \mathrm{E}+07 & 0.107 \mathrm{E}+08 \\ 169 & 33.878 & 0.553 \mathrm{E}+07 & -0.495 \mathrm{E}+07 & 0.105 \mathrm{E}+08 \\ 170 & 34.035 & 0.554 \mathrm{E}+07 & -0.466 \mathrm{E}+07 & 0.102 \mathrm{E}+08 \\ 171 & 34.181 & 0.506 \mathrm{E}+07 & -0.495 \mathrm{E}+07 & 0.100 \mathrm{E}+08 \\ 172 & 34.340 & 0.517 \mathrm{E}+07 & -0.438 \mathrm{E}+07 & 0.955 \mathrm{E}+07 \\ 173 & 34.494 & 0.478 \mathrm{E}+07 & -0.361 \mathrm{E}+07 & 0.839 \mathrm{E}+07 \\ 174 & 34.643 & 0.449 \mathrm{E}+07 & -0.389 \mathrm{E}+07 & 0.838 \mathrm{E}+07 \\ 175 & 34.795 & 0.420 \mathrm{E}+07 & -0.360 \mathrm{E}+07 & 0.780 \mathrm{E}+07 \\ 176 & 34.927 & 0.199 \mathrm{E}+07 & -0.351 \mathrm{E}+07 & 0.5507+07 \\ 177 & 35.095 & 0.343 \mathrm{E}+07 & -0.112 \mathrm{E}+07 & 0.455 \mathrm{E}+07 \\ 178 & 35.244 & 0.285 \mathrm{E}+07 & -0.265 \mathrm{E}+07 & 0.550 \mathrm{E}+07 \\ 179 & 35.540 & 0.199 \mathrm{E}+07 & -0.227 \mathrm{E}+07 & 0.426 \mathrm{E}+07 \\ 180 & 35.699 & 0.228 \mathrm{E}+07 & -0.141 \mathrm{E}+07 & 0.369 \mathrm{E}+07\end{array}$



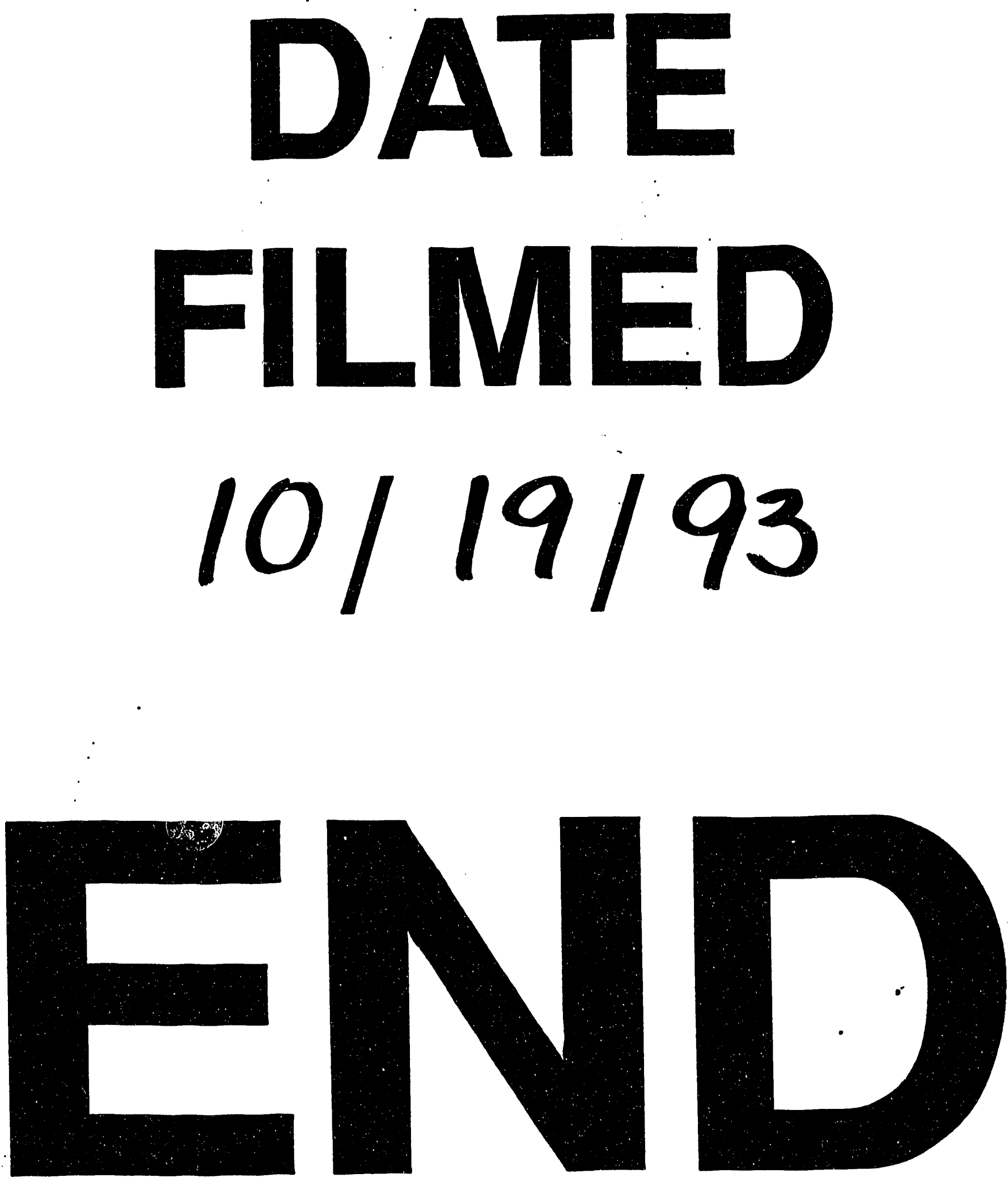
